\title{
Biosynthetic circ-PLEKHA5 stabilized by SRSF7 promotes the vasculogenic mimicry of glioblastoma cells by encoding a novel protein $622 a a$
}

\section{Rui Su}

China Medical University

Xiaobai Liu

Shengjing Hospital of China Medical University

Hao Teng

Shengjing Hospital of China Medical University

Xuelei Ruan

China Medical University

Di Wang

Shengjing Hospital of China Medical University

Chunqing Yang

Shengjing Hospital of China Medical University

Lianqi Shao

China Medical University

Yunhui Liu

Shengjing Hospital of China Medical University

Heng Cai

Shengjing Hospital of China Medical University

Zhen Li

Shengjing Hospital of China Medical University

Bo Yu

Shengjing Hospital of China Medical University

YixueXue ( $\nabla$ xyxvv0325@163.com )

China Medical University

\section{Research}

Keywords: Glioblastoma, RBPs, circRNAs, vasculogenic mimicry

Posted Date: November 5th, 2020

DOI: https://doi.org/10.21203/rs.3.rs-100305/v1 
License: (c) (i) This work is licensed under a Creative Commons Attribution 4.0 International License. Read Full License 


\section{Abstract}

Background: Increasing studies have been demonstrated that circRNAs play vital regulatory roles in the biological behaviors of glioblastoma cells, and increasing circRNAs are found to have the capacity of encoding small peptides, which are involved in the regulatory process.

Methods: Western blot and qRT-PCR were conducted to confirm the expression of SRSF7 and circPLEKHA5 respectively. RNase R digestion assay and fluorescence in situ hybridization assays were conducted to evaluate the existence and cellular location of circ-PLEKHA5. RIP assay was used to access the relationship between SRSF7 and circ-PLEKHA5. Dual-luciferase assay and FLAG tag assays were performed to test the coding capability of circ-PLEKHA5. Immunofluorescence assay was conducted to evaluate the location of circ-PLEKHA5-622aa. CCK-8, vasculogenic mimicry (VM) formation and transwell assays were used to evaluate the roles of SRSF7, circ-PLEKHA5, circ-PLEKHA5-622aa on proliferation, VM formation, migration and invasion. Nude mice xenograft studys with PAS-CD34 staining were used to clarify the functional roles of SRSF7 and circ-PLEKHA5 on VM formation in vivo.

Results: SRSF7 was up-regulated in glioma, and promoted the proliferation, migration, invasion, VM formation and the expression of VM-associated proteins of glioma cells by increasing the expression of circ-PLEKHA5. Circ-PLEKHA5 was mainly localized in cytoplasm and promoted the proliferation, migration, invasion, VM formation and the expression of VM-associated proteins of glioma cells by encoding a novel protein circ-PLEKHA5-622aa. The application of SRSF7 and circ-PLEKHA5 inhibitor significantly suppressed the tumor growth and VM formation in vivo.

Conclusions: This study first demonstrated the coding ability of circ-PLEKHA5, and identified the regulatory roles of SRSF7/circ-PLEKHA5/circ-PLEKHA5-622aa pathway in VM formation of glioblastoma cells. Our findings might provide a novel strategy for glioma treatment.

\section{Background}

As the most common form of central nervous system cancers in adolescents, gliomas are accounting for approximately $70 \%$ of primary intracranial tumors and classified as grade I-IV according to the World Health Organization classification (WHO). Glioblastoma (WHO grade IV) is the most malignant type of gliomas with a median survival time within 2 years ${ }^{[1]}$. Although numerous efforts in treatment have been made, the prognosis for glioblastoma remains poor, which is due to its highly aggressive, vascularized and infiltrating pathological characteristics. Vasculogenic mimicry (VM) is a microvascular structure that formed not by endothelial cells but tumor cells independently, and participates in the delivery of blood, oxygen and nutrients for tumor tissues in vivo ${ }^{[2]}$. The existence of VM in tumor tissues is reported to be highly correlated with the malignancy degree, poor prognosis and metastasis in various tumors including glioblastoma ${ }^{[3]}$. Therefore, researches into the mechanism of angiogenesis and the development of antiangiogenesis inhibitors may provide valuable strategy for glioblastoma diagnosis and therapy. 
RNA-binding protein serine/arginine-rich splicing factor 7 (SRSF7) belongs to the SR splicing factor family, which is known for its regulatory roles in alternative precursor mRNA (pre-mRNA) splicing ${ }^{[4]}$. Besides pre-mRNA splicing, SRSFs also have been considered to regulate mRNA stability, translation and export, thereby affecting a series of cell behaviors and disease developments ${ }^{[5]}$. In a pathway of DNA damage response, SRSF7 binds to the precursor mRNA of p53 and promotes its alternative splicing into $p 53 \beta$, which affect the senescence and aging process of mammalian cells ${ }^{[6]}$. Furthermore, SRSF7 is indicated to be up-regulated and act as an oncogene in various cancer types, such as renal cancer, gastric cancer, colon cancer and lung cancer ${ }^{[7]}$. In glioblastoma, SRSFs can act as target of the m6A methyltransferase METTL3 caused nonsense-mediated mRNA decay, which lead to a disorder of alternative spliceosome expressions ${ }^{[8]}$. SRSF3 is up-regulated and promotes the proliferation, self-renewal and tumorigenic processes of glioma-stem like cells ${ }^{[5]}$. Nevertheless, the effects of SRSF7 on glioma genesis remain unclear.

Circular RNAs (circRNAs) are a class of non-canonical RNA transcripts that first discovered in the 1990s and identified to be widely expressed in eukaryotes. Unlike the linear RNA transcripts, most circRNAs are basically generated through pre-mRNA alternative back-splicing of exons, which forming a covalently circular structure with no $5^{\prime}$ and $3^{\prime}$ ends ${ }^{[9]}$. As RNA deep-sequencing technologies develops and comprehensive studies of circRNAs continues, increasing circRNAs have been identified along with their participation in biological processes, such as innate immune responses and tumorigenesis ${ }^{[10]}$. Endogenous circRNAs have previously been considered as a member of non-coding RNAs until Chen $\mathrm{CY}$ et al. first discovered the translation ability of them ${ }^{[11]}$. In recent years, more and more endogenous circRNAs are found to encode functional polypeptides or proteins through the open read frames (ORFs) contained, which could further play specific roles in the tumorigenesis and development of various tumors including glioma ${ }^{[12-14]}$. Despite the development of ribosome profiling technique and the increasing of computational databases, there are still few studies on the functional peptides that encoded by circRNAs.

In this study, we identified circ-PLEKHA5 (hsa_circ_0098068) which was up-regulated in glioma tissues and cells, and promoted by SRSF7. Furthermore, a 622 amino acid (aa) peptide encoded by circ-PLEKHA5 ORF was up-regulated in glioma tissues and cells. We also explored the molecular mechanisms among them and their effects on the VM formation of glioma cells. Our results provided a new sight for discovering the VM formation in glioma and a new strategy for the treatment of glioma.

\section{Materials And Methods}

\section{Cell lines and human tissue samples}

All cells that used in this study, including human astrocyte (HA) cell, human glioma cells (U373, U251) and human embryonic kidney (HEK) 293T cell were purchased from Shanghai Institutes for Biological Sciences Cell Resource Center. HA cell was cultured in RPMI-1640 culture medium (Gibco, Grand Island, 
NY, USA) supplemented with 10\% fetal bovine serum (FBS, Gibco, Carlsbad, CA, USA). U373, U251 and 293T cells were cultured in Dulbecco's modified Eagle medium (DMEM)/high glucose with 10\% FBS. All cells were maintained at $37^{\circ} \mathrm{C}$ with $5 \% \mathrm{CO}_{2}$. All human glioma tissues and normal brain tissues (NBTs) were collected from the Department of Neurosurgery of Shengjing Hospital of China Medical University with informed consent, and the study was approved by the Ethics Committee of Shengjing Hospital of China Medical University.

\section{Quantitative real-time PCR (qRT-PCR) assays}

The extraction of total RNA was isolated using Trizol reagent (Life Technologies Corporation, Carlsbad, CA, USA), and the concentration and purity were of all samples were determined via Nanodrop Spectrophotometer (Thermo Scientific, Wilmington, DE, USA) at 260/280 nm absorbance. The expression of PLEKHA5 pre-mRNA was evaluated using One Step SYBR Prime Script RT-PCR kit (TakaraBio, Inc., Japan) and 7500 Fast RT-PCR System. One Step Prime Script ${ }^{T M}$ RT-PCR kit (TakaraBio, Inc., Japan) was used to evaluate the expression of circ-PLEKHA5. Besides, RNase-R treatment (20U/ $\mu$ l) was performed to eliminate the expression and effect of linear PLEKHA5. GAPDH was used as the endogenous control and the fold changes were calculated through the relative quantification method $\left(2^{-\triangle \triangle} \mathrm{Ct}\right)$. The primers used are as follows: linear-PLEKHA5 (convergent): F: 5'-GCAGTGCATCCAATGAGCCC-3', R: 5'ACCTCGTCTGACAACCGGTG-3'『circ-PLEKHA5(divergent): F: 5'-GCCCAC AGCCCAAAGAATGA-3', R: 5'CCTGTGACTGGATCTTTGCAGG-3'; GAPDH: F: 5'-GGACCTGACCTGCCGTCTAG-3', R: 5'TAGCCCAGGATGCCCTTGAG-3'.

\section{Plasmid Construction and Cell transfection}

The silencing plasmids of SRSF7 and circ-PLEKHA5 gene with their nontargeting sequences were ligated into pGPU6/GFP/Neo vectors. Human SRSF7 mRNA sequence was ligated into the pcDNA3.1 vector (GenePharma, Shanghai, China). Human circ-PLEKHA5 overexpressed vector and the control plasmid were obtained from GenePharma Company. Full length circ-PLEKHA5-622aa gene and respective nontargeting sequence were ligated into pIRES2-EGFP.

Transfection was performed using Lipofectamine 3000 and Opti-MEM (Life Technologies, Carlsbad, USA), and the stable transfected cells were selected by Geneticin (G418) and Puromycin (Sigma-Aldrich, St Louis, USA). The transfection efficiency was evaluated by qRT-PCR and western blot.

\section{CircRNAs microarray}

The circRNAs analysis and microarray hybridization were performed by Kangchen Biotechnology Corporation (Shanghai, China).

\section{RNA fluorescence in situ hybridization (FISH)}

To identify the distribution of circ-PLEKHA5, the probe of circ-PLEKHA5 (5'-TTATGGCTGATGATCCAAATA -3', green-labeled, Biosense, Guangzhou, China) were designed and used. Briefly, U373 and U251 were first 
seed in 6-well plates and climbed to the carry sheet glass subsequently. Cells were next washed by cold PBS solution, fixed by $4 \%$ RNase-free paraformaldehyde (PFA) solution for $15 \mathrm{~min}$ and permeabilized by $0.5 \%$ Triton X-100 at room temperature for $5 \mathrm{~min}$. After dehydrated by graded ethanol, cells were then added prepared hybridization mix with circ-PLEKHA5 probe and hybridized at $50^{\circ} \mathrm{C}$ overnight. Next day, the carry glass was washed using $50 \%$ formamide with $0.1 \%$ saline sodium citrate (SSC) solution for $10 \mathrm{~min}$ and stained with 4',6-diamidino-2-phenylindole (DAPI, Beyotime, China) for $5 \mathrm{~min}$ at time temperature. Finally, cells were covered with cover glass and visualized using the confocal microscopy.

\section{Immunofluorescence (IF) assay}

Cells were seeded on chamber slides, fixed with $4 \%$ paraformaldehyde and permeabilized in PBS containing $0.2 \%$ Triton X-100 for 10 min at $-20^{\circ} \mathrm{C}$, and then blocked with $5 \%$ BSA for 2 hours at room temperature. The immunostaining was carried out with primary antibody against GFP fusion proteins (1:100; Abcam, MA, USA) (overnight at $4^{\circ} \mathrm{C}$ ) and anti-rabbit IgG secondary antibody (1:500; Beyotime Institute of Biotechnology, Jiangsu, China) ( $2 \mathrm{~h}$ at room temperature). Then the nuclei were counterstained with DAPI (Beyotime Institute of Biotechnology, Jiangsu, China) for $5 \mathrm{~min}$, and the images were captured using confocal microscope.

\section{Western blot assay}

Western blot procedures were performed as previously described ${ }^{[15]}$. Briefly, total protein was obtained from tissues and cells by using RIPA buffer (Beyotime Institute of Biotechnology, Jiangsu, China), then evaluated by running on SDS-PAGE gels and transferring to PVDF membranes subsequently. Next the membranes were blocked in Tween-Tris-buffered saline (TTBS) containing $5 \%$ non-fat milk for $2 \mathrm{~h}$ and then incubated with specific antibodies as follows: SRSF7 (1:800, ABclonal Technology, Hubei, China), MMP-2 (1:1000, Proteintech Group, Rosement, USA), VE-cadherin (1:1000, Abcam, MA, USA), GAPDH (1:5000, Cell Signaling Technology, MA, USA), circ-PLEKHA5-622aa (1:500, Huada Protein Technology, Beijing, China), Flag-tag (1:1000, Huada Protein Technology, Beijing, China). Membranes were then washed with TTBS and incubated with secondary antibodies for $2 \mathrm{~h}$ at room temperature. Finally, the immunoblots were visualized by Chemlmager 5500 V2.03 software and analyzed using Fluor Chem2.0 software based on GAPDH as an internal control.

\section{Cell proliferation assay}

Proliferation assay of glioma cells were performed using Cell Counting Kit-8 (CCK-8, Beyotime Institute of Biotechnology, Jiangsu, China) as previously described ${ }^{[15]}$. Briefly, cells were seeded at a density of 2500 cells per field, $20 \mu$ l CCK-8 was added subsequently, then the absorbance was analyzed at $450 \mathrm{~nm}$.

\section{Transwell assay}

Cell migration and invasion abilities were evaluated by transwell assays as previously described ${ }^{[15]}$. Briefly, cells were resuspended and seeded onto the upper transwell chamber (Corning, UY, USA), and the 
medium with 10\% FBS was added into the lower chamber. Cells on the lower surface of membrane were then fixed and captured after $48 \mathrm{~h}$ under a light microscope.

\section{In Vitro VM formation assay}

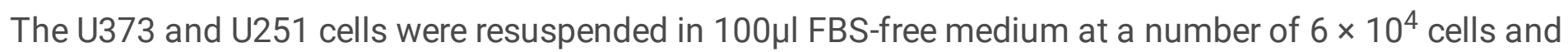
seeded into 96-well culture plates, which was covered by $60 \mu$ l Matrigel Basement Membrane Matrix (BD Bioscience, MA, USA) before. Next, cells were incubated at $37^{\circ} \mathrm{C}$ for $8 \mathrm{~h}$, then visualized and captured under an inverted microscope (Olympus, Tokyo, Japan).

\section{RNA-protein immunoprecipitation (RIP) assay}

RIP assay was performed using EZ-Magna RIP Kit (Millipore, MA, USA) according to the manufacturer's instruction. Briefly, cells were lysed by RNA lysis buffer with protease inhibitor, and incubated with RIP buffer that contains magnetic beads conjugated with anti-SRSF7 antibody or with negative control antiIgG respectively. Next, wash buffer was added into RIP reactions and vortex gently. The fold enrichments of immunoprecipitated RNAs was next isolated and purified, and then analyzed followed qRT-PCR.

\section{Nude mice xenograft model}

For the in vivo study, four weeks old female BALB/C nude mice were purchased from the Cancer Institute of the Chinese Academy of Medical Science and subcutaneously injected with U373 or U251 cells with stable knockdown of SRSF7 and circ-PLEKHA5 $\left(3 \times 10^{5}\right.$ cells each mouse $)$ in the right flank area. Mice were divided into five groups: Control, SRSF7(-)NC+circ-PLEKHA5(-)NC, SRSF7(-), Circ-PLEKHA5(-) and SRSF7(-)+circ-PLEKHA5(-) groups ( $\mathrm{n}=6$ each group), and the volume of transplanted tumors were observed and recorded every 5 days after the inoculation following length $\times$ width $2 / 2 \mathrm{~mm}^{3}$ formula. Tumors were isolated out of the mice after sacrificing them. The experiment was complied with the Administrate Panel on Laboratory Animal Care of China Medical University.

\section{Immunohistochemical dual-staining of CD34 and Periodic Acid-Schiff (PAS)}

The tumor slices were dewaxed under $60^{\circ} \mathrm{C}$ for $30 \mathrm{~min}$, hydrated by xylene and ethanol solution in turn, and then soaked in citric acid buffer at $90^{\circ} \mathrm{C}$ for antigen retrieval. Next, slices were blocked using BSA (Thermo Scientific, MA, USA), incubated with the specific rabbit anti-human antibody of CD34 (Beijing Zhongshan Golden bridge, China) and left in the fridge at $4{ }^{\circ} \mathrm{C}$ overnight. Next day, the goat anti-rabbit secondary antibody and the color reagent DAB (Fuzhou MaiXin Biotech, China) were subsequently added onto the slides. For the staining of PAS, slices were stained with periodic for $10 \mathrm{~min}$, Schiff solution for $10 \mathrm{~min}$, and counterstained with hematoxylin (Baso, Guangdong, China) for $1 \mathrm{~min}$, and PBS solution was used for washing at each interval. Finally, by using the microscope, CD34 and PAS signals were captured evaluated.

\section{Statistical analysis}


In this work, all data were described as mean \pm standard deviation (SD) from at least three times independent experiments. All statistical analysis was conducted using GraphPad Prism 7 software with student's $t$ test (between two groups) or one-way ANOVA analysis (three or more) of variance. $P$ value < 0.05 was considered to be statistically significant.

\section{Results}

\section{SRSF7 was up-regulated in glioma, knockdown of SRSF7 inhibited the VM formation of glioma cells}

The elevated expression level of SRSF7 in glioma samples was first found by using The Cancer Genome Atlas (TCGA) database (Figure S1A), and western blot was further used to verify the prediction. As shown in Figure 1A-B, compared with in normal brain tissues (NBTs) and human astrocyte (HA) cell, the expression level of SRSF7 was significantly up-regulated in glioma tissues and cells respectively, and the expression level was positively correlated with the histopathological grade. To further elucidate the role of SRSF7 in glioma, we constructed SRSF7 silenced U373 and U251 cell lines, and SRSF7 re-expressed cell lines respectively, and evaluated the cell proliferation, VM formation, migration and invasion ability. The results of CCK-8 assay, in vitro VM formation assay and transwell assay indicated that knockdown SRSF7 significantly inhibited the cell proliferation, VM formation, migration and invasion abilities of glioma cells and re-expression of SRSF7 significantly restored the inhibitory effect (Figure 1C-E). Matrix metallopeptidase 2 (MMP-2) and vascular endothelial cadherin (VE-cadherin) are critical VM-associated proteins $^{[16,17]}$. As shown in Figure 1F, knockdown of SRSF7 expressly restrained the expression levels of MMP-2 and VE-cadherin in glioma cells, while re-expressed SRSF7 restored their expression significantly.

\section{Circ-PLEKHA5, not linear PLEKHA5, was up-regulated in glioma.}

By using circRNA microarray analysis, we obtained the effect of SRSF7 on the expression levels of dysregulated circRNAs in glioma, and we found that has_circ_0098068 was up-regulated in glioma cells and significantly down-regulated by transient knockdown of SRSF7 (Figure S1B). Through matching the circRNA database circRNADb, we obtained the generation of hsa_circ_0098068, also regarded as circPLEKHA5, was formed by the circularization of exon4 to exon15 of the pre-mRNA of PLEKHA5 (Figure 2A). In order to confirm the existence of circ-PLEKHA5, we used convergent and divergent primers to detect the existence of linear and circular PLEKHA5, and RNase $R$ was used to eliminate the interference of linear PLEKHA5. As shown in Figure 2B, circ-PLEKHA5 was detected in DNA samples with or without RNase R, while linear PLEKHA5 was only detected in RNase R - group. Furthermore, no circ-PLEKHA5 was found in genomic DNA (gDNA), which confirmed the existence of endogenous circ-PLEKHA5. Next, qRTPCR was carried out to evaluate the expression of circ-PLEKHA5 in glioma tissues and cells, as shown in Figure 2C, circ-PLEKHA5 was significantly up-regulated in glioma tissues and cells, and positively correlated with the pathological grades of glioma tissues. In the meantime, as shown in Figure S1C, there was no dysregulated expression of linear PLEKHA5 was found in glioma tissues or cells. Moreover, circPLEKHA5 was almost located in the cytoplasm of HA, U373 and U251 cells, and was visually elevated in glioma cells (Figure 2D). To evaluate the effect of circ-PLEKHA5 in glioma, stable circ-PLEKHA5 
knockdown glioma cells were established. As shown in Figure 2E-H, knockdown of circ-PLEKHA5 significantly inhibited the proliferation, VM formation, migration and invasion abilities of glioma cells, and also inhibited the expression of MMP-2 and VE-cadherin, while re-expressed circ-PLEKHA5 restored these inhibitory effects.

\section{SRSF7 promoted VM formation of glioma cells by increasing the expression of circ-PLEKHA5}

As previously mentioned, the expression of circ-PLEKHA5 was significantly decreased in SRSF7 silenced cells (Figure S1B), and several studies have found that RNA-binding proteins (RBPs) could increase the generation of circRNAs by binding to the upstream and downstream of their circRNA-forming pre-mRNAs that near the junction sites ${ }^{[18]}$. By using the RNA-binding protein database RBPDb, the putative binding sites between SRSF7 and PLEKHA5 pre-mRNA (300 bases upstream of exon4; 300 bases downstream of exon 15) was found (Figure S1D), therefore, we proposed that circ-PLEKHA5 might be involved in the regulation of SRSF7 on glioma cells. We firstly checked the effect of SRSF7 on circ-PLEKHA5 via qRT-PCR and results showed the expression of circ-PLEKHA5 was reduced in stable SRSF7 silenced glioma cells while re-expressed SRSF7 restored circ-PLEKHA5(Figure 3A). We next carried out the RIP assay and the result showed that PLEKHA5 pre-mRNA was significantly enriched in Anti-SRSF7 groups compared with Anti-IgG group, which confirmed our prediction (Figure 3B). Moreover, as shown in Figure 3C-F, overexpression or knockdown of circ-PLEKHA5 significantly counteracted the inhibitory or promoting role of SRSF7 on the proliferation, VM, migration, invasion and the expression of VM-associated proteins in glioma cells, implied that circ-PLEKHA5 is associated with the effect of SRSF7 on glioma cells.

\section{Circ-PLEKHA5 encoded a novel peptide through its ORF}

By matching circ-PLEKHA5 in circRNADb, a predicted ORF sequence and an IRES sequence were found and circ-PLEKHA5 may encode a 622aa peptide protein by initiation-termination codon "ATG-TGA" (Figure 2A). To investigate the existence of circ-PLEKHA5-622aa, a specific antibody was designed and western blot was carried out. As shown in Figure 4B, compared with circ-PLEKHA5(-)NC group, knockdown of circPLEKHA5 significantly reduced the expression of circ-PLEKHA5-622aa, while re-expressed circ-PLEKHA5 restored the expression of circ-PLEKHA5-622aa. Furthermore, we analyzed the activity of predicted IRES in circ-PLEKHA5 by performing dual-luciferase assay. The full-length and mutated IRES sequence of circPLEKHA5 were cloned and constructed between Rluc and Luc reporters along with their own initiation and termination codons, and the relative luciferase (Luc/Rluc) were analyzed. As shown in Figure 4C, the mutation significantly reduced the luciferase activity, which confirmed the activity of IRES in circPLEKHA5. Moreover, to further verify that endogenous 622aa is translated from circ-PLEKHA5 ORF, we added FLAG tag sequence separately at each end of circ-PLEKHA5 ORF along with flanking sequences for helping cyclization (2\#FLAG-circ-PLEKHA5). For a negative control, one flanking sequence was deleted (3\#AG-circ-PLEKHA5-FL). For a positive control, the integrated sequence that encodes 622aa was constructed with FLAG tag forward termination codon (4\#FLAG-circ-PLEKHA5-ORF). All plasmids above were transfected into U373 and U251 subsequently, and the results followed western blot showed that FLAG tag was found in FLAG-circ-PLEKHA5 group and FLAG-circ-PLEKHA5-ORF group, and the 
expression of 622aa was visually elevated in these two groups compared with in control and negative groups (Figure 4D). Furthermore, the expression level of circ-PLEKHA5 only up-regulated in FLAG-circPLEKHA5 group but not in FLAG-circ-PLEKHA5-ORF group (Figure S1E), and these results further suggested that 622 aa was encoded by circ-PLEKHA5 ORF.

\section{2aa was up-regulated in glioma and promoted VM formation of glioma cells}

We further evaluated the expression level of circ-PLEKHA5-622aa, and as shown in Figure 5A-B, circPLEKHA5-622aa was significantly up-regulated in glioma tissues and cells, and the expression level was positively correlated with the histopathological grade. Moreover, compared with in glioma cells that transfected with GFP vector alone, the localization of GFP was visually more concentrated in the cytoplasm of cells that transfected with 622aa-GFP (Figure 5C). By using bioinformatic software SMART, a pleckstrin homology $(\mathrm{PH})$ domain was found in the amino acid sequence of 622aa (Figure S1F). PH domain was known to be shared with key mediators of cellular biological behaviors due to its phospholipid-binding specificities ${ }^{[19]}$. To further investigate the role of circ-PLEKHA5-622aa but not circPLEKHA5 in glioma, we constructed 622aa overexpressed glioma cells by using FLAG-circ-PLEKHA5-ORF vector, and analyzed the changes in biological behaviors of these cells. As shown in Figure 5D-G, U373 and U251 cells with overexpressed 622aa exhibited increased proliferation, VM formation, migration and invasion abilities, and increased expression of MMP-2 and VE-cadherin. Moreover, overexpressed 622aa also counteracted the inhibitory effect that caused by circ-PLEKHA5 knockdown. These results indicated that circ-PLEKHA5 regulated the malignant biological behaviors by encoding circ-PLEKHA5-622aa. It has been demonstrated that $\mathrm{PH}$ domain-containing proteins are important components that involved in the

regulation of signal transduction pathways on cell behaviors ${ }^{[20]}$. In order to comprehend the potential regulatory mechanism of circ-PLEKHA5-622aa in glioma cells VM formation, we evaluated the effect of PH domain in circ-PLEKHA5-622aa on the expression of p-Akt as well. As shown in Figure S1G, the expression level of p-Akt was significantly increased in circ-PLEKHA5-622aa $(+)$ group, while remained static in circ-PLEKHA5-622aa (+) with mutated PH domain group.

\section{The combination using of SRSF7 and circ-PLEKHA5 inhibitors suppressed tumor growth and VM formation in nude mice}

In order to further determine the roles of SRSF7 and circ-PLEKHA5 in vivo, the nude mice model was used. As shown in Figure 6A-B, the volume of transplanted tumor in SRSF7(-) group and circ-PLEKHA5(-) group was significantly reduced compared with control and negative control groups. In addition, the combined use of SRSF7 and circ-PLEKHA5 inhibitors produced the smallest tumor volume than single use of them respectively. Moreover, the result followed CD34-PAS showed that knockdown of SRSF7 and circPLEKHA5 respectively reduced the VM number of the transplanted tumors and the VM number in SRSF7(-)+circ-PLEKHA5(-) group was the least (Figure 6C).

\section{Discussion}


As critical regulators of various cellular biological processes, RBPs play roles in gene expression, RNA splicing, localization, translation and degradation at post-transcriptional level. Based on this, RBPs can also participated in the development of tumors by influencing specific RNA expression ${ }^{[21,22]}$. SRSF7 is a member of SR protein family which was first found by Cavaloc $Y$ et al. at 1994. SRSF7 contains a motif with function of recognizing specific RNAs at the N-terminus and a structure with function of facilitating spliceosome assembly, and based on this, SRSF7 participates in alternative splicing processes of multiple pre-mRNAs ${ }^{[23]}$. So far SRSF7 is known to express abnormally and play regulatory roles in multiple cancers including lung cancer, kidney cancer and colon cancer ${ }^{[7,23,24]}$. In this study, based on the TCGA database, we found for the first time that SRSF7 was highly expressed in glioma tissues and cells, especially in high grade. Knockdown of SRSF7 significantly inhibited the proliferation, VM formation, migration and invasion abilities of glioma cells, and also decreased the expression level of VM-related proteins MMP-2 and VE-cadherin. Furthermore, the re-expression of SRSF7 eliminated the effect of SRSF7 inhibition on glioma cells, suggesting that SRSF7 plays a role as an oncogene in glioma. Similar to our research, SRSF7 was found to highly express in lung cancer and colon cancer, knockdown of SRSF7 inhibited the proliferation and promoted the apoptosis of tumor cells. In addition, SRSF7 is also upregulated in gastric and prostate cancers, and the expression level is positively correlated with poor prognosis of patients ${ }^{[25]}$.

PLEKHA5 (Pleckstrin homology domain-containing protein family A member 5) is a member of the PLEKHA family which is known to contain Trp-Trp (WW) and pleckstrin homology (PH) domains. Yamada et al. found that two forms of PLEKHA5 mRNA are widely expressed in human tissues and play a role in brain development due to contain $\mathrm{PH}$ domains and their ability to associate with $\mathrm{PI} 3 \mathrm{P}, \mathrm{PI}(3.5) \mathrm{P} 2$ and other specific phosphoinositides compounds ${ }^{[26]}$. In addition, PLEKHA5 is also been found to abundantly expressed in the cytoplasm and cell membrane, and closely related to the process of cell migration and vascular formation ${ }^{[27]}$. In the cell model of brain metastasis of melanoma, knockdown of PLEKHA5 inhibits the proliferation of tumor cells, blocks cell cycle at G1-S progression, thereby inhibiting the tumorigenesis of tumor cells in vivo ${ }^{[28]}$. CircRNAs is a class of endogenous RNA with an atypical structure of covalently binding of 5 '- and 3 '- ends. As the forefront of biological researches, a growing number of circRNAs have been found to be involved in various tumor progression and viewed as potential therapeutic targets ${ }^{[29]}$. Many circRNAs including circ-U2AF1, circ-SMARCA5 and circ-DENND2A are abnormally expressed in gliomas and involved in regulating glioma cell behaviors ${ }^{[30-32]}$. Yang $\mathrm{P}$ et al. found that knockdown of circ-ZNF292 could down-regulate the proliferation and angiogenesis of glioma cells by inhibiting the activity of Wnt/ $\beta$ pathway ${ }^{[33]}$. Circ-PLEKHA5, by matching in database CircBase (hsa_circ_0098067) and CircRNADb (hsa_circ_00571), is composed of 12 exons of PLEKHA5 pre-mRNA with 1810 nucleotides long. In our study, we first identified the existence of circ-PLEKHA5 and found that circ-PLEKHA5 was up-regulated in glioma tissues and cells and mainly located in cytoplasm. Knockdown of circ-PLEKHA5 significantly inhibited the proliferation, VM formation, migration and invasion abilities of glioma cells, and also decreased the expression level of VM-related proteins MMP-2 and VE-cadherin. 
Furthermore, the re-expression of circ-PLEKHA5 eliminated the effect of circ-PLEKHA5 inhibition on glioma cells, indicating circ-PLEKHA5 as an oncogene in glioma.

Several studies have found that RBPs could bind to multiple pre-mRNAs at the upstream or downstream of circRNAs forming exon adjacent sites, especially flanking sequences or intronic repeated sequences, thereby promoting the back-splicing of pre-mRNA along with the covalent binding of adjacent exons, and the generation of circRNAs ${ }^{[18]}$. Based on UCSC and RBPmap database, two potential binding sites of SRSF7 and PLEKHA5 pre-mRNA were found th the upstream and downstream of the circ-PLEKHA5 sequence respectively. After a series of experiments, we confirmed the molecular mechanism that SRSF7 promoted the formation and expression level of circ-PLEKHA5 through binding to PLEKHA5 pre-mRNA. Similar to our finding, RBP-Sam68 has been reported to promote the circularization of SMN exons along with the generation of circ-SMN by binding to SMN pre-mRNA ${ }^{[34]}$. RBP-QKI binds to the upstream and downstream of SMARCA5 pre-mRNA flanking sequence and promotes the cyclization of adjacent exons to form circ-SMARCA5 ${ }^{[31]}$.

With the technical evolution of deep RNA sequencing and ribosomal profiling technologies, circRNAs that previously considered as non-coding RNAs, have been identified to encode small peptides through its own open reading frames (ORFs) and driven by internal ribosome entry site (IRES) ${ }^{[35]}$. In addition, the peptide proteins, instead of their initial circRNAs, could regulate the development of various cancers including glioma according to their amino acid sequence and functional structure ${ }^{[36]}$. For instance, circ-PPP1R12A73aa that encoded by circ-PPP1R12A ORF is highly expressed in colon cancer and promotes colon cancer cell proliferation, migration and invasion abilities by activating Hippo-YAP signaling pathway ${ }^{[37]}$. In liver cancer, $\beta$-catenin-370aa that encoded by circ- $\beta$-catenin protects $\beta$-catenin by prevent it from binding GSK3 $\beta$ and ubiquitination, thereby promoting tumor growth ${ }^{[38]}$. Based on the prediction on database circRNADb, we investigated the coding ability of circ-PLEKHA5 and confirmed that circ-PLEKHA5 could encode a 622 amino acid (aa) peptide circ-PLEKHA5-622aa. Moreover, the expression level of 622aa was significantly elevated in glioma. We next investigated the potential function of circ-PLEKHA5-622aa, and the results showed that the elevated 622aa, independent of circ-PLEKHA5, significantly increased the proliferation, migration, invasion and VM formation abilities of glioma cells and also reversed the inhibitory effects caused by circ-PLEKHA5-depletion. These results indicated that circ-PLEKHA5 regulated the malignant behaviors of glioma cells by encoding circ-PLEKHA5-622aa.

Pleckstrin homology (PH) domain is a region of approximately 100 to 120 amino acids that mostly occurs in a wide range of proteins which are involved in intracellular signaling or as constituents of the cytoskeleton ${ }^{[39]}$. It has been reported that the $\mathrm{PH}$ domain is essential for $\mathrm{PH}$-domain-containing proteins, especially cytosolic signaling proteins, to interact with phosphatidylinositol-(3, 4, 5)-triphosphate (PIP3) and recruit proteins to participated in multiple signal pathways ${ }^{[40]}$. For instance, the $\mathrm{PH}$ domain in Akt pathway regulator PDK1 is recognized and binds to PIP3, which activates Akt signaling and promotes cell angiogenesis subsequently ${ }^{[41]}$. As a critical modulating molecule, the phosphorylation of Akt has been found to promote the proliferation, migration and VM formation of glioma cells by regulating the 
downstream effector MMP-2 ${ }^{[42,43]}$. Due to the PH domain that PLEKHA5 contains, PLEKHA5 was supposedly to be associated with multiple phosphoinositide binding properties and PI3K-AKT pathway, thereby participating in intracellular functions ${ }^{[44]}$. It was reported that the expression of phosphorylated AKT (p-Akt) was decreased in PLEKHA5-depleted melanoma cells ${ }^{[28]}$. By scanning the amino acid sequence, $\mathrm{PH}$ domain was also found in circ-PLEKHA5-622aa. In our study, we found that the PH domain in circ-PLEKHA5-622aa significantly increased the expression level of p-Akt, indicating that circ-PLEKHA5622aa may play the roles by activating p-Akt. Similarly, circ-SHPRH and circ-SHPRH-146aa were downregulated and functioned as tumor suppressors in glioma ${ }^{[13]}$, circ-PINT suppressed the proliferation and migration of glioma cells via encoding circ-PINT-87aa ${ }^{[14]}$.

Finally, by performing the in vivo study, we demonstrated that the alone or combined use of SRSF7 inhibitor and circ-PLEKHA5 inhibitor observably inhibited the tumor growth and prolonged the survival times of nude mice, and the combined use resulted in the smallest tumors and the highest survival times. Moreover, the CD34-PAS that performed in xenografted tumors showed that knockdown SRSF7 or circPLEKHA5 significantly inhibited the VM formation in vivo, and the combined use resulted in the least VMs in vivo. These suggested that the combination use of SRSF7 inhibitor and circ-PLEKHA5 inhibitor might has potential clinical application value in the treatment of glioma.

\section{Conclusion}

Collectively, our study found the elevated expression levels of SRSF7, circ-PLEKHA5 in glioma tissues and cells, and knockdown of SRSF7 or circ-PLEKHA5 inhibited VM formation of glioma cells in vitro and in vivo. SRSF7 promoted the generation of circ-PLEKHA5 through binding to PLEKHA5 pre-mRNA and a novel peptide protein 622aa that encoded by circ-PLEKHA5 ORF was identified. Moreover, we found that circ-PLEKHA5-622aa was elevated in glioma and promoted the VM formation of glioma cells itself. In summary, our finding first reveled that SRSF7/circ-PLEKHA5/circ-PLEKHA5-622aa module regulated the biological behaviors and VM formation of glioma cells, as well as provided a novel insight for the treatment of glioma.

\section{Abbreviations}

VM Vasculogenic mimicry

SRSF7 Serine/arginine-rich splicing factor 7

FISH RNA fluorescence in situ hybridization

RIP RNA-binding protein immunoprecipitation

PAS Periodic Acid-Schiff

NBTs Normal brain tissues 
HA Human astrocyte

ORFs Open read frames

IRES Internal ribosome entry site

aa Amino acid

PH Pleckstrin homology

\section{Declarations}

\section{Ethics approved and consent to participate}

Each patient was provided informed consent and all experiments of this study were approved by the Ethics Committee of Shengjing Hospital of China Medical University.

\section{Consent for publication}

In this article, the material original research and has not been published elsewhere in whole or in part. All authors have read and approved the content, and agree to submit for consideration for publication in the Journal of Experimental \& Clinical Cancer Research.

\section{Availability of data and materials}

All data in our study are available upon request.

\section{Competing interests}

The authors declare no competing interests.

\section{Funding}

This work is supported by grants from the Natural Science Foundation of China $(81872503,81872073$, 81802507); China Postdoctoral Science Foundation (2019M661172); Liaoning Science and Technology Plan Project (2020-BS-097and 2017225020).

\section{Authors' contributions}

$\mathrm{XL}$ and $\mathrm{YL}$ contributed to the design and conception of this study. RS conceived the experiment and wrote the manuscript. LS and $Y X$ contributed to the manuscript revision. $\mathrm{XR}, \mathrm{CY}$ and $\mathrm{HC}$ performed the cellular experiments. DW and BY performed the experiment implementation. HT and ZL contributed to animal experiments. All authors read and approved the final manuscript.

\section{Acknowledgements}


We thank the Department of Neurobiology of China Medical University for providing equipment and assistance to support this research.

\section{References}

[1]. Gusyatiner O, Hegi ME. Glioma epigenetics: From subclassification to novel treatment options[J]. Semin Cancer Biol. 2018;51:50-8.

[2]. Delgado-Bellido D, Serrano-Saenz S, Fernandez-Cortes M, et al. Vasculogenic mimicry signaling revisited: focus on non-vascular VE-cadherin[J]. Mol Cancer. 2017;16(1):65.

[3]. El Hallani S, Boisselier B, Peglion F, et al. A new alternative mechanism in glioblastoma vascularization: tubular vasculogenic mimicry[J]. Brain. 2010;133(Pt 4):973-82.

[4]. Zhang J, Lieu YK, Ali AM, et al. Disease-associated mutation in SRSF2 misregulates splicing by altering RNA-binding affinities[J]. Proc Natl Acad Sci U S A. 2015;112(34):E4726-34.

[5]. Song X, Wan X, Huang T, et al. SRSF3-Regulated RNA Alternative Splicing Promotes Glioblastoma Tumorigenicity by Affecting Multiple Cellular Processes[J]. Cancer Res. 2019;79(20):5288-301.

[6]. Chen J, Crutchley J, Zhang D, et al. Identification of a DNA Damage-Induced Alternative Splicing Pathway That Regulates p53 and Cellular Senescence Markers[J]. Cancer Discov. 2017;7(7):766-81.

[7]. Boguslawska J, Sokol E, Rybicka B, et al. microRNAs target SRSF7 splicing factor to modulate the expression of osteopontin splice variants in renal cancer cells[J]. Gene. 2016;595(2):142-9.

[8]. Li F, Yi Y, Miao Y, et al. N(6)-Methyladenosine Modulates Nonsense-Mediated mRNA Decay in Human Glioblastoma[J]. Cancer Res. 2019;79(22):5785-98.

[9]. Legnini I, Di Timoteo G, Rossi F, et al. Circ-ZNF609 Is a Circular RNA that Can Be Translated and Functions in Myogenesis[J]. Mol Cell. 2017;66(1):22-37 e9.

[10]. Li X, Yang L, Chen LL. The Biogenesis, Functions, and Challenges of Circular RNAs[J]. Mol Cell. 2018;71(3):428-42.

[11]. Chen CY, Sarnow P. Initiation of protein synthesis by the eukaryotic translational apparatus on circular RNAs[J]. Science. 1995;268(5209):415-7.

[12]. Wang J, Zhu S, Meng N, et al. ncRNA-Encoded Peptides or Proteins and Cancer[J]. Mol Ther. 2019;27(10):1718-25.

[13]. Zhang M, Huang N, Yang X, et al. A novel protein encoded by the circular form of the SHPRH gene suppresses glioma tumorigenesis[J]. Oncogene. 2018;37(13):1805-14. 
[14]. Zhang M, Zhao K, Xu X, et al. A peptide encoded by circular form of LINC-PINT suppresses oncogenic transcriptional elongation in glioblastoma[J]. Nat Commun. 2018;9(1):4475.

[15]. Su R, Cao S, Ma J, et al. Knockdown of SOX2OT inhibits the malignant biological behaviors of glioblastoma stem cells via up-regulating the expression of miR-194-5p and miR-122[J]. Mol Cancer. 2017;16(1):171.

[16]. Gory-Faure S, Prandini MH, Pointu H, et al. Role of vascular endothelial-cadherin in vascular morphogenesis[J]. Development. 1999;126(10):2093-102.

[17]. Seftor RE, Seftor EA, Koshikawa N, et al. Cooperative interactions of laminin 5 gamma2 chain, matrix metalloproteinase-2, and membrane type-1-matrix/metalloproteinase are required for mimicry of embryonic vasculogenesis by aggressive melanoma[J]. Cancer Res. 2001;61(17):6322-7.

[18]. Liang D, Wilusz JE. Short intronic repeat sequences facilitate circular RNA production[J]. Genes \& development. 2014;28(20):2233-47.

[19]. Dowler S, Currie RA, Campbell DG, et al. Identification of pleckstrin-homology-domain-containing proteins with novel phosphoinositide-binding specificities[J]. Biochem J. 2000;351(Pt 1):19-31.

[20]. Workman P, Clarke PA, Guillard S, et al. Drugging the PI3 kinome[J]. Nat Biotechnol. 2006;24(7):7946.

[21]. Chatterji P, Rustgi AK. RNA Binding Proteins in Intestinal Epithelial Biology and Colorectal Cancer[J]. Trends Mol Med. 2018;24(5):490-506.

[22]. Pereira B, Billaud M, Almeida R. RNA-Binding Proteins in Cancer: Old Players and New Actors[J]. Trends Cancer. 2017;3(7):506-28.

[23]. Fu Y, Wang Y. SRSF7 knockdown promotes apoptosis of colon and lung cancer cells[J]. Oncol Lett. 2018;15(4):5545-52.

[24]. Saijo S, Kuwano Y, Masuda K, et al. Serine/arginine-rich splicing factor 7 regulates p21-dependent growth arrest in colon cancer cells[J]. J Med Invest. 2016;63(3-4):219-26.

[25]. Chen Z, Hu H. Identification of prognosis biomarkers of prostatic cancer in a cohort of 498 patients from TCGA[J]. Curr Probl Cancer. 2019;43(6):100503.

[26]. Yamada K, Nomura N, Yamano A, et al. Identification and characterization of splicing variants of PLEKHA5 (Plekha5) during brain development[J]. Gene. 2012;492(1):270-5.

[27]. Jilaveanu LB, Parisi F, Barr ML, et al. PLEKHA5 as a Biomarker and Potential Mediator of Melanoma Brain Metastasis[J]. Clin Cancer Res. 2015;21(9):2138-47. 
[28]. Zhang H, Zhu H, Deng G, et al. PLEKHA5 regulates tumor growth in metastatic melanoma[J]. Cancer. 2019.

[29]. Meng S, Zhou H, Feng Z, et al. CircRNA: functions and properties of a novel potential biomarker for cancer[J]. Mol Cancer. 2017;16(1):94.

[30]. Li G, Huang M, Cai Y, et al. Circ-U2AF1 promotes human glioma via derepressing neuro-oncological ventral antigen 2 by sponging hsa-miR-7-5p[J]. J Cell Physiol. 2019;234(6):9144-55.

[31]. Barbagallo D, Caponnetto A, Cirnigliaro M, et al. CircSMARCA5 Inhibits Migration of Glioblastoma Multiforme Cells by Regulating a Molecular Axis Involving Splicing Factors SRSF1/SRSF3/PTB[J]. Int J Mol Sci. 2018;19(2).

[32]. Su H, Zou D, Sun Y, et al. Hypoxia-associated circDENND2A promotes glioma aggressiveness by sponging miR-625-5p[J]. Cell Mol Biol Lett. 2019;24:24.

[33]. Yang P, Qiu Z, Jiang Y, et al. Silencing of cZNF292 circular RNA suppresses human glioma tube formation via the Wnt/beta-catenin signaling pathway[J]. Oncotarget. 2016;7(39):63449-55.

[34]. Pagliarini V, Jolly A, Bielli P, et al. Sam68 binds Alu-rich introns in SMN and promotes pre-mRNA circularization[J]. Nucleic Acids Res. 2020;48(2):633-45.

[35]. Wu P, Mo Y, Peng M, et al. Emerging role of tumor-related functional peptides encoded by IncRNA and circRNA[J]. Mol Cancer. 2020;19(1):22.

[36]. Kong S, Tao M, Shen X, et al. Translatable circRNAs and IncRNAs: Driving mechanisms and functions of their translation products[J]. Cancer Lett. 2020;483:59-65.

[37]. Zheng X, Chen L, Zhou Y, et al. A novel protein encoded by a circular RNA circPPP1R12A promotes tumor pathogenesis and metastasis of colon cancer via Hippo-YAP signaling[J]. Mol Cancer. 2019;18(1):47.

[38]. Liang WC, Wong CW, Liang PP, et al. Translation of the circular RNA circbeta-catenin promotes liver cancer cell growth through activation of the Wnt pathway[J]. Genome Biol. 2019;20(1):84.

[39]. Rebecchi MJ, Scarlata S. Pleckstrin homology domains: a common fold with diverse functions[J]. Annu Rev Biophys Biomol Struct. 1998;27:503-28.

[40]. Park H, Lee S, Shrestha P, et al. AMIGO2, a novel membrane anchor of PDK1, controls cell survival and angiogenesis via Akt activation[J]. J Cell Biol. 2015;211(3):619-37.

[41]. Lim MA, Kikani CK, Wick MJ, et al. Nuclear translocation of 3'-phosphoinositide-dependent protein kinase 1 (PDK-1): a potential regulatory mechanism for PDK-1 function[J]. Proc Natl Acad Sci U S A. 2003;100(24):14006-11. 
[42]. Cai HP, Wang J, Xi SY, et al. Tenascin-cmediated vasculogenic mimicry formation via regulation of MMP2/MMP9 in glioma[J]. Cell Death Dis. 2019;10(12):879.

[43]. Wu HB, Yang S, Weng HY, et al. Autophagy-induced KDR/VEGFR-2 activation promotes the formation of vasculogenic mimicry by glioma stem cells[J]. Autophagy. 2017;13(9):1528-42.

[44]. Eisele SC, Gill CM, Shankar GM, et al. PLEKHA5: A Key to Unlock the Blood-Brain Barrier?[J]. Clin Cancer Res. 2015;21(9):1978-80.

\section{Figures}

A

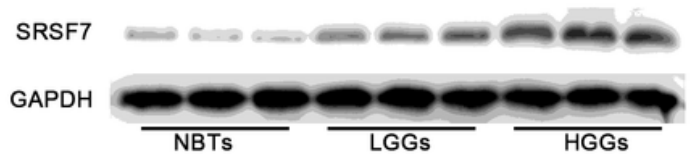

C

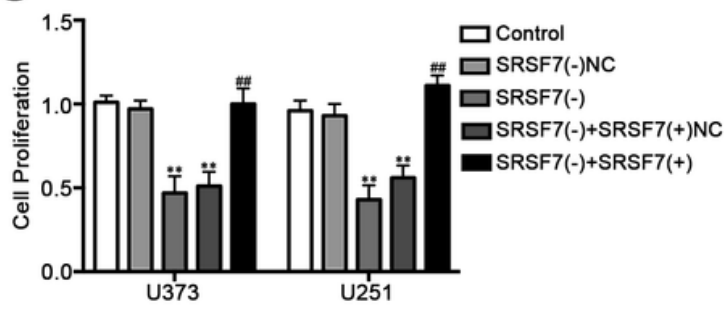

$\mathrm{E}$

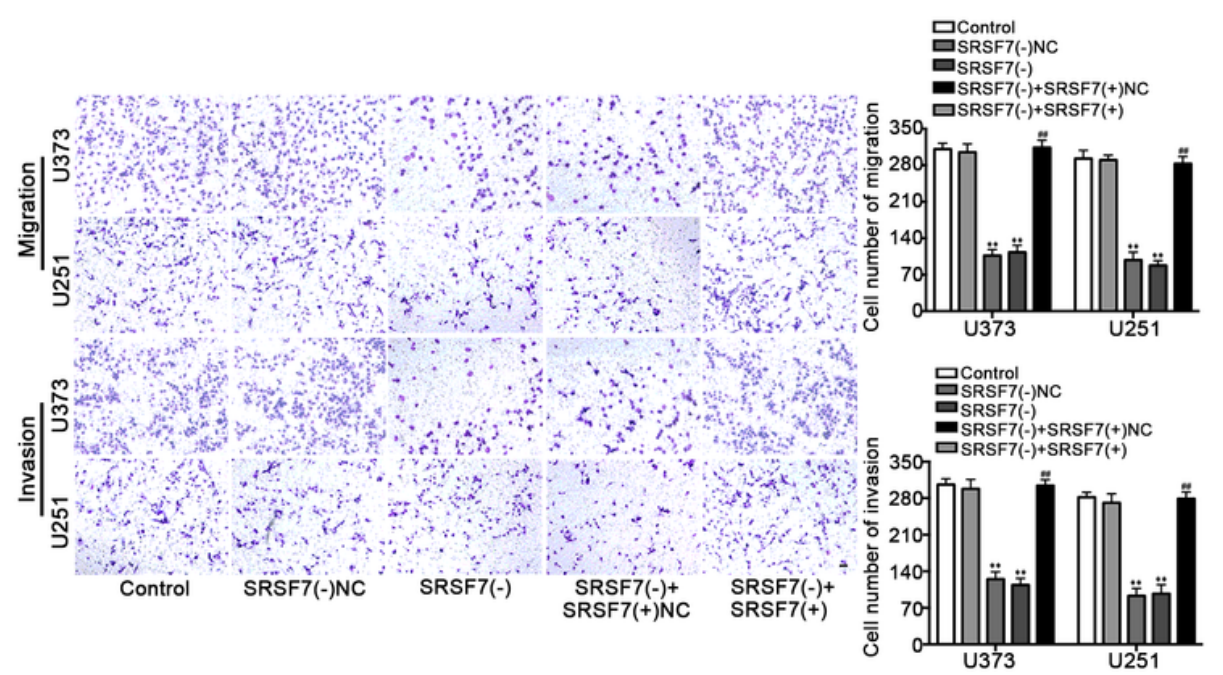

B
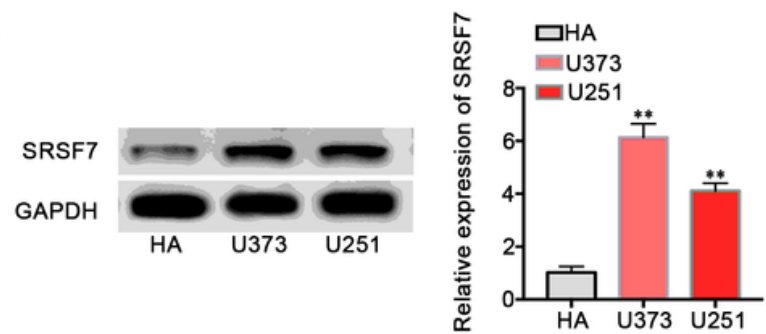

D
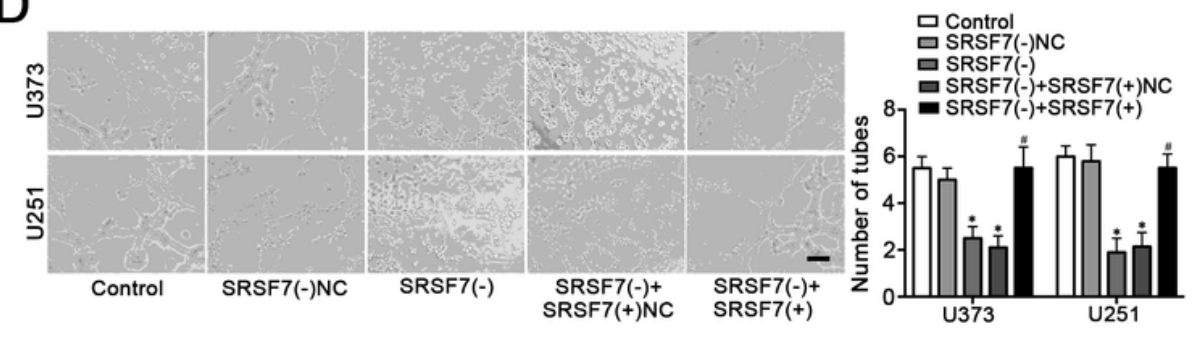

$\mathrm{F}$
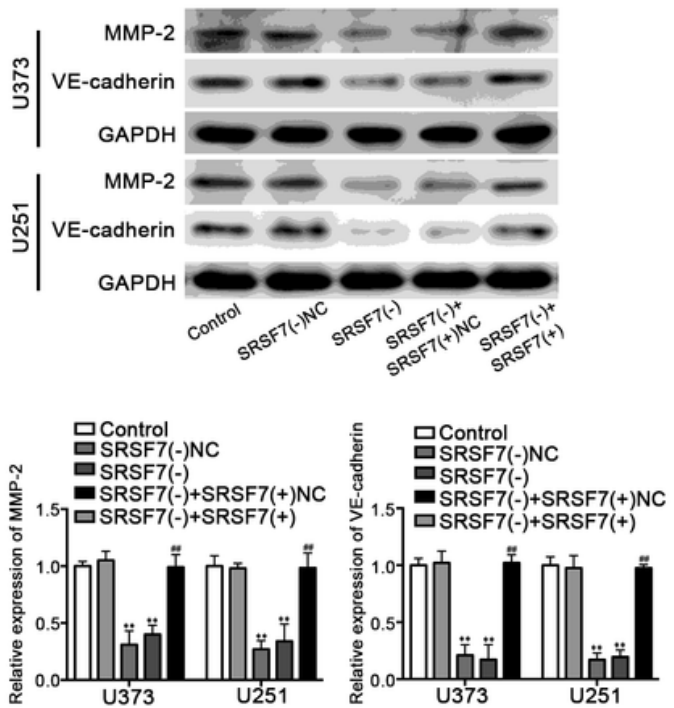

Figure 1

SRSF7 was up-regulated in glioma, knockdown of SRSF7 inhibited VM formation of glioma cells. A. The expression level of SRSF7 in nontumorous brain tissues (NBTs), low-grade glioma tissues (LGGs, WHO III) and high-grade glioma tissues (HGGs, WHO III-IV). Data were presented as the mean $\pm S D(n=3$, each 
group). ${ }^{*} \mathrm{P}<0.01$ versus NBTs group; \#\#P<0.01 versus LGGs group. $B$. The expression level of SRSF7 in human astrocyte (HA) cells and glioma cells $U 373$ and U251. Data were presented as the mean $\pm S D(n=3$, each group). ${ }^{*} \mathrm{P}<0.01$ versus HA group. C. The effect of SRSF7 on the proliferation of U373 and U251 was evaluated by CCK-8 assays. D. The effect of SRSF7 on the VM formation of U373 and U251 was evaluated by in vivo VM formation assays. E. The effect of SRSF7 on the migration and invasion of U373 and U251 was evaluated by transwell assays. F. The effect of SRSF7 on the VM-related proteins MMP-2 and VE-cadherin in U373 and U251 was analyzed by western blot assays, and GAPDH was used as internal control. Values are the average $\pm S D\left(n=3\right.$, each group). ${ }^{*} P<0.01$ or ${ }^{*} P<0.05$ versus SRSF7(-)NC group, \#\#P<0.01 or \#P<0.05 versus SRSF7(-)+SRSF7(+)NC group. Scale bar represents $30 \mu \mathrm{m}$.

A

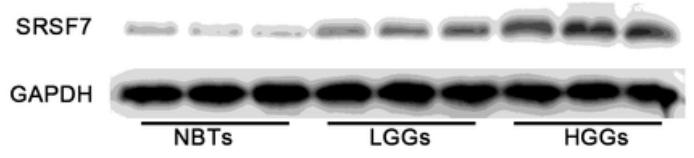

C

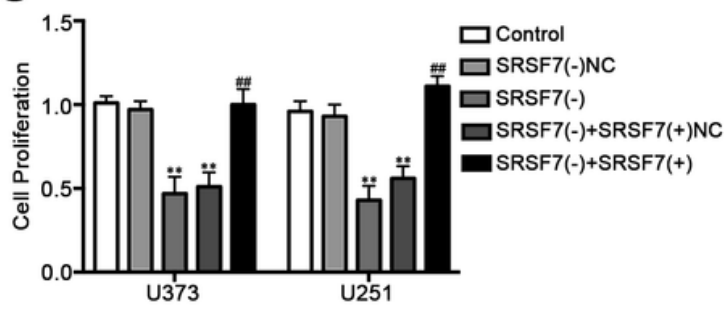

$\mathrm{E}$

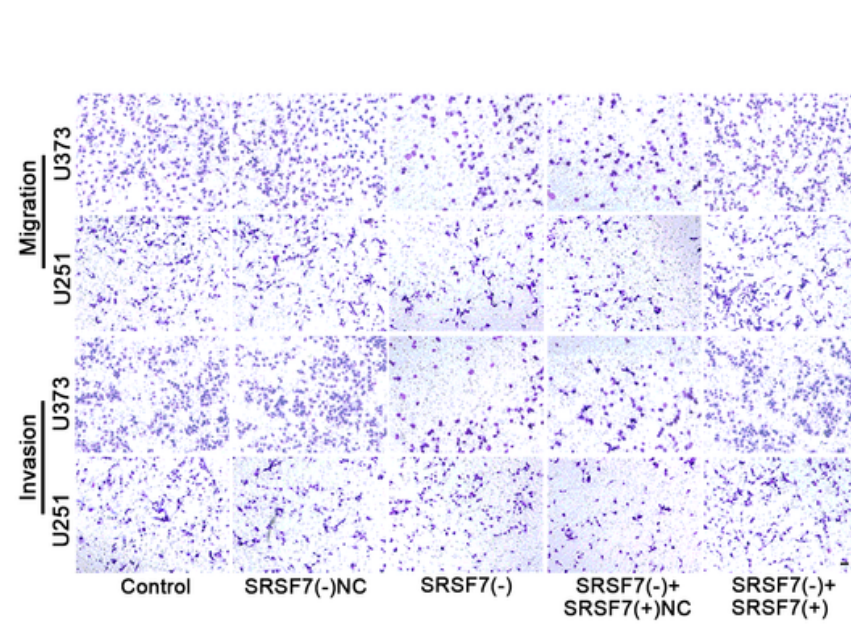

$\mathrm{D}$

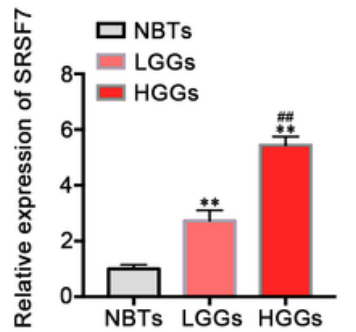

B
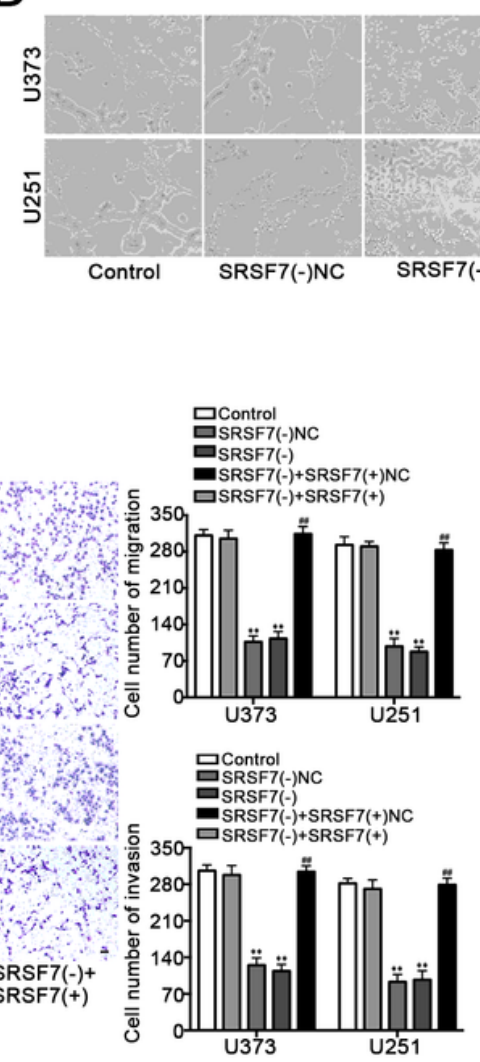

$\mathrm{F}$
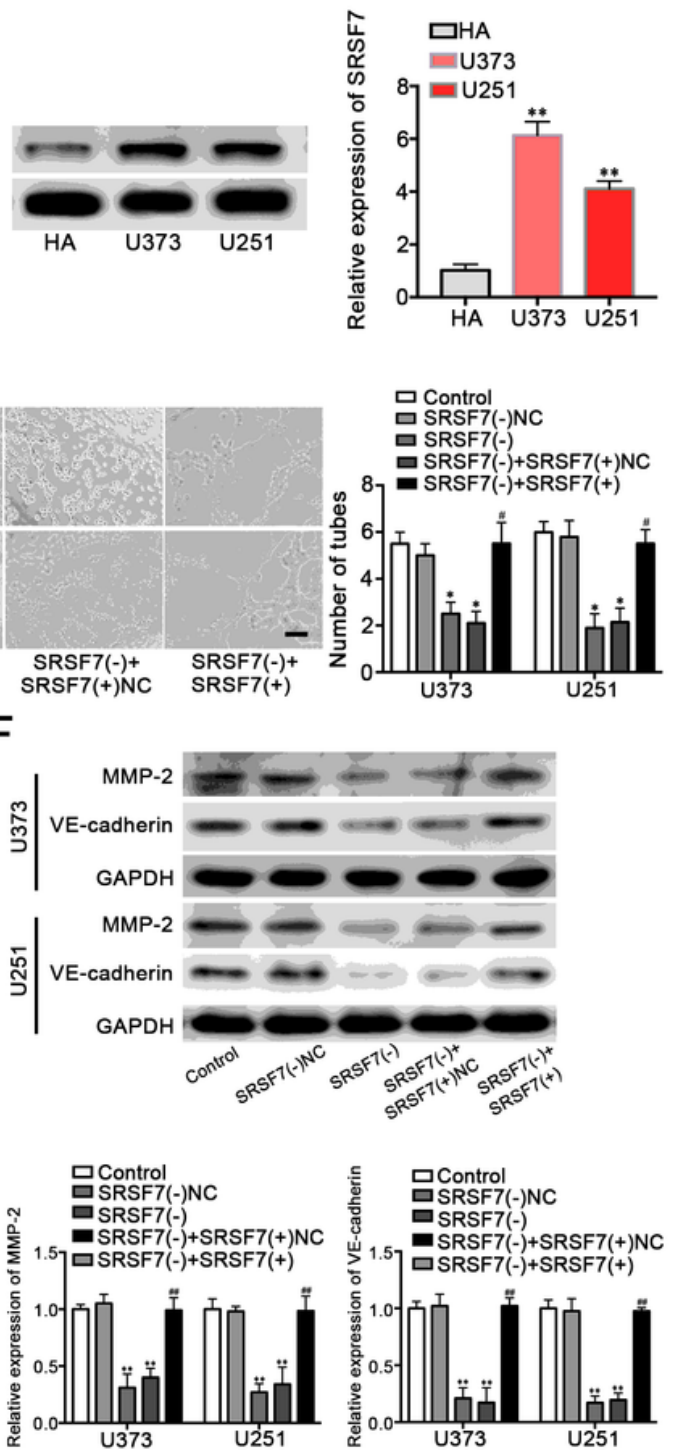

Figure 1

SRSF7 was up-regulated in glioma, knockdown of SRSF7 inhibited VM formation of glioma cells. A. The expression level of SRSF7 in nontumorous brain tissues (NBTs), low-grade glioma tissues (LGGs, WHO III) and high-grade glioma tissues (HGGs, WHO III-IV). Data were presented as the mean $\pm S D(n=3$, each group). ${ }^{*} \mathrm{P}<0.01$ versus NBTs group; \#\#P<0.01 versus LGGs group. $B$. The expression level of SRSF7 in human astrocyte (HA) cells and glioma cells U373 and U251. Data were presented as the mean $\pm S D(n=3$, 
each group). ${ }^{\star \star} \mathrm{P}<0.01$ versus HA group. C. The effect of SRSF7 on the proliferation of U373 and U251 was evaluated by CCK-8 assays. D. The effect of SRSF7 on the VM formation of U373 and U251 was evaluated by in vivo VM formation assays. E. The effect of SRSF7 on the migration and invasion of U373 and U251 was evaluated by transwell assays. F. The effect of SRSF7 on the VM-related proteins MMP-2 and VE-cadherin in U373 and U251 was analyzed by western blot assays, and GAPDH was used as internal control. Values are the average $\pm S D\left(n=3\right.$, each group). ${ }^{\star} * P<0.01$ or $* P<0.05$ versus SRSF7(-)NC group, \#\#P<0.01 or \#P<0.05 versus SRSF7(-)+SRSF7(+)NC group. Scale bar represents $30 \mu \mathrm{m}$.

A
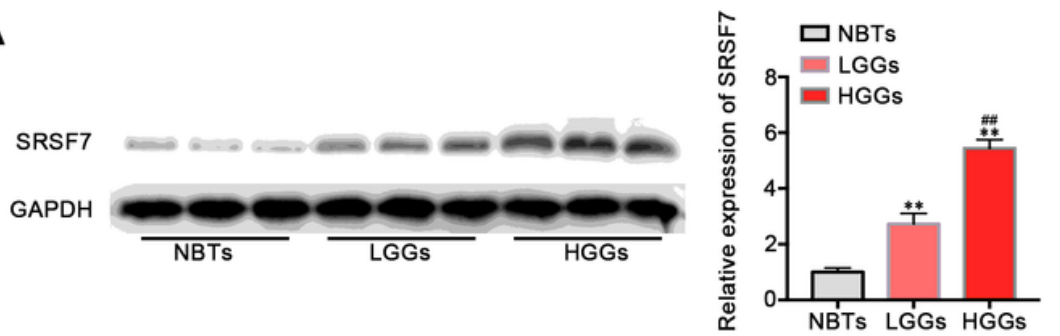

B

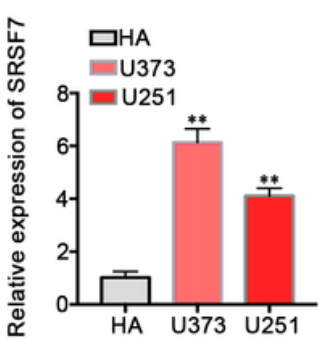

C

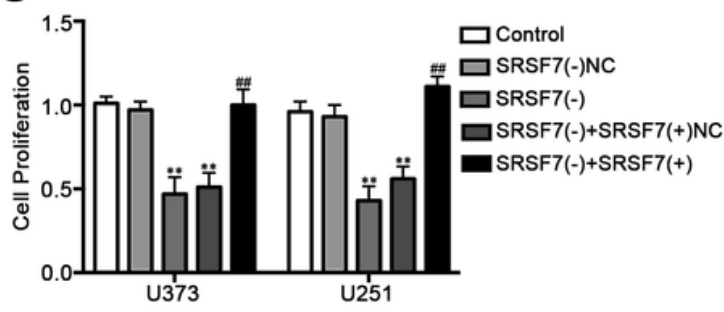

$E$

D
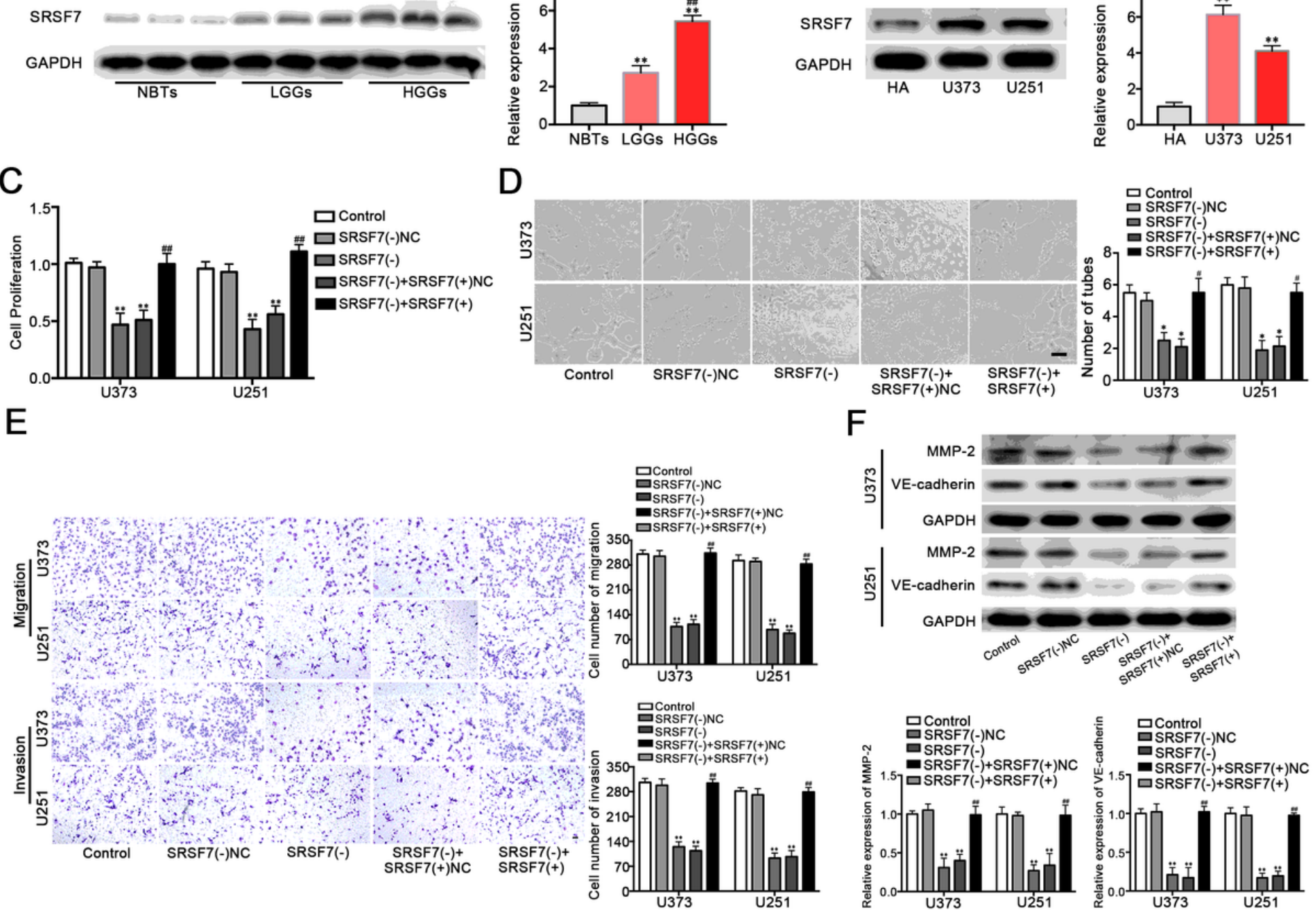

$\mathrm{F}$
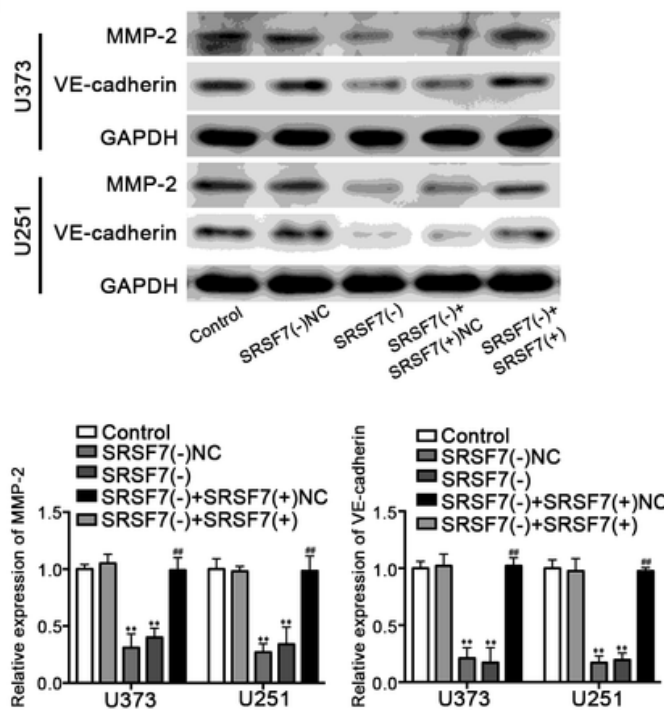

Figure 1

SRSF7 was up-regulated in glioma, knockdown of SRSF7 inhibited VM formation of glioma cells. A. The expression level of SRSF7 in nontumorous brain tissues (NBTs), low-grade glioma tissues (LGGs, WHO III) and high-grade glioma tissues (HGGs, WHO III-IV). Data were presented as the mean $\pm S D(n=3$, each group). ${ }^{*} \mathrm{P}<0.01$ versus NBTs group; \#\#P<0.01 versus $L G G$ s group. $B$. The expression level of $S R S F 7$ in human astrocyte (HA) cells and glioma cells $U 373$ and U251. Data were presented as the mean $\pm S D(n=3$, each group). ${ }^{\star \star} \mathrm{P}<0.01$ versus HA group. $\mathrm{C}$. The effect of SRSF7 on the proliferation of U373 and U251 was evaluated by CCK-8 assays. D. The effect of SRSF7 on the VM formation of U373 and U251 was 
evaluated by in vivo VM formation assays. E. The effect of SRSF7 on the migration and invasion of U373 and U251 was evaluated by transwell assays. F. The effect of SRSF7 on the VM-related proteins MMP-2 and VE-cadherin in U373 and U251 was analyzed by western blot assays, and GAPDH was used as internal control. Values are the average $\pm S D\left(n=3\right.$, each group). ${ }^{*} P<0.01$ or ${ }^{*} P<0.05$ versus SRSF7(-)NC group, \#\#P<0.01 or \#P<0.05 versus SRSF7(-)+SRSF7(+)NC group. Scale bar represents $30 \mu \mathrm{m}$.

A

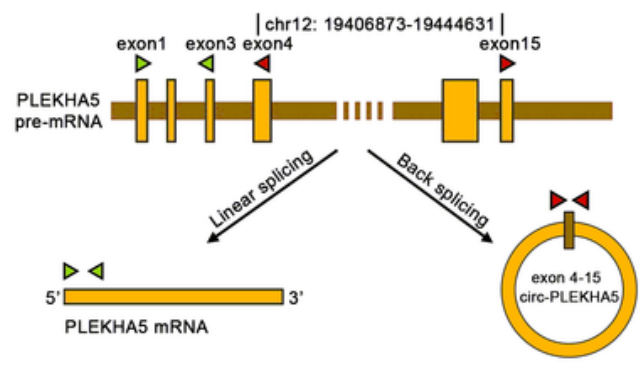

B

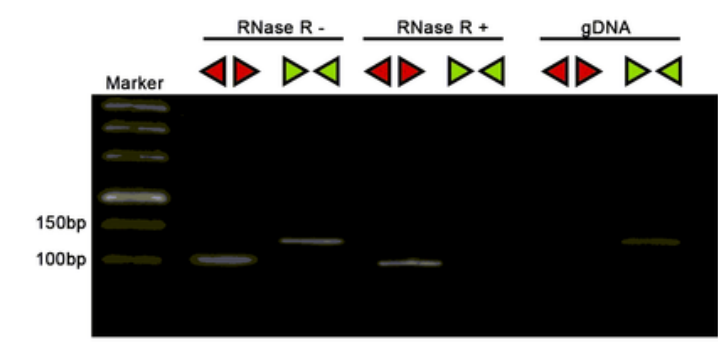

C

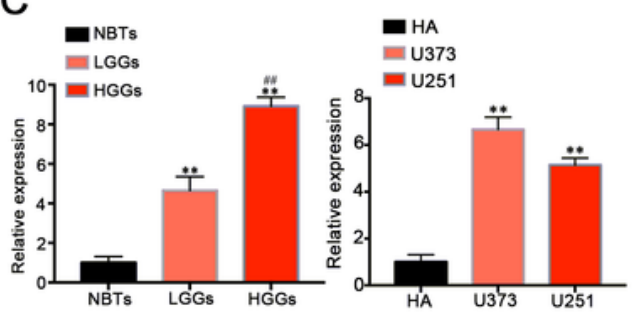

$\mathrm{F}$

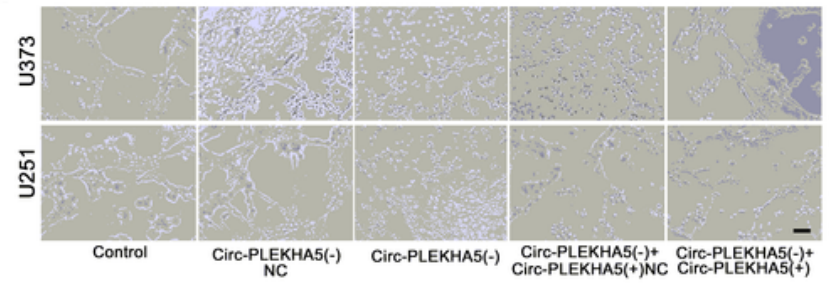

D

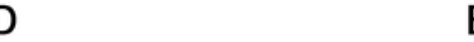

E D control

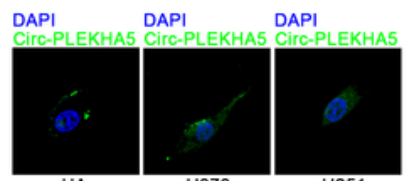

$\square$ Circ-PLEKHA5(-)NC

$\square$ Circ-PLEKHA5(-)
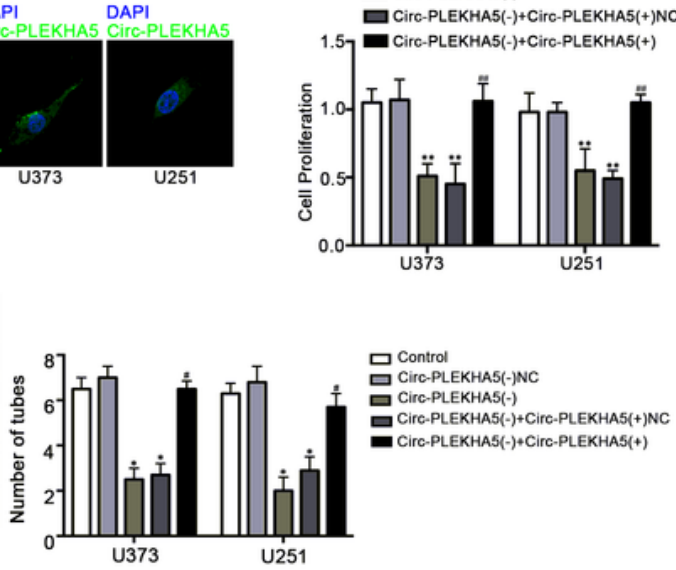

G
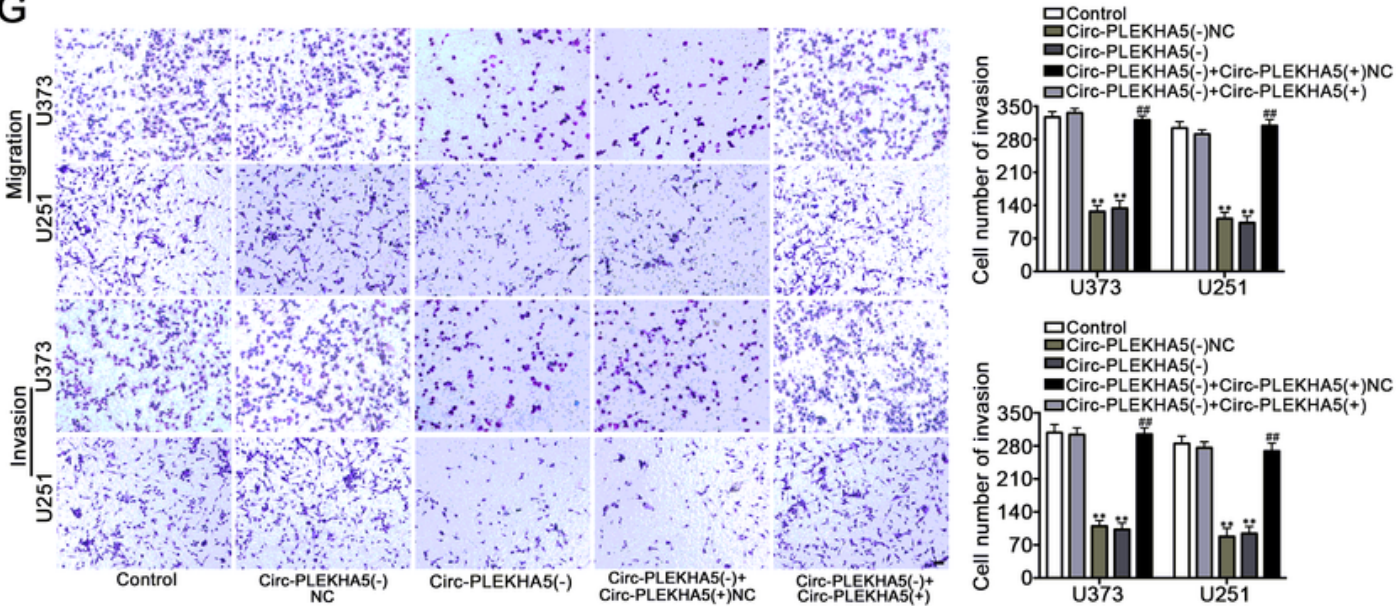

H

$H_{\text {MMP-2 }}$
H
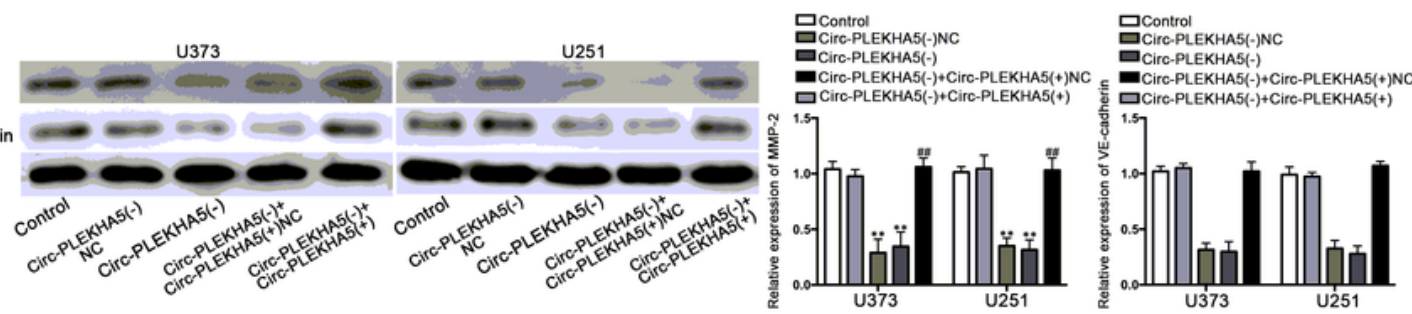

Figure 2 
Circ-PLEKHA5 was up-regulated in glioma, knockdown of circ-PLEKHA5 inhibited VM formation of glioma cells. A. Illustration of how circ-PLEKHA5 arose from PLEKHA5 pre-mRNA based on circBase, and how the convergent (green) and divergent (red) primers were designed to detect the linear-PLEKHA5 and circPLEKHA5. B. The presence of circ-PLEKHA5 was detected by divergent primer in cDNA but not in gDNA. C. The expression levels of circ-PLEKHA5 in glioma tissues and cells were analyzed by qRT-PCR respectively. Values are the average $\pm S D\left(n=3\right.$, each group). ${ }^{* *} P<0.01$ versus NBTs or HA groups, $\# \# P<0.01$ versus HGGs group. D. The visual expression and location of circ-PLEKHA5 in HA and glioma cells were determined by FISH. (green: circ-PLEKHA5; blue: DAPI nuclear staining). E. The effect of circPLEKHA5 on the proliferation of glioma cells. F. The effect of circ-PLEKHA5 on the VM formation of U373 and U251. G. The effect of circ-PLEKHA5 on the migration and invasion of glioma cells. H. The effect of circ-PLEKHA5 on the VM-related proteins MMP-2 and VE-cadherin in U373 and U251. Values are the average $\pm S D$ ( $n=3$, each group). ${ }^{*} P<0.01$ or ${ }^{*} P<0.05$ versus circ-PLEKHA5(-)NC group, $\# \# P<0.01$ or $\# P<0.05$ versus circ-PLEKHA5(-)+circ-PLEKHA5(+)NC group. Scale bar represents $30 \mu \mathrm{m}$. 
A

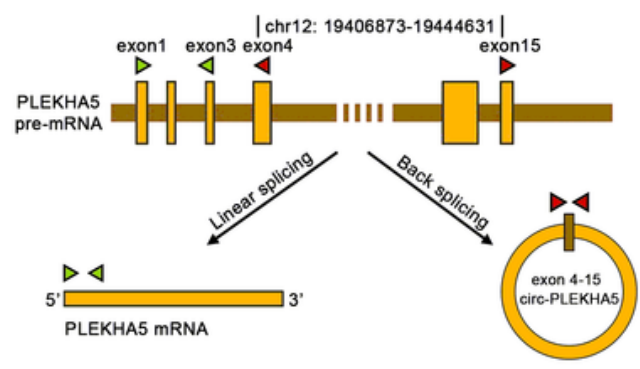

B

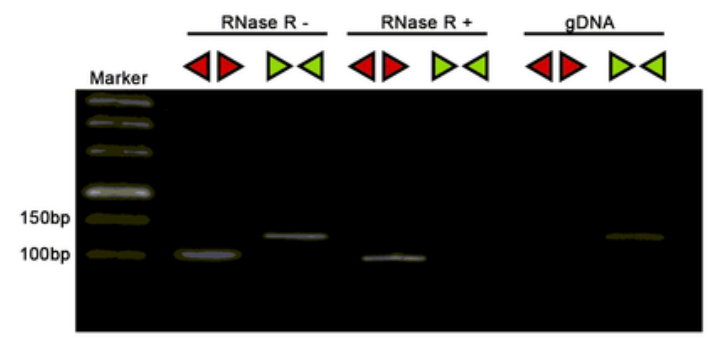

E acontrol

口 Control

口 CirC-PLEKHA5(-)

口Circ-PLEKHA5(-)+Circ-PLEKHA5(+)NC
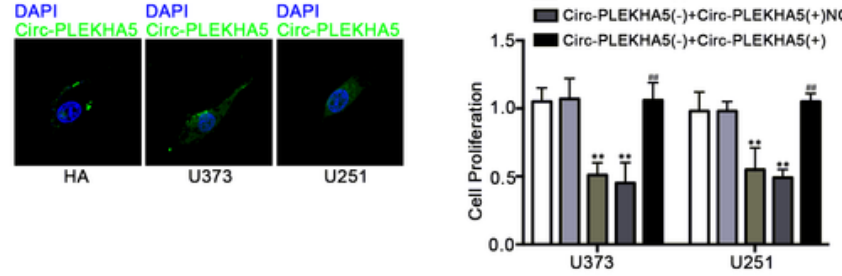

U373

J251

F
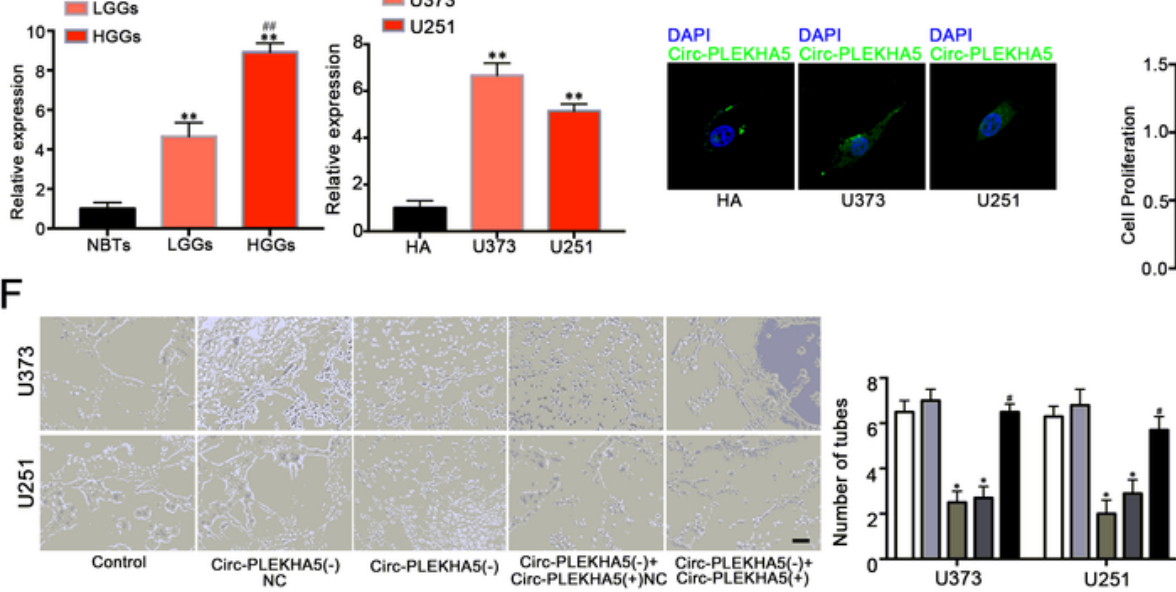

ㅁ Control

CirC-PLEKHA5(-)NC

Circ-PLEKHA5(-)+Circ-PLEKHA5(+)NC

- Circ-PLEKHAS(-)+Circ-PLEKHA5(+)

G

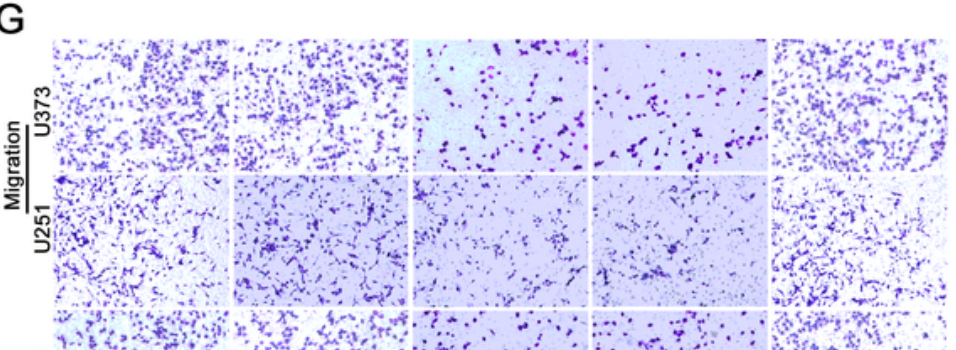

口Control
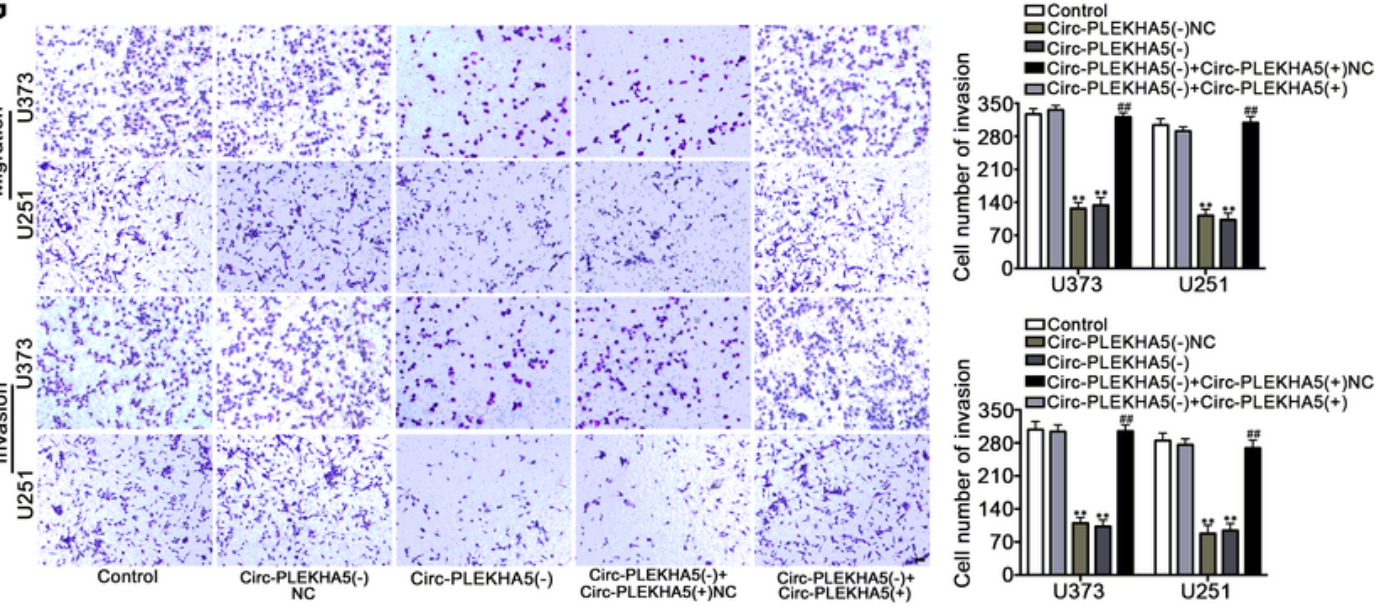

$\mathrm{H}$
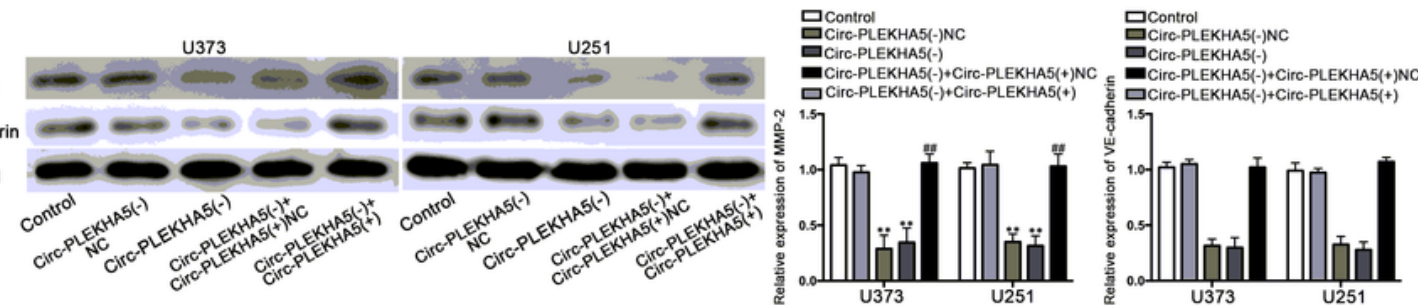

Figure 2

Circ-PLEKHA5 was up-regulated in glioma, knockdown of circ-PLEKHA5 inhibited VM formation of glioma cells. A. Illustration of how circ-PLEKHA5 arose from PLEKHA5 pre-mRNA based on circBase, and how the convergent (green) and divergent (red) primers were designed to detect the linear-PLEKHA5 and circPLEKHA5. B. The presence of circ-PLEKHA5 was detected by divergent primer in cDNA but not in gDNA. C. The expression levels of circ-PLEKHA5 in glioma tissues and cells were analyzed by qRT-PCR 
respectively. Values are the average $\pm S D\left(n=3\right.$, each group). ${ }^{* \star} P<0.01$ versus NBTs or HA groups, $\# \# P<0.01$ versus HGGs group. D. The visual expression and location of circ-PLEKHA5 in HA and glioma cells were determined by FISH. (green: circ-PLEKHA5; blue: DAPI nuclear staining). E. The effect of circPLEKHA5 on the proliferation of glioma cells. F. The effect of circ-PLEKHA5 on the VM formation of U373 and U251. G. The effect of circ-PLEKHA5 on the migration and invasion of glioma cells. H. The effect of circ-PLEKHA5 on the VM-related proteins MMP-2 and VE-cadherin in U373 and U251. Values are the average $\pm S D$ ( $n=3$, each group). ${ }^{*} P<0.01$ or ${ }^{*} P<0.05$ versus circ-PLEKHA5(-)NC group, $\# \# P<0.01$ or $\# P<0.05$ versus circ-PLEKHA5(-)+circ-PLEKHA5(+)NC group. Scale bar represents $30 \mu \mathrm{m}$. 
A

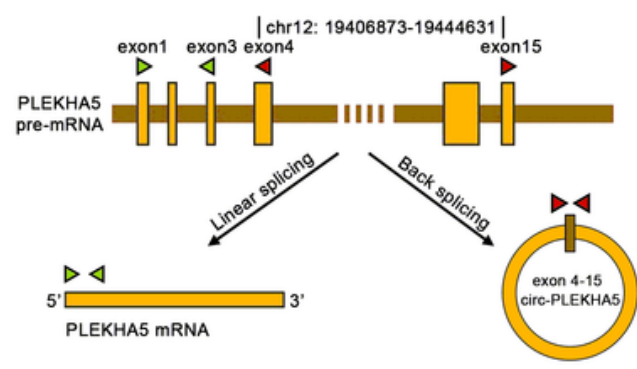

C

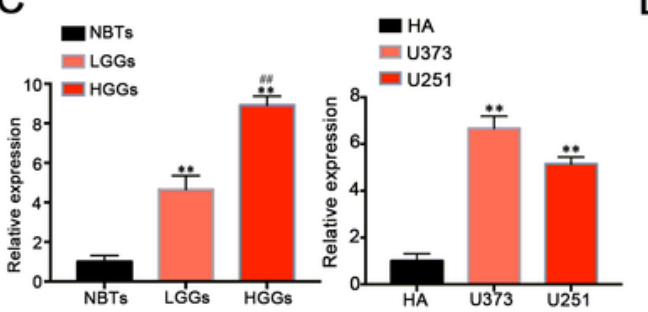

$\mathrm{F}$

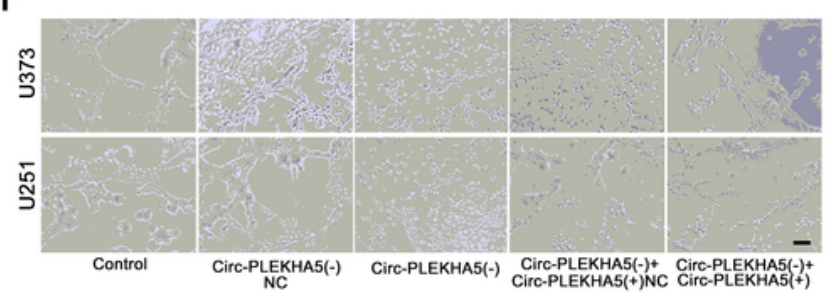

B

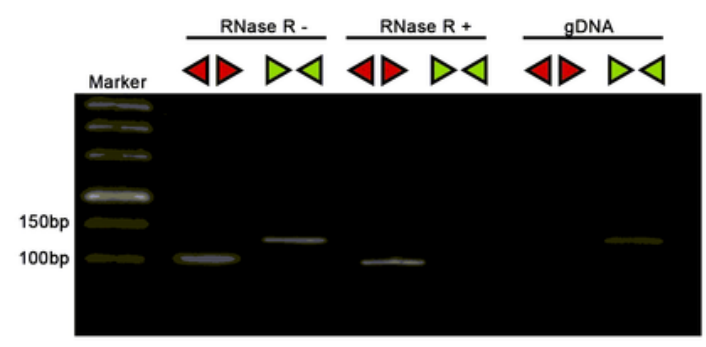

E

E 口 contro

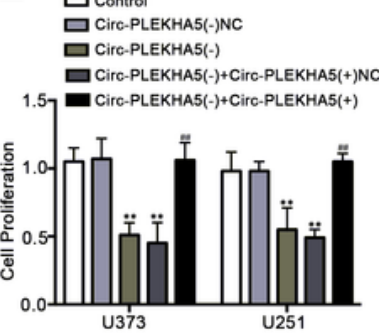

\section{G}
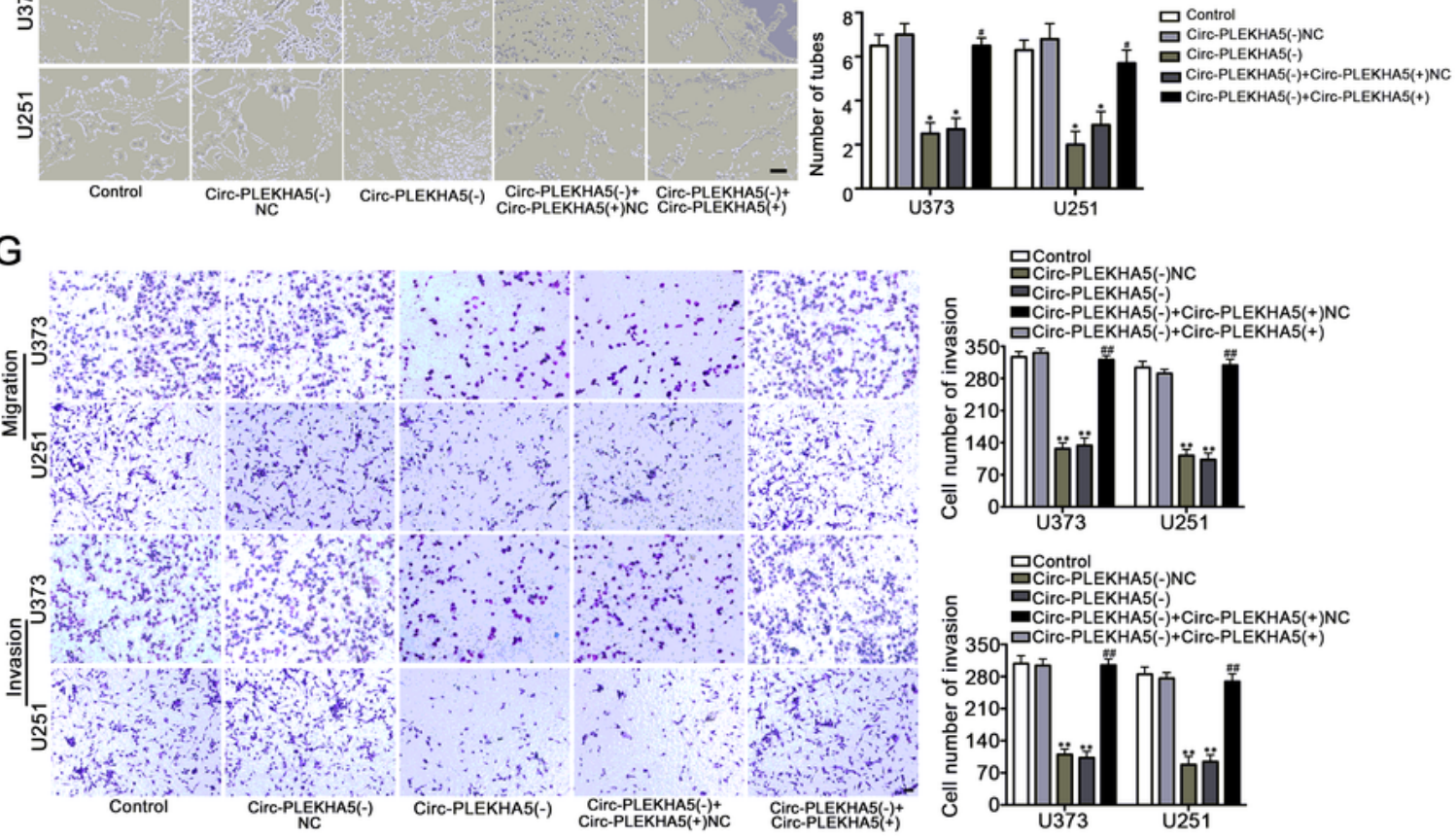

$\mathrm{H}$
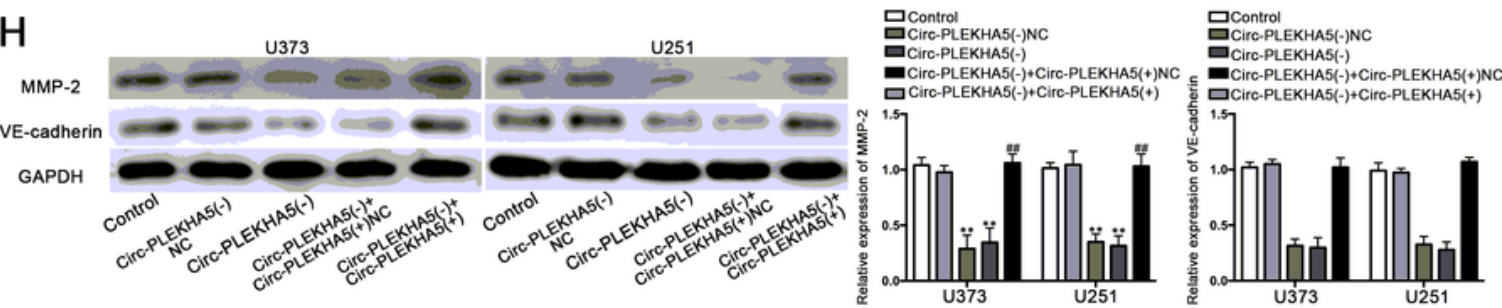

Figure 2

Circ-PLEKHA5 was up-regulated in glioma, knockdown of circ-PLEKHA5 inhibited VM formation of glioma cells. A. Illustration of how circ-PLEKHA5 arose from PLEKHA5 pre-mRNA based on circBase, and how the convergent (green) and divergent (red) primers were designed to detect the linear-PLEKHA5 and circPLEKHA5. B. The presence of circ-PLEKHA5 was detected by divergent primer in cDNA but not in gDNA. C. The expression levels of circ-PLEKHA5 in glioma tissues and cells were analyzed by qRT-PCR 
respectively. Values are the average $\pm S D\left(n=3\right.$, each group). ${ }^{* \star} P<0.01$ versus NBTs or HA groups, $\# \# P<0.01$ versus HGGs group. D. The visual expression and location of circ-PLEKHA5 in HA and glioma cells were determined by FISH. (green: circ-PLEKHA5; blue: DAPI nuclear staining). E. The effect of circPLEKHA5 on the proliferation of glioma cells. F. The effect of circ-PLEKHA5 on the VM formation of U373 and U251. G. The effect of circ-PLEKHA5 on the migration and invasion of glioma cells. H. The effect of circ-PLEKHA5 on the VM-related proteins MMP-2 and VE-cadherin in U373 and U251. Values are the average $\pm S D$ ( $n=3$, each group). ${ }^{*} P<0.01$ or ${ }^{*} P<0.05$ versus circ-PLEKHA5(-)NC group, $\# \# P<0.01$ or $\# P<0.05$ versus circ-PLEKHA5(-)+circ-PLEKHA5(+)NC group. Scale bar represents $30 \mu \mathrm{m}$. 
A

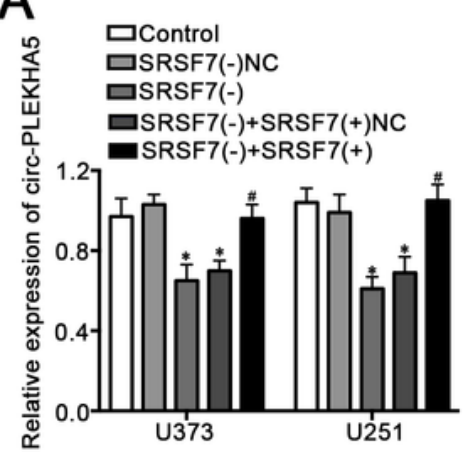

D

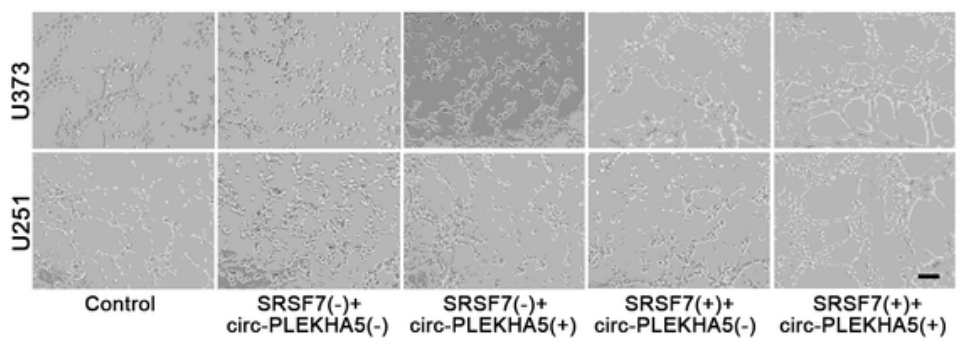

$\mathrm{E}$

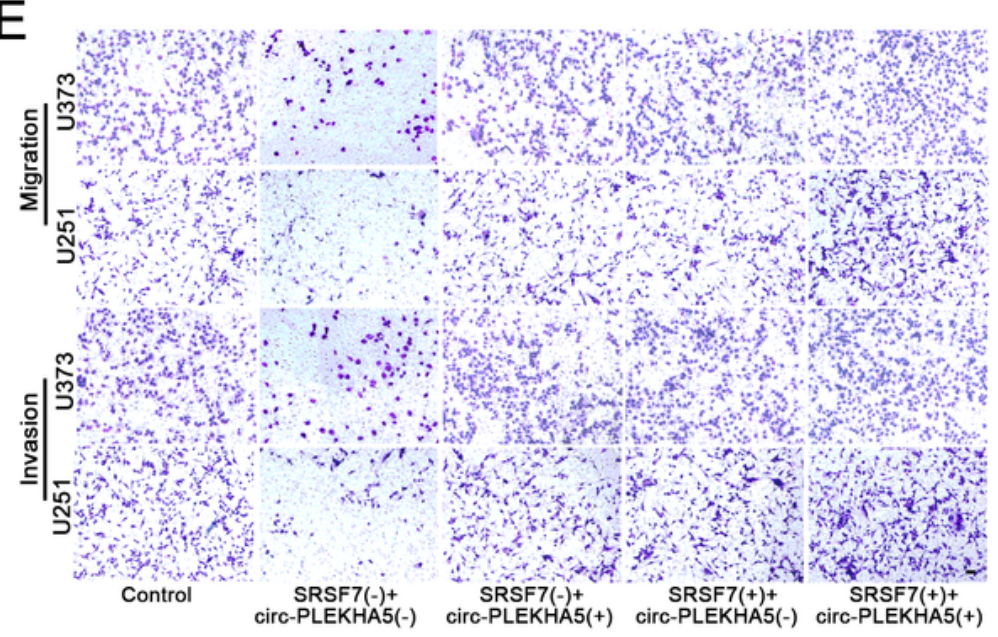

$\mathrm{F}$
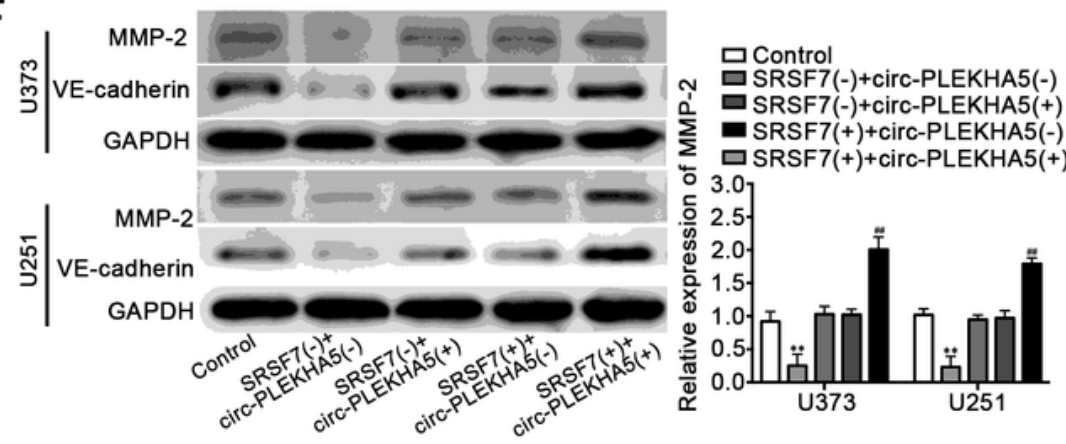

C

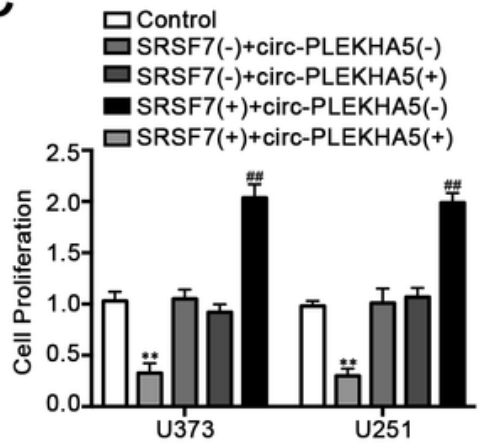

$\square$ Control

$\square$ SRSF7(-)+circ-PLEKHA5(-)

$\square$ SRSF7(-)+circ-PLEKHA5(+)

- SRSF7(+)+circ-PLEKHA5(-)
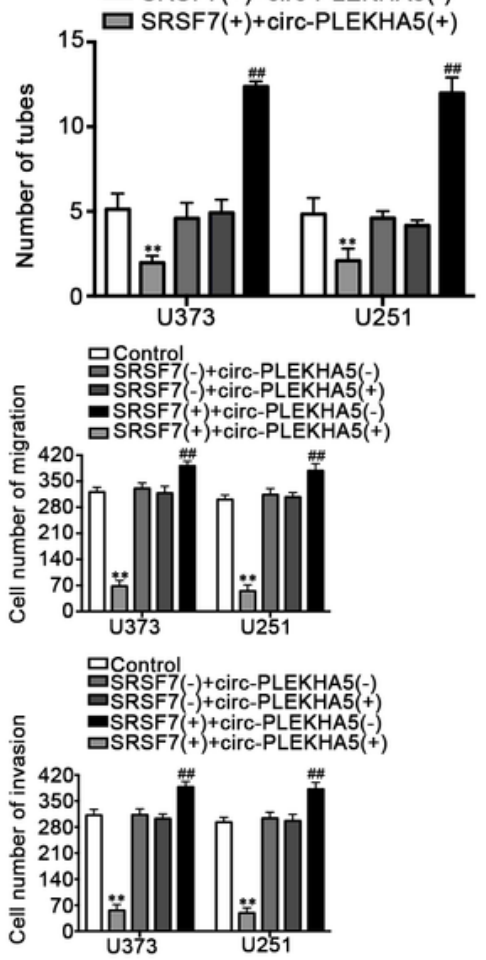

Figure 3

SRSF7 promoted VM formation of glioma cells by regulating circ-PLEKHA5. A. The effect of SRSF7 on the expression level of circ-PLEKHA5 was detected by qRT-PCR. Values are the average $\pm S D(n=3$, each group). ${ }^{*}<0.05$ versus SRSF7(-)NC group, \#P<0.05 versus SRSF7(-)+SRSF7(+)NC group. B. The relative enrichment of PLEKHA5 pre-mRNA in anti-IgG and anti-SRSF7 was determined by RIP assay. ${ }^{*} \mathrm{P}<0.01$ versus Anti-lgG group. C. The co-effects of SRSF7 and circ-PLEKHA5 on the proliferation, D. VM 
formation, E. migration and invasion of U373 and U251 cells. F. The co-effects of SRSF7 and circPLEKHA5 on the expression level of MMP-2 and VE-cadherin. Values are the average $\pm S D(n=3$, each group). ${ }^{*} \mathrm{P}<0.01$ versus Control group, \#\#P<0.01 versus SRSF7(+)+circ-PLEKHA5(+) group. Scale bar represents $30 \mu \mathrm{m}$.
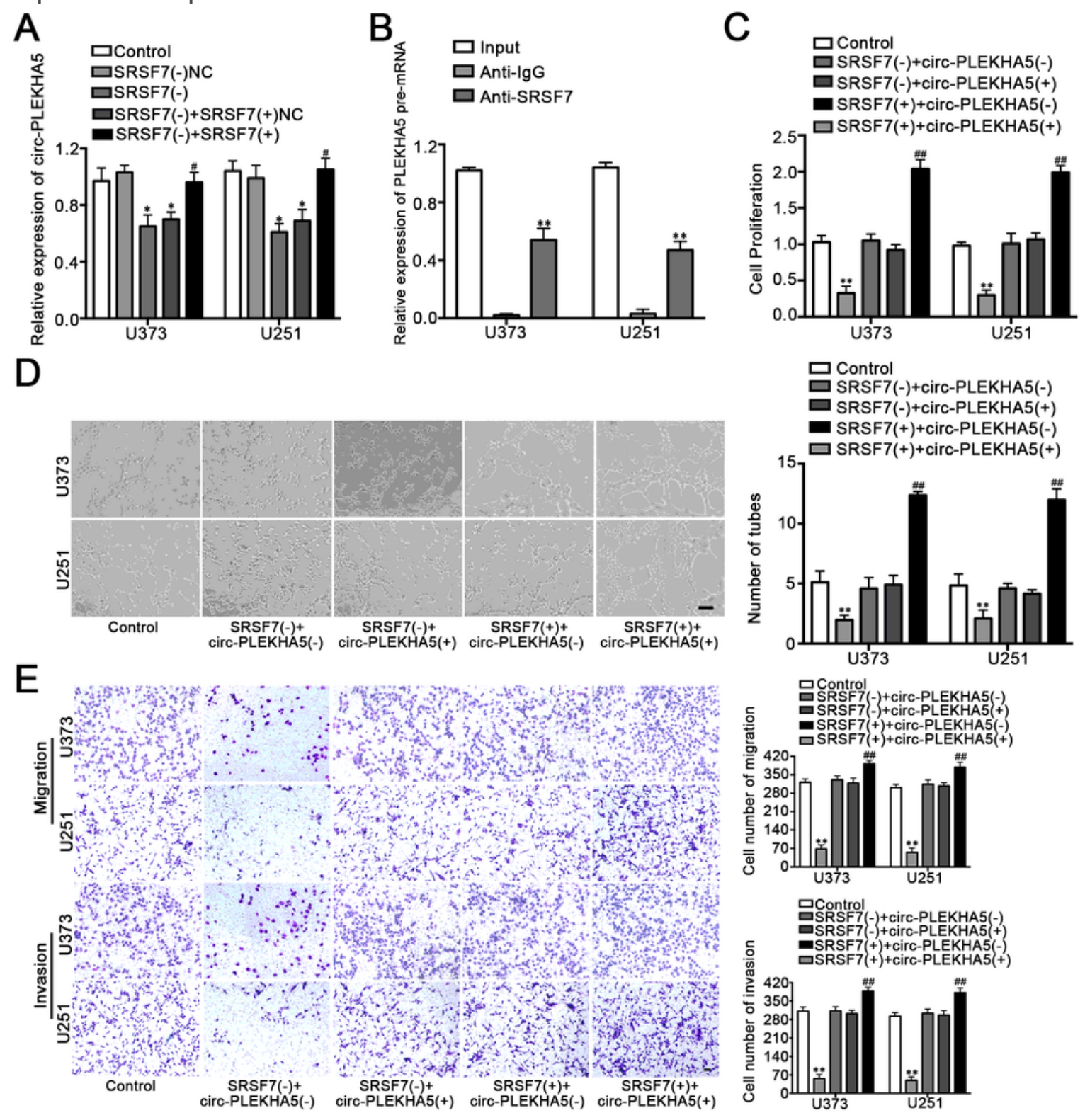

$\mathrm{F}$
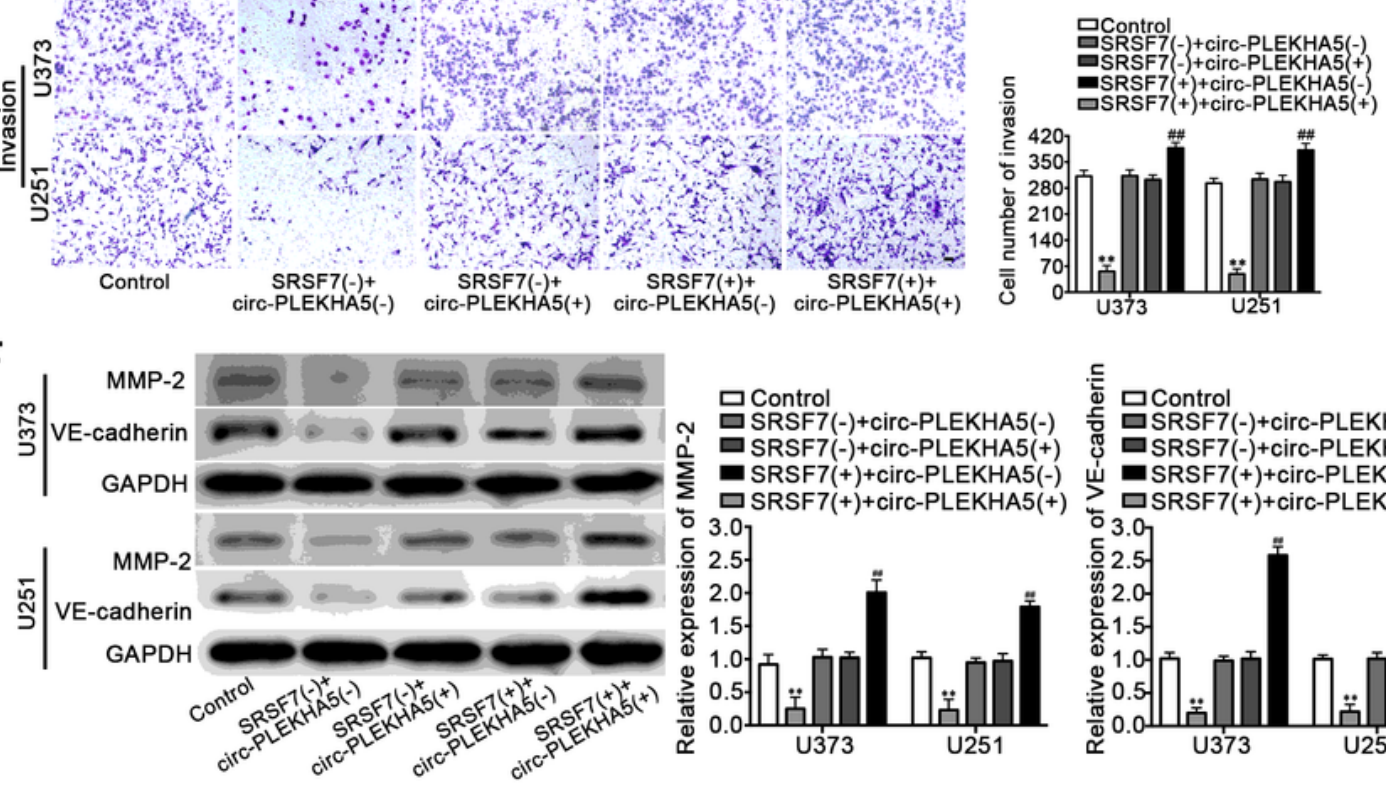

Figure 3 
SRSF7 promoted VM formation of glioma cells by regulating circ-PLEKHA5. A. The effect of SRSF7 on the expression level of circ-PLEKHA5 was detected by qRT-PCR. Values are the average $\pm S D(n=3$, each group). ${ }^{*} \mathrm{P}<0.05$ versus SRSF7(-)NC group, \#P<0.05 versus SRSF7(-)+SRSF7(+)NC group. $B$. The relative enrichment of PLEKHA5 pre-mRNA in anti-IgG and anti-SRSF7 was determined by RIP assay. ${ }^{*} P<0.01$ versus Anti-IgG group. C. The co-effects of SRSF7 and circ-PLEKHA5 on the proliferation, D. VM formation, E. migration and invasion of U373 and U251 cells. F. The co-effects of SRSF7 and circPLEKHA5 on the expression level of MMP-2 and VE-cadherin. Values are the average $\pm S D(n=3$, each group). ${ }^{*} \mathrm{P}<0.01$ versus Control group, \#\#P<0.01 versus SRSF7(+)+circ-PLEKHA5(+) group. Scale bar represents $30 \mu \mathrm{m}$. 
A

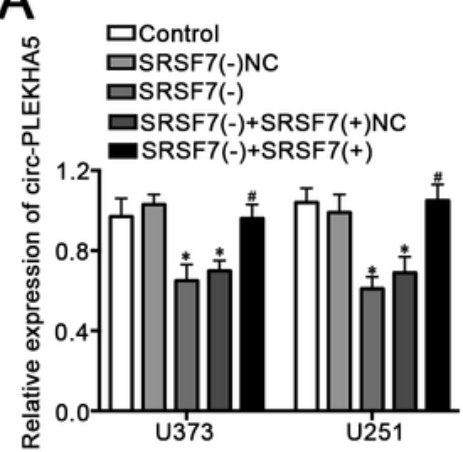

D

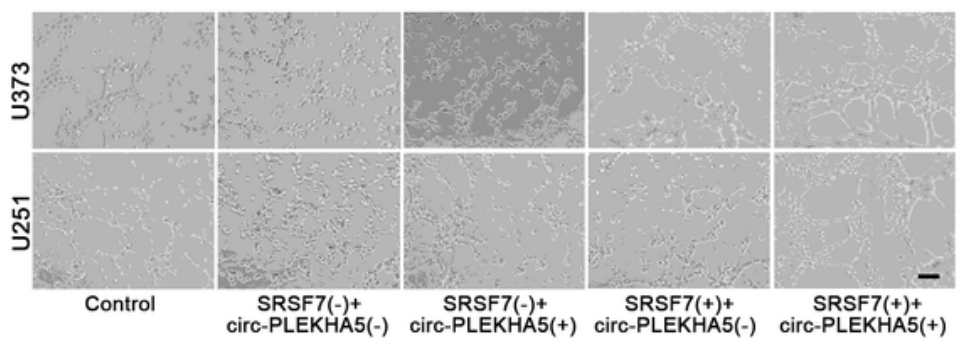

$\mathrm{E}$

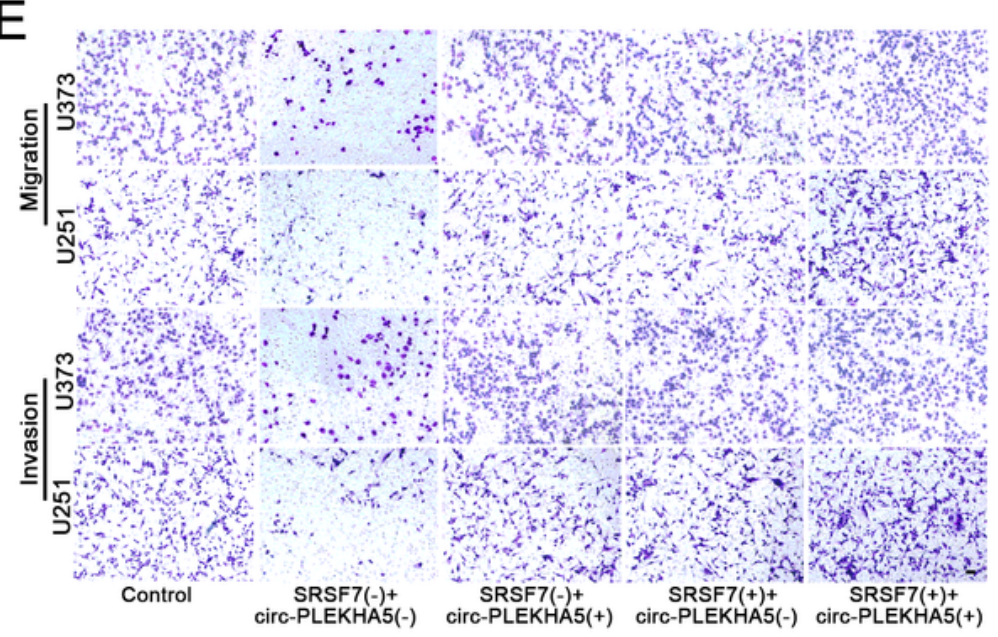

$\mathrm{F}$
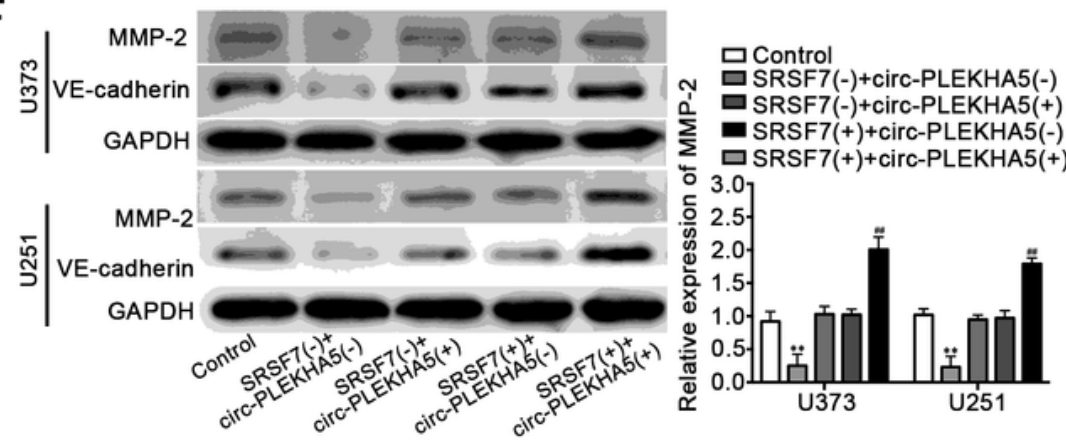

C

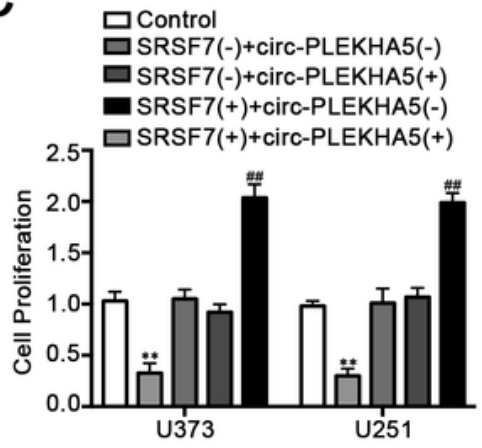

$\square$ Control

$\square$ SRSF7(-)+circ-PLEKHA5(-)

$\square$ SRSF7(-)+circ-PLEKHA5(+)

- SRSF7(+)+circ-PLEKHA5(-)
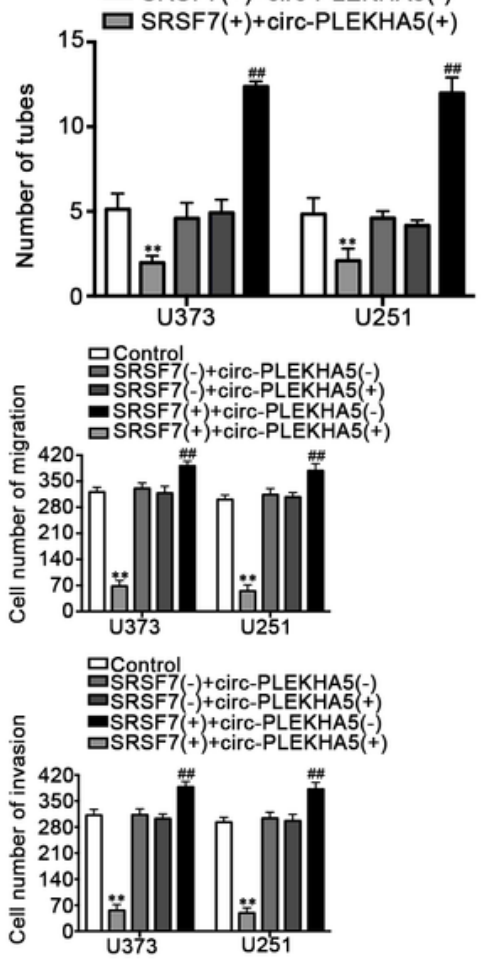

Figure 3

SRSF7 promoted VM formation of glioma cells by regulating circ-PLEKHA5. A. The effect of SRSF7 on the expression level of circ-PLEKHA5 was detected by qRT-PCR. Values are the average $\pm S D(n=3$, each group). ${ }^{*}<0.05$ versus SRSF7(-)NC group, \#P<0.05 versus SRSF7(-)+SRSF7(+)NC group. B. The relative enrichment of PLEKHA5 pre-mRNA in anti-IgG and anti-SRSF7 was determined by RIP assay. ${ }^{*} \mathrm{P}<0.01$ versus Anti-lgG group. C. The co-effects of SRSF7 and circ-PLEKHA5 on the proliferation, D. VM 
formation, E. migration and invasion of U373 and U251 cells. F. The co-effects of SRSF7 and circPLEKHA5 on the expression level of MMP-2 and VE-cadherin. Values are the average $\pm S D(n=3$, each group). ${ }^{*} \mathrm{P}<0.01$ versus Control group, \#\#P<0.01 versus SRSF7(+)+circ-PLEKHA5(+) group. Scale bar represents $30 \mu \mathrm{m}$.

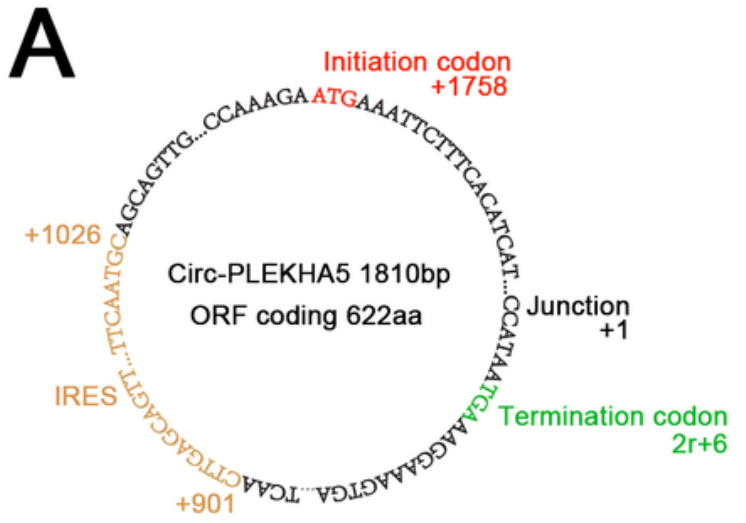

Circ-PLEKHA5-622aa

MKFFHIISKGTPYIWIISHNERKVTCKHPVTGQPSQDNCIFVVNEQTVATM TSEEKKERPISMINEASNYNVTSDYAVHPMSPVGRTSRASKKVHNFGKR SNSIKRNPNAPVVRRGWLYKQDSTGMKLWKKRWFVLSDLCLFYYRDEK EEGILG...HRVLIKPEIQNNQKNKEMSKIEEKKALEAEK...SIREHTLAQLMQ LKLEAHSPKNEILSHHLQRNTIYLDHQP

Anti-circ-PLEKHA5-622aa

\section{$\stackrel{+901}{+1026}$}
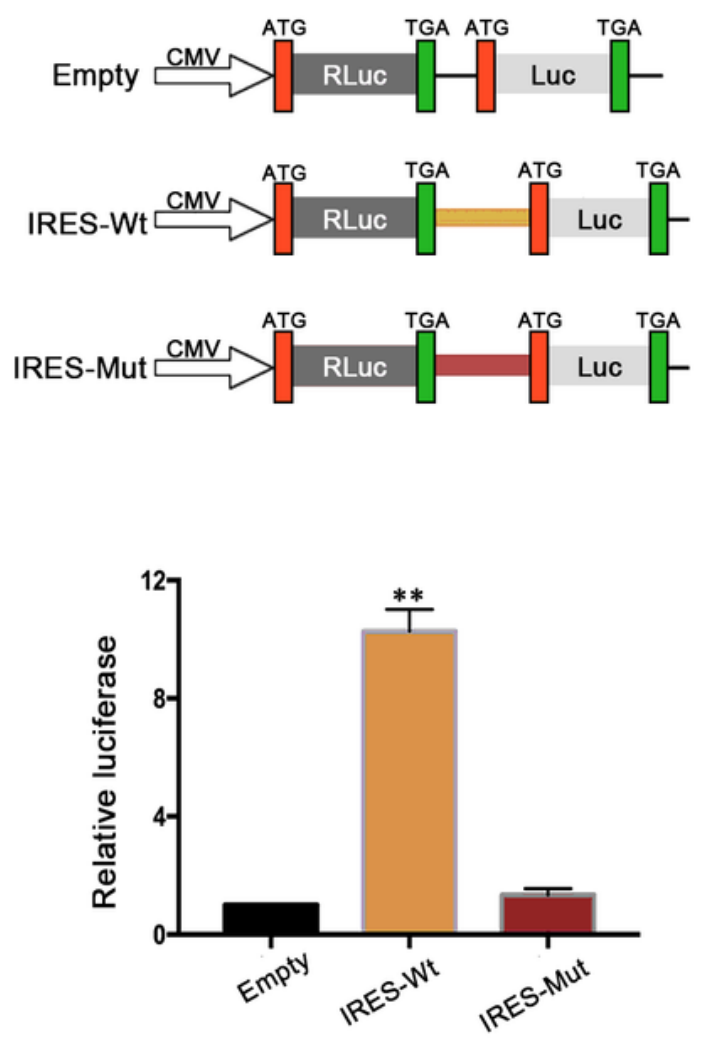
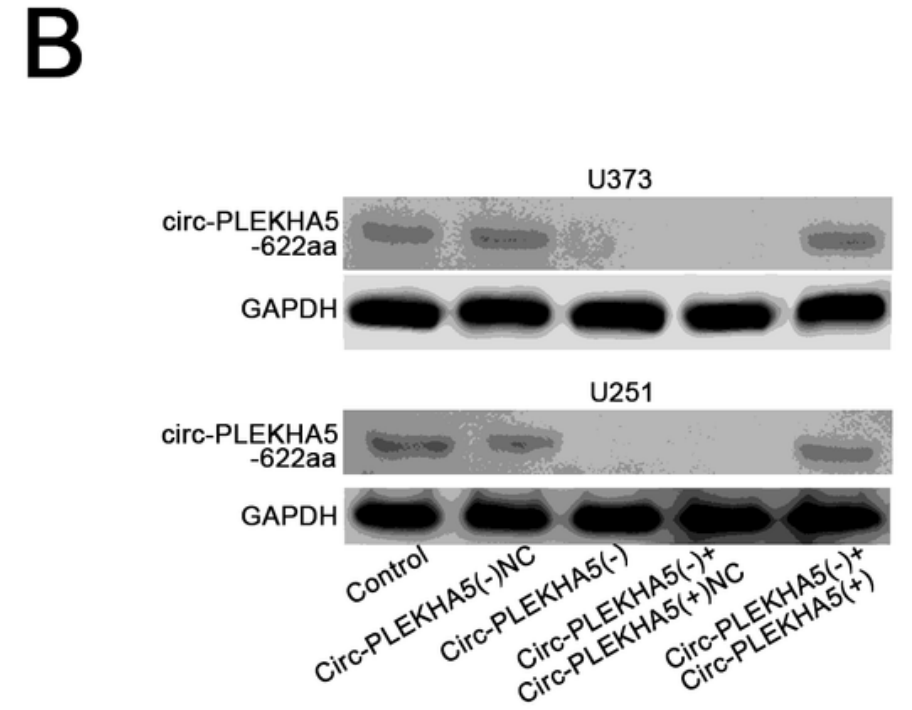

1\# Circ-PLEKHA5

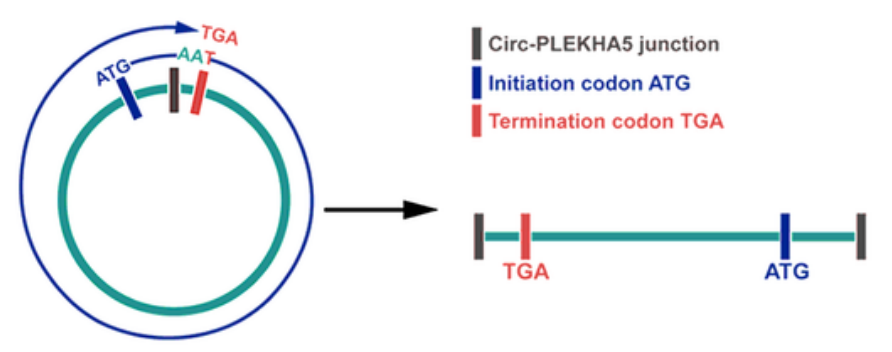

2\# Flag-circ-PLEKHA5

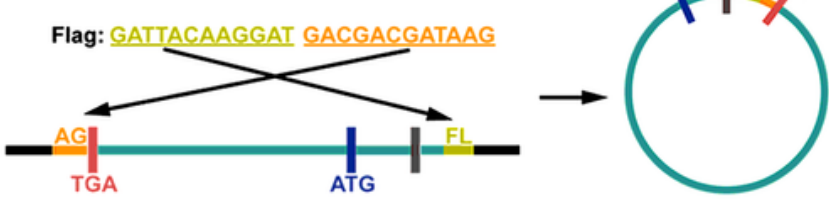

3\# AG-Linear-PLEKHA5-FL

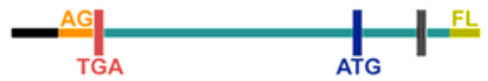

4\# FLAG-circ-PLEKHA5-ORF

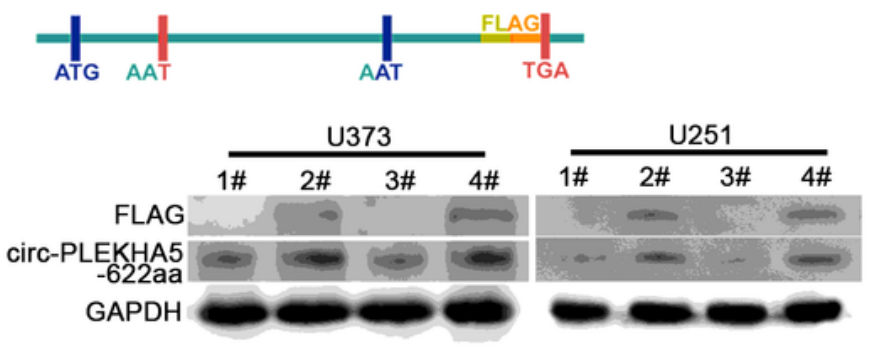

Figure 4 
Circ-PLEKHA5 encodes a novel peptide protein circ-PLEKHA5-622aa. A. Illustration of the potential ability of circ-PLEKHA5 to encode the novel protein circ-PLEKHA5-622aa. B. The expression level of circPLEKHA5-622aa after circ-PLEKHA5 overexpression or knockdown. C. The activity of the putative IRES in circ-PLEKHA5 was evaluated by dual-luciferase assay. Full-length (yellow) and mutated (brick-red) circPLEKHA5 IRES sequences were cloned and constructed between Rluc and Luc reporters along with their own initiation and termination (ATG/TGA) codons. Values are the average $\pm S D(n=3$, each group).

$\star \star P<0.01$ versus Empty group. D. The schematic diagram of FLAG tag transfection and the expression of FLAG tag and circ-PLEKHA5-622aa were analyzed by western blot. 
A

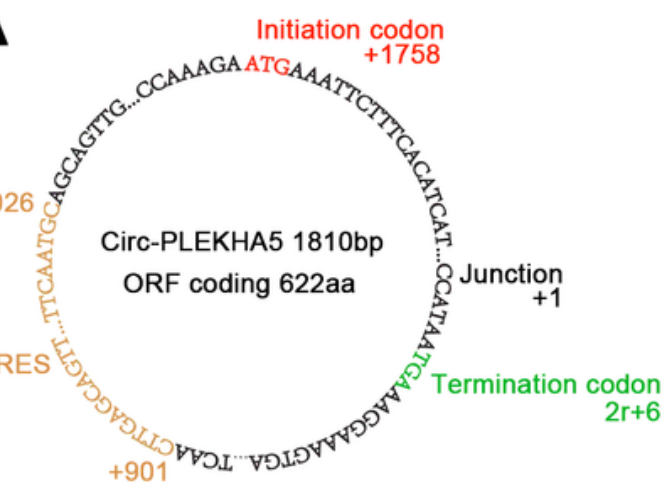

Circ-PLEKHA5-622aa

MKFFHIISKGTPYIWIISHNERKVTCKHPVTGQPSQDNCIFVVNEQTVATM TSEEKKERPISMINEASNYNVTSDYAVHPMSPVGRTSRASKKVHNFGKR SNSIKRNPNAPVVRRGWLYKQDSTGMKLWKKRWFVLSDLCLFYYRDEK EEGILG...HRVLIKPEIQNNQKNKEMSKIEEKKALEAEK...SIREHTLAQLMQ LKLEAHSPKNEILSHHLQRNTIYLDHQP

Anti-circ-PLEKHA5-622aa

C
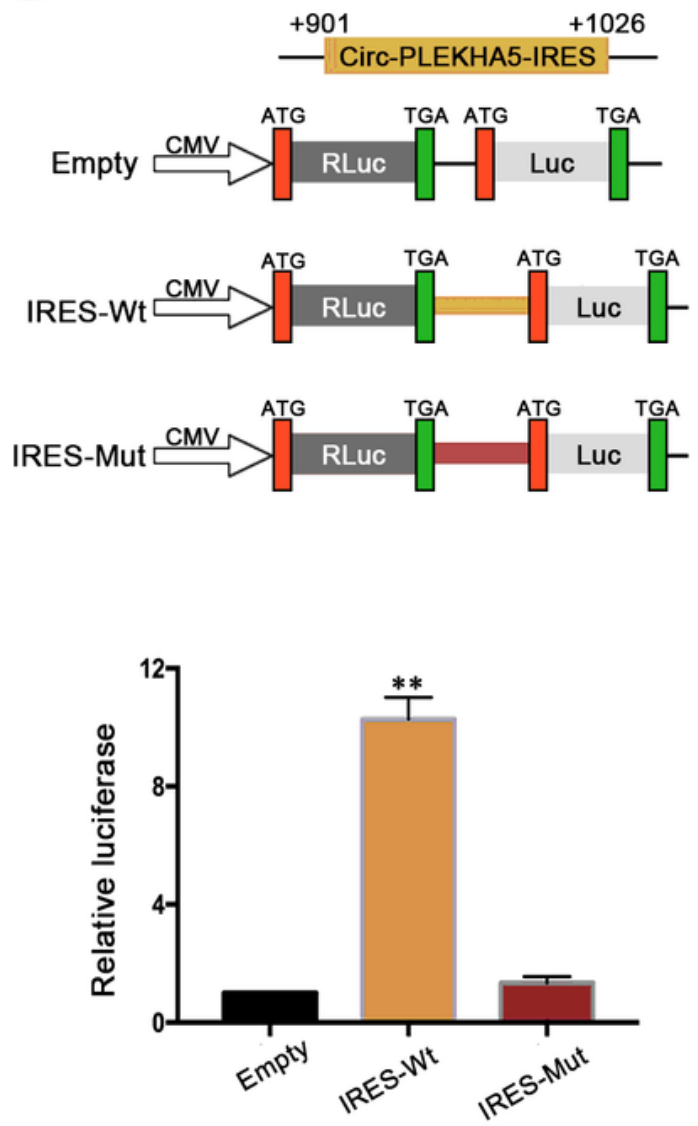

D

1\# Circ-PLEKHA5

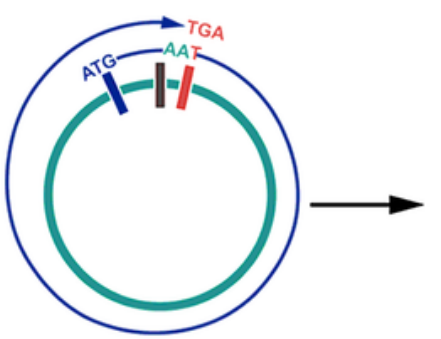

|Circ-PLEKHA5 junction

Initiation codon ATG

Termination codon TGA

2\# Flag-circ-PLEKHA5

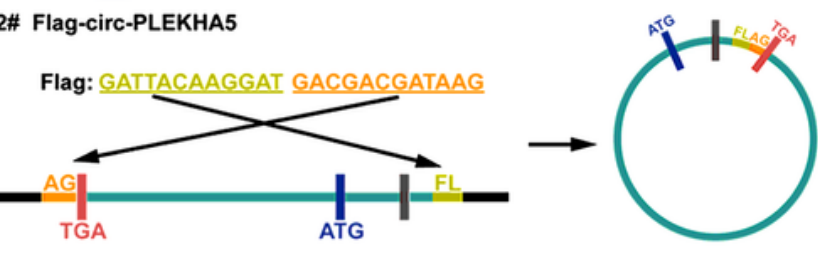

3\# AG-Linear-PLEKHA5-FL

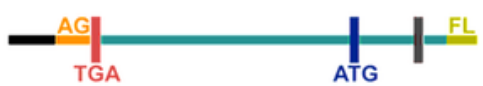

4\# FLAG-circ-PLEKHA5-ORF
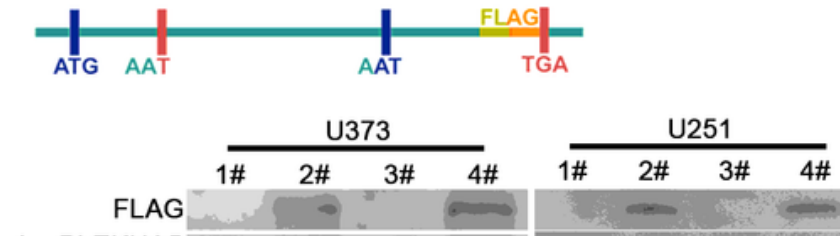

circ-PLEKHA5

GAPDH

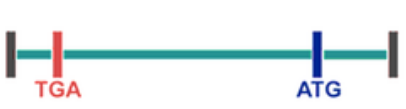

U251

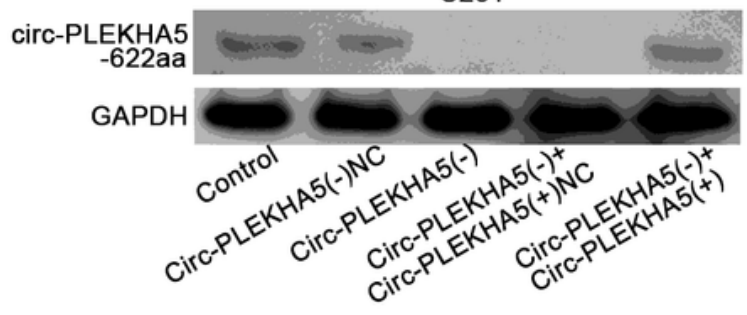


own initiation and termination (ATG/TGA) codons. Values are the average $\pm S D$ ( $n=3$, each group). ${ }^{*} \mathrm{P}<0.01$ versus Empty group. D. The schematic diagram of FLAG tag transfection and the expression of FLAG tag and circ-PLEKHA5-622aa were analyzed by western blot.

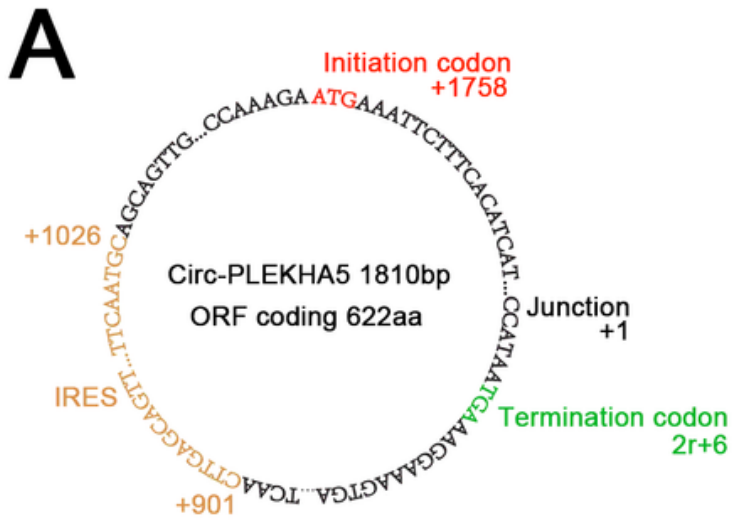

Circ-PLEKHA5-622aa

MKFFHIISKGTPYIWIISHNERKVTCKHPVTGQPSQDNCIFVVNEQTVATM TSEEKKERPISMINEASNYNVTSDYAVHPMSPVGRTSRASKKVHNFGKR SNSIKRNPNAPVVRRGWLYKQDSTGMKLWKKRWFVLSDLCLFYYRDEK EEGILG...HRVLIKPEIQNNQKNKEMSKIEEKKALEAEK...SIREHTLAQLMQ LKLEAHSPKNEILSHHLQRNTIYLDHQP

Anti-circ-PLEKHA5-622aa
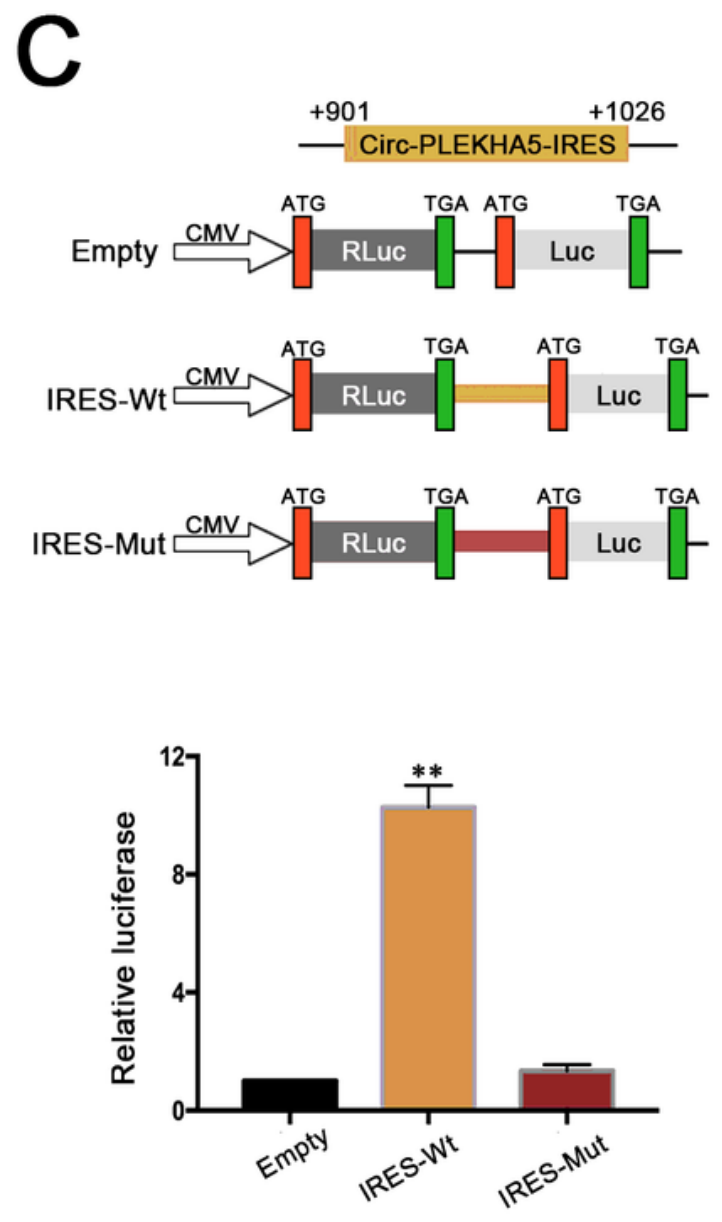
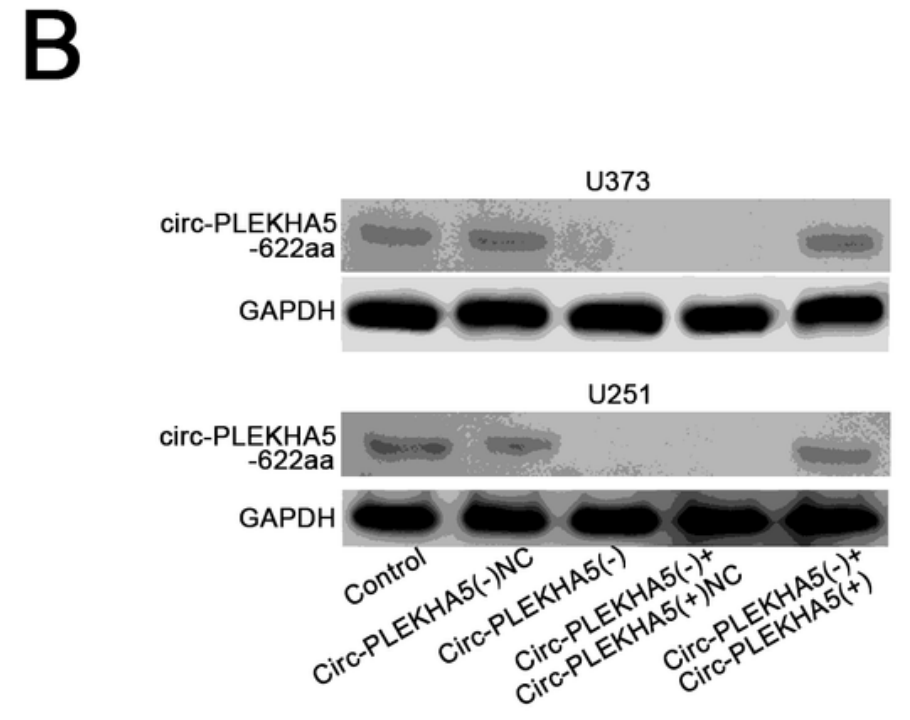

D

1\# Circ-PLekHA5

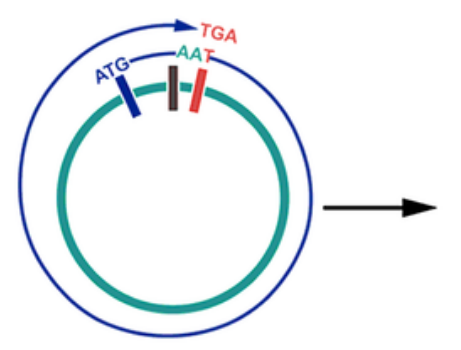

I Circ-PLEKHA5 junction

Initiation codon ATG

ITermination codon TGA

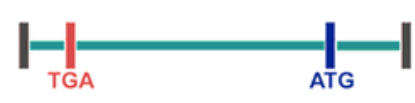

2\# Flag-circ-PLEKHA5

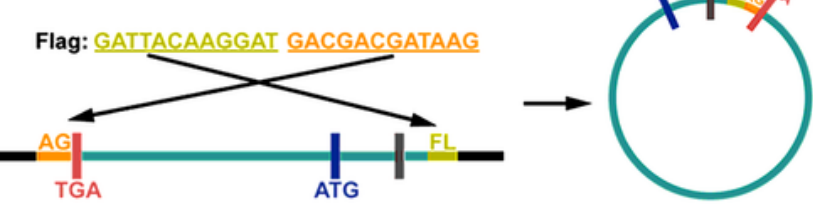

3\# AG-Linear-PLEKHA5-FL

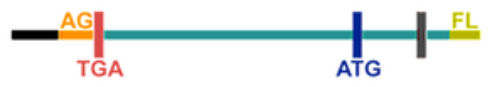

4\# FLAG-circ-PLEKHA5-ORF
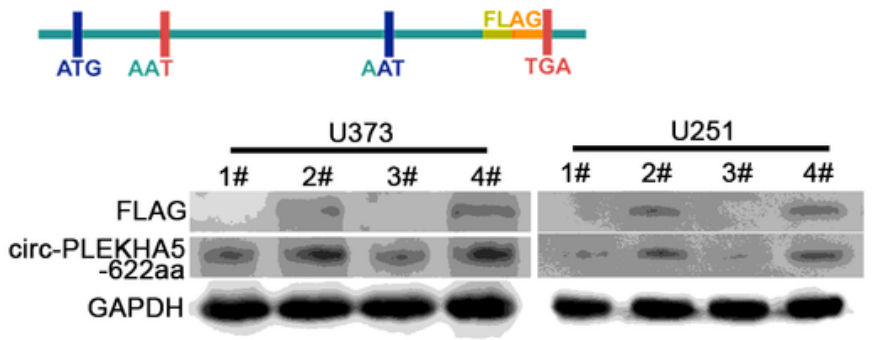

Figure 4

Circ-PLEKHA5 encodes a novel peptide protein circ-PLEKHA5-622aa. A. Illustration of the potential ability of circ-PLEKHA5 to encode the novel protein circ-PLEKHA5-622aa. B. The expression level of circ- 
PLEKHA5-622aa after circ-PLEKHA5 overexpression or knockdown. C. The activity of the putative IRES in circ-PLEKHA5 was evaluated by dual-luciferase assay. Full-length (yellow) and mutated (brick-red) circPLEKHA5 IRES sequences were cloned and constructed between Rluc and Luc reporters along with their own initiation and termination (ATG/TGA) codons. Values are the average $\pm S D(n=3$, each group).

$\star * P<0.01$ versus Empty group. D. The schematic diagram of FLAG tag transfection and the expression of FLAG tag and circ-PLEKHA5-622aa were analyzed by western blot.

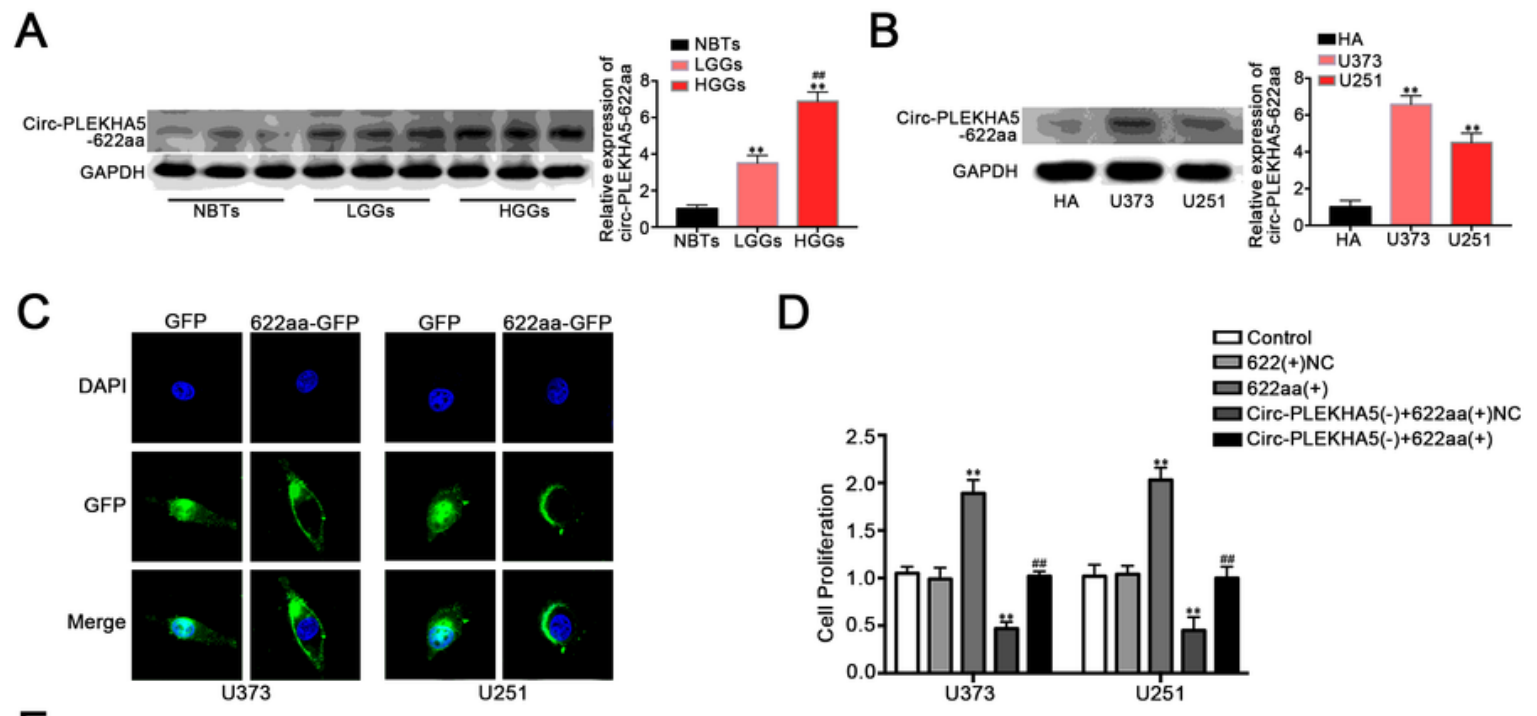

E

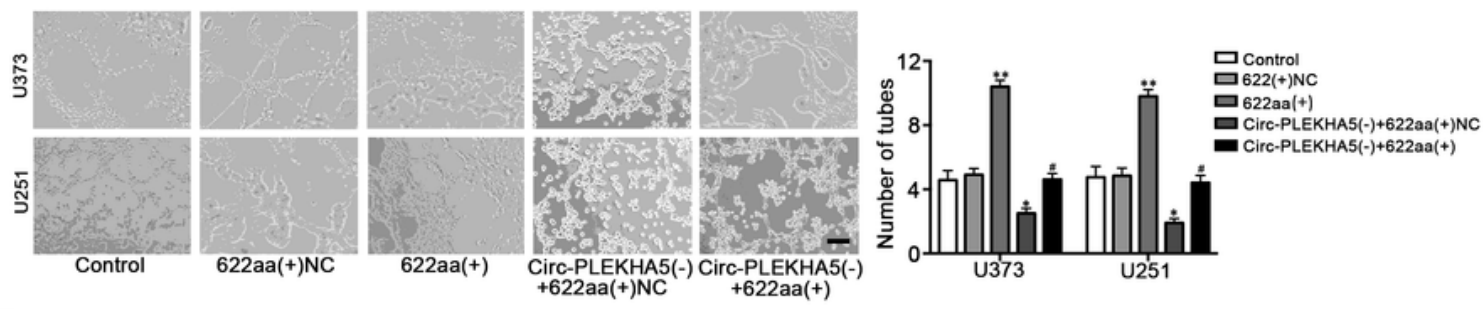

$\mathrm{F}$
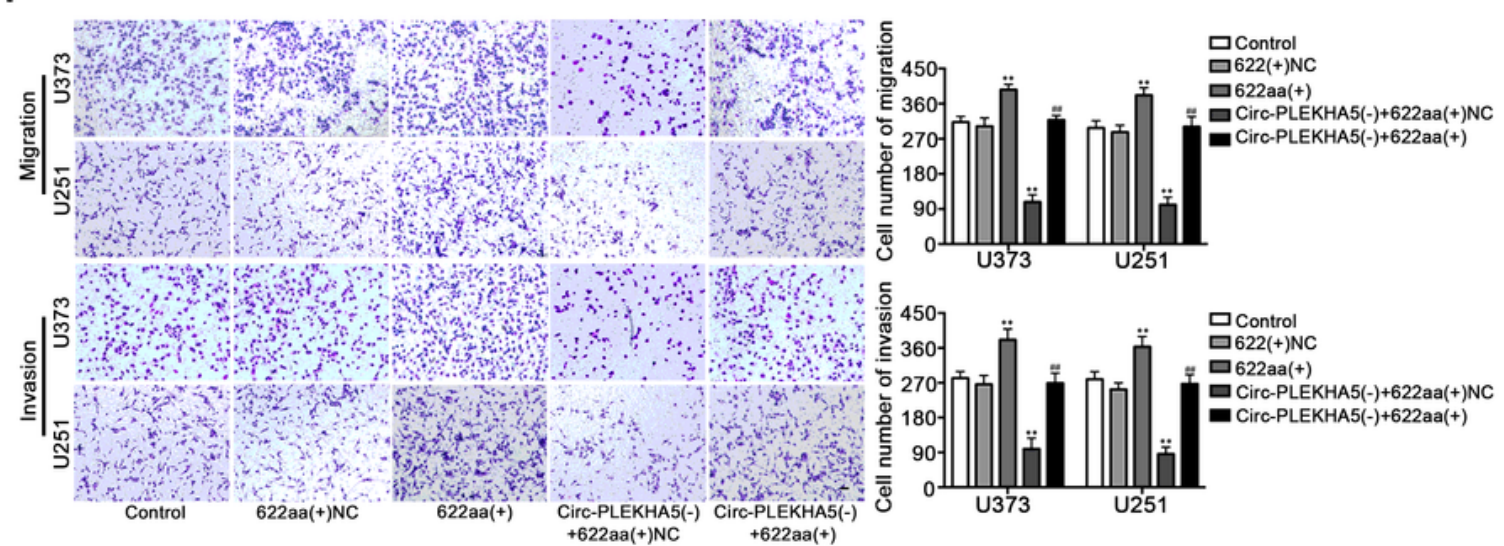

G

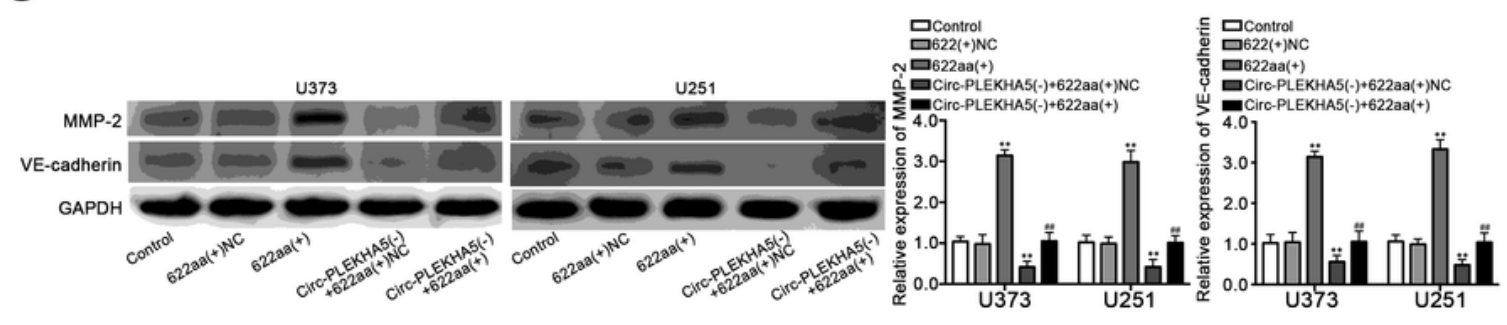

Figure 5 
Circ-PLEKHA5-622aa promoted VM formation of glioma cells. A. The expression level of circ-PLEKHA5$622 \mathrm{aa}$ in NBTs, LGGs and HGGs. Values are the average $\pm S D$ ( $n=3$, each group). ${ }^{*} P<0.01$ versus NBTs group; \#\#P<0.01 versus LGGs group. B. The expression level of circ-PLEKHA5-622aa in HA cells and glioma cells. Values are the average $\pm S D\left(n=3\right.$, each group). ${ }^{\star \star} P<0.01$ versus HA group. $C$. The cellular localization of circ-PLEKHA5-622aa was evaluated using IF assays. D. The effects of 622aa overexpression on the proliferation, E. VM formation, F. migration and invasion of U373 and U251 cells. G. The effect of overexpressed 622aa on the expression level of MMP-2 and VE-cadherin. Values are the average $\pm S D\left(n=3\right.$, each group). ${ }^{*} \mathrm{P}<0.01$ or ${ }^{*} \mathrm{P}<0.05$ versus $622 \mathrm{aa}(+) \mathrm{NC}$ group, $\# \# \mathrm{P}<0.01$ or $\# \mathrm{P}<0.05$ versus Circ-PLEKHA5(-)+622(+)NC group. Scale bar represents $30 \mu \mathrm{m}$. 
A
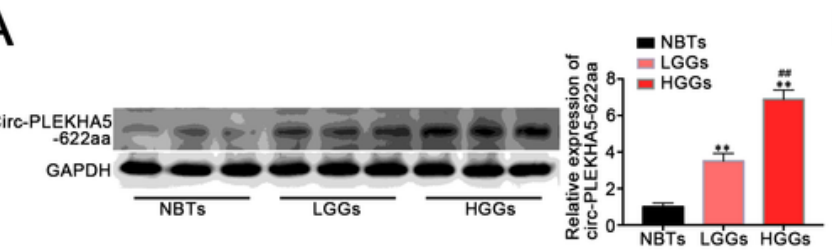

B

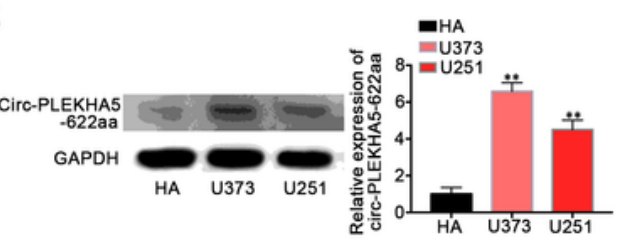

C
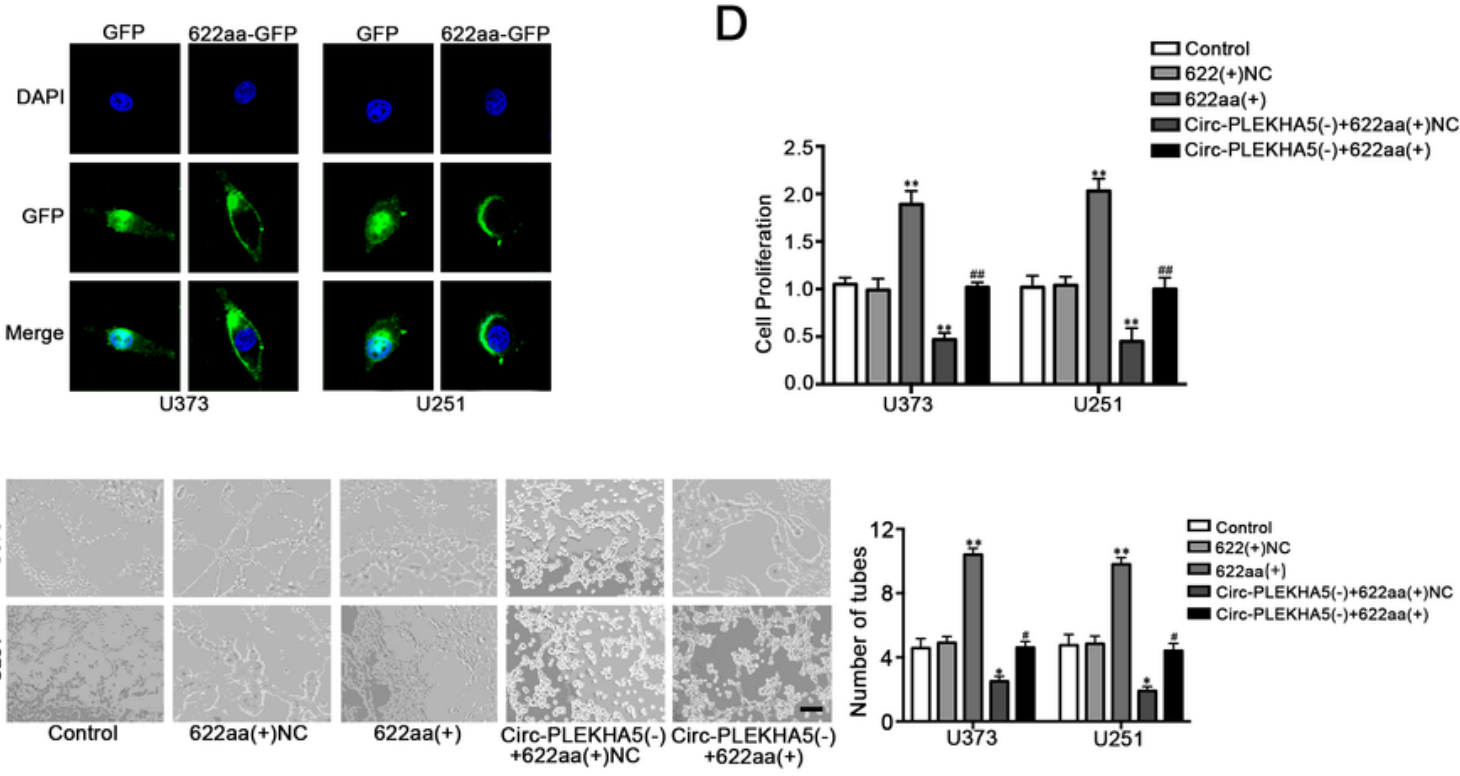

$\mathrm{F}$
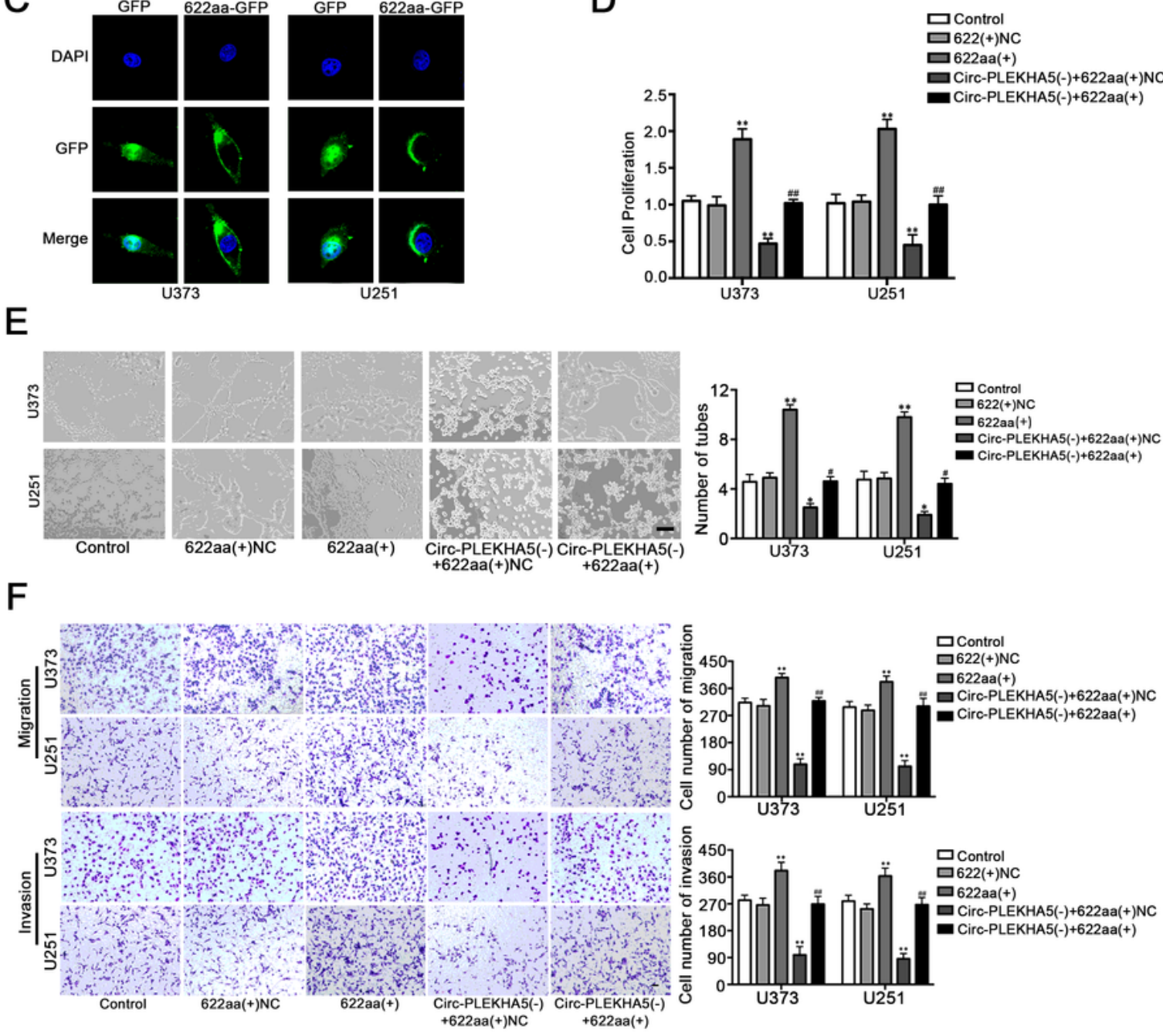

G
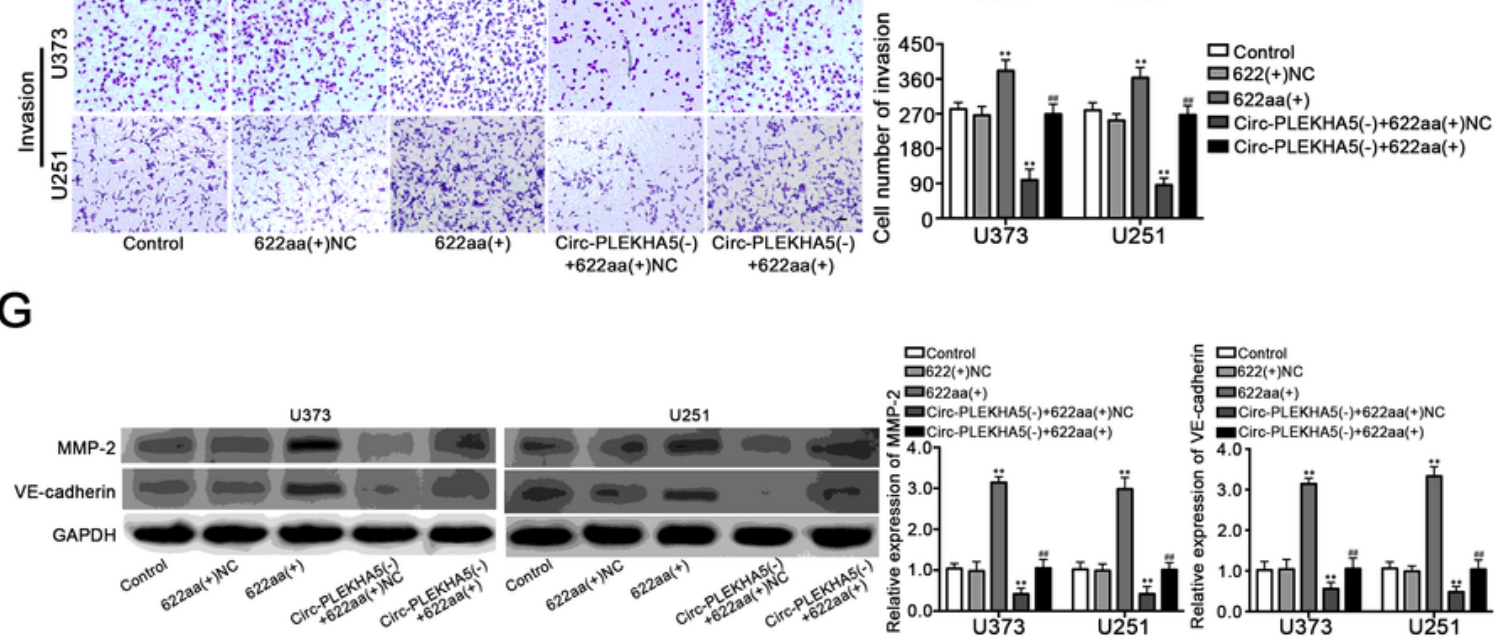

\section{Figure 5}

Circ-PLEKHA5-622aa promoted VM formation of glioma cells. A. The expression level of circ-PLEKHA5622aa in NBTs, LGGs and HGGs. Values are the average $\pm S D$ ( $n=3$, each group). ${ }^{*} P<0.01$ versus NBTs group; \#\#P<0.01 versus LGGs group. B. The expression level of circ-PLEKHA5-622aa in HA cells and glioma cells. Values are the average $\pm S D\left(n=3\right.$, each group). ${ }^{\star *} P<0.01$ versus HA group. $C$. The cellular localization of circ-PLEKHA5-622aa was evaluated using IF assays. D. The effects of 622aa 
overexpression on the proliferation, E. VM formation, F. migration and invasion of U373 and U251 cells. G. The effect of overexpressed 622aa on the expression level of MMP-2 and VE-cadherin. Values are the

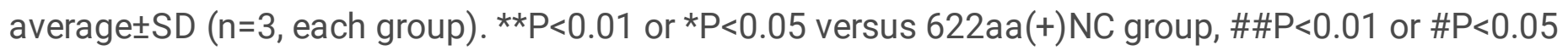
versus Circ-PLEKHA5(-)+622(+)NC group. Scale bar represents $30 \mu \mathrm{m}$.

A

CirC-PLEKHA5 GAPDH
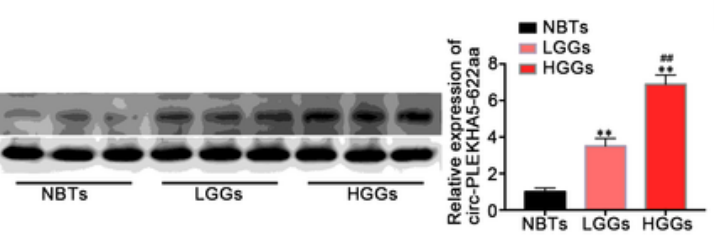

B

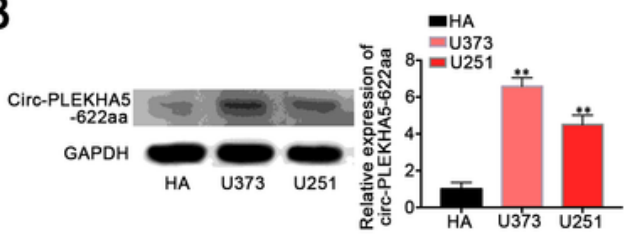

C

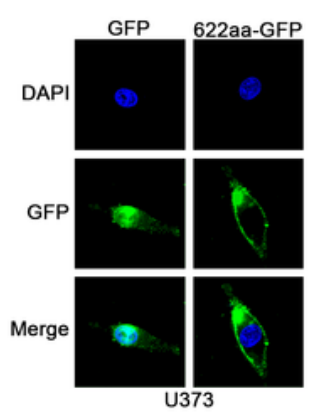

E

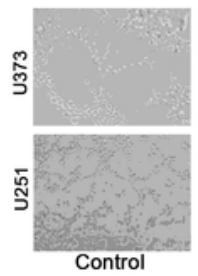

F
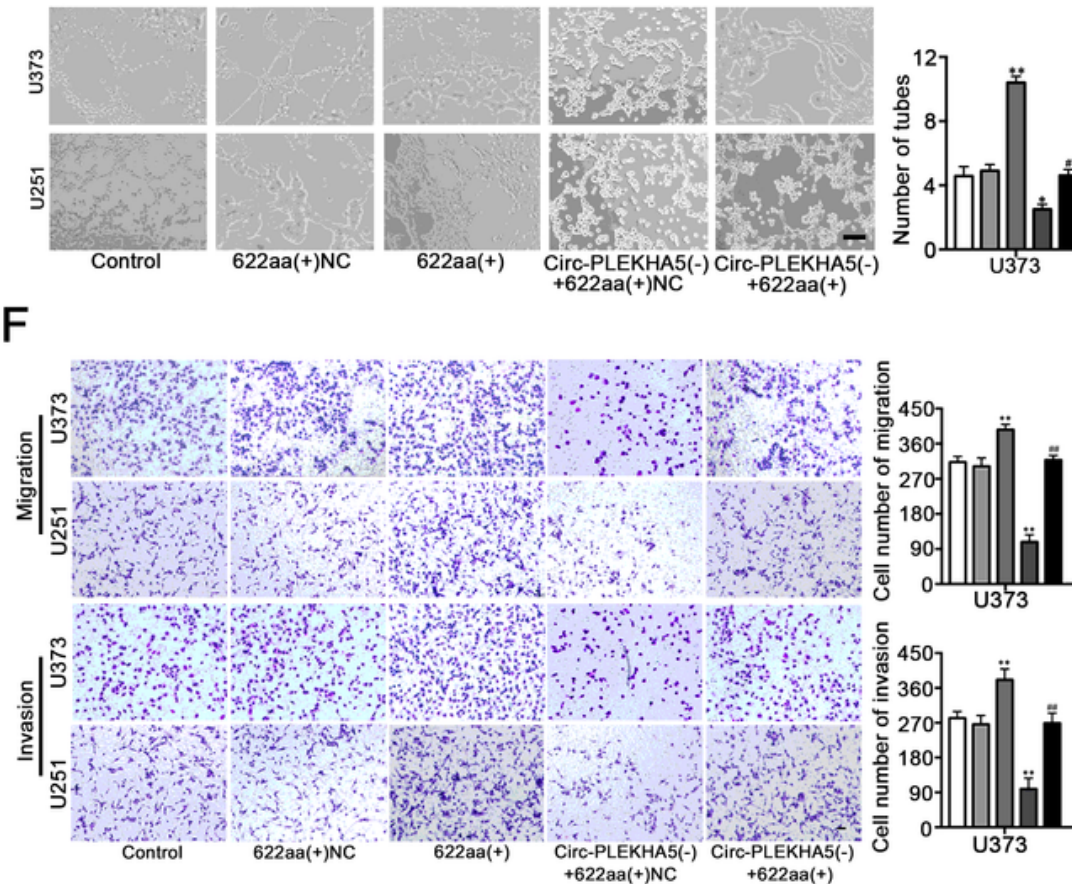

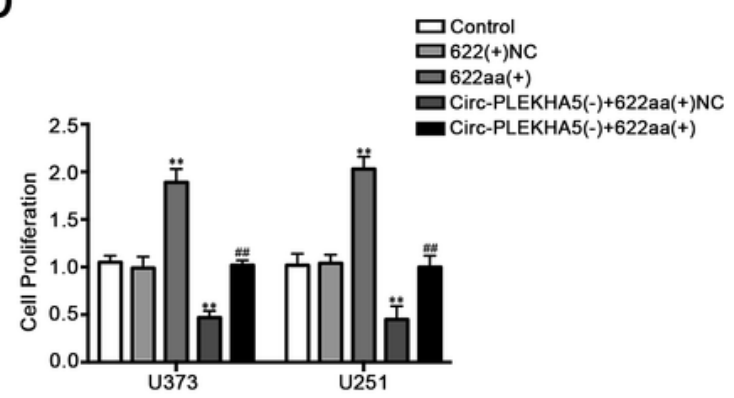

G
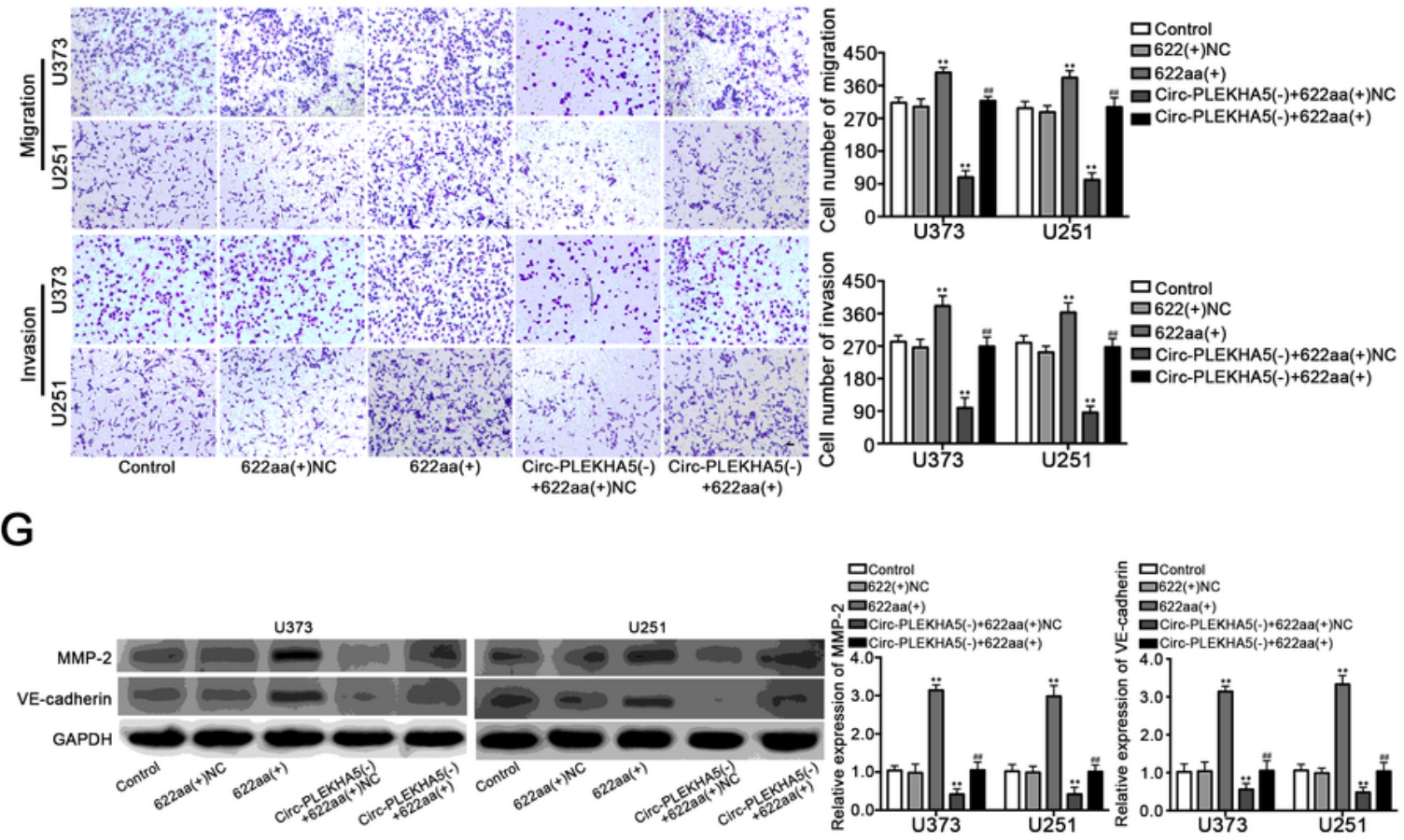

Figure 5 
Circ-PLEKHA5-622aa promoted VM formation of glioma cells. A. The expression level of circ-PLEKHA5$622 \mathrm{aa}$ in NBTs, LGGs and HGGs. Values are the average $\pm S D$ ( $n=3$, each group). ${ }^{*} P<0.01$ versus NBTs group; \#\#P<0.01 versus LGGs group. B. The expression level of circ-PLEKHA5-622aa in HA cells and glioma cells. Values are the average $\pm S D\left(n=3\right.$, each group). ${ }^{\star \star} P<0.01$ versus HA group. $C$. The cellular localization of circ-PLEKHA5-622aa was evaluated using IF assays. D. The effects of 622aa overexpression on the proliferation, E. VM formation, F. migration and invasion of U373 and U251 cells. G. The effect of overexpressed 622aa on the expression level of MMP-2 and VE-cadherin. Values are the average $\pm S D\left(n=3\right.$, each group). ${ }^{*} \mathrm{P}<0.01$ or ${ }^{*} \mathrm{P}<0.05$ versus $622 \mathrm{aa}(+) \mathrm{NC}$ group, $\# \# \mathrm{P}<0.01$ or $\# \mathrm{P}<0.05$ versus Circ-PLEKHA5(-)+622(+)NC group. Scale bar represents $30 \mu \mathrm{m}$. 

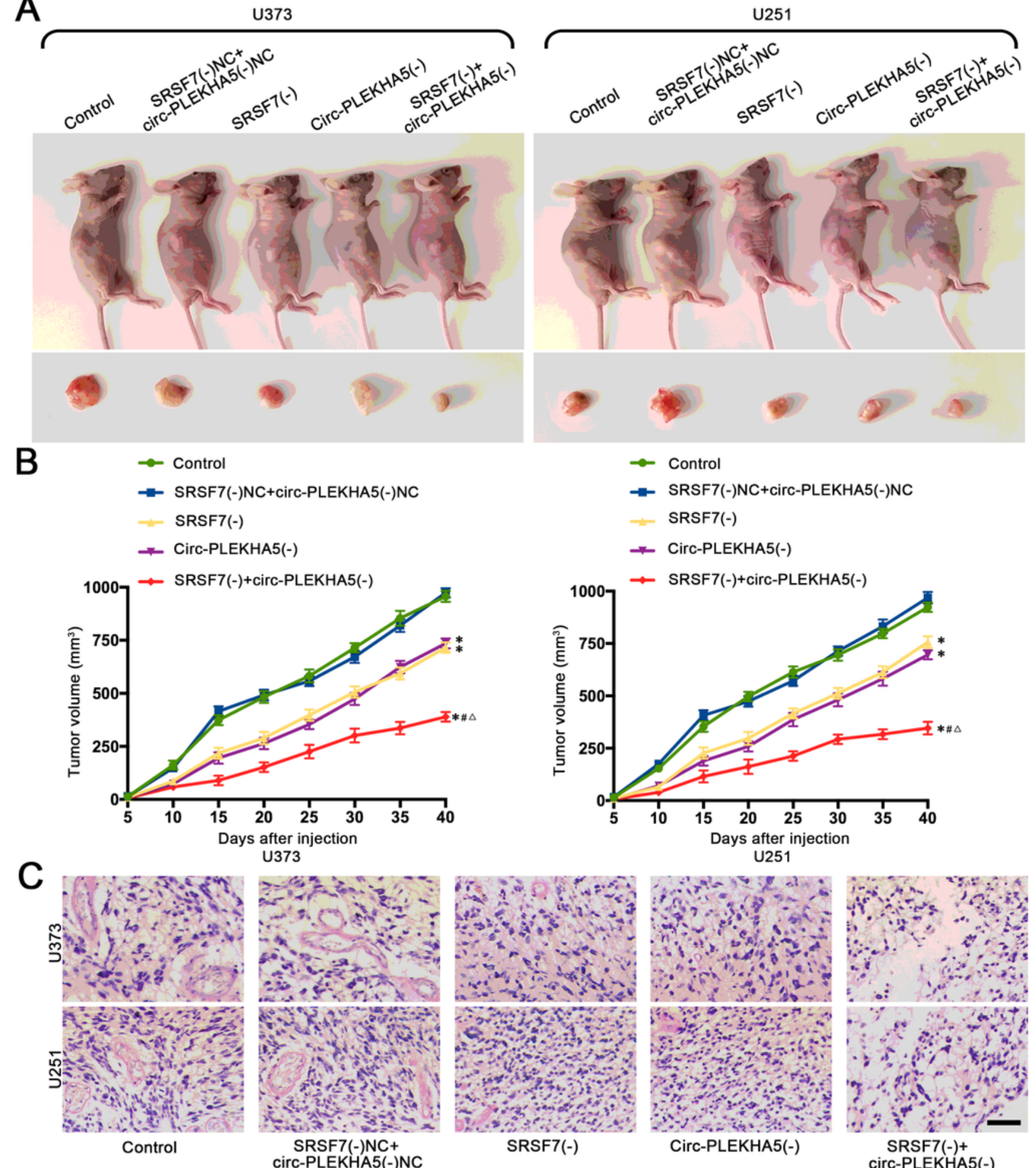
U373
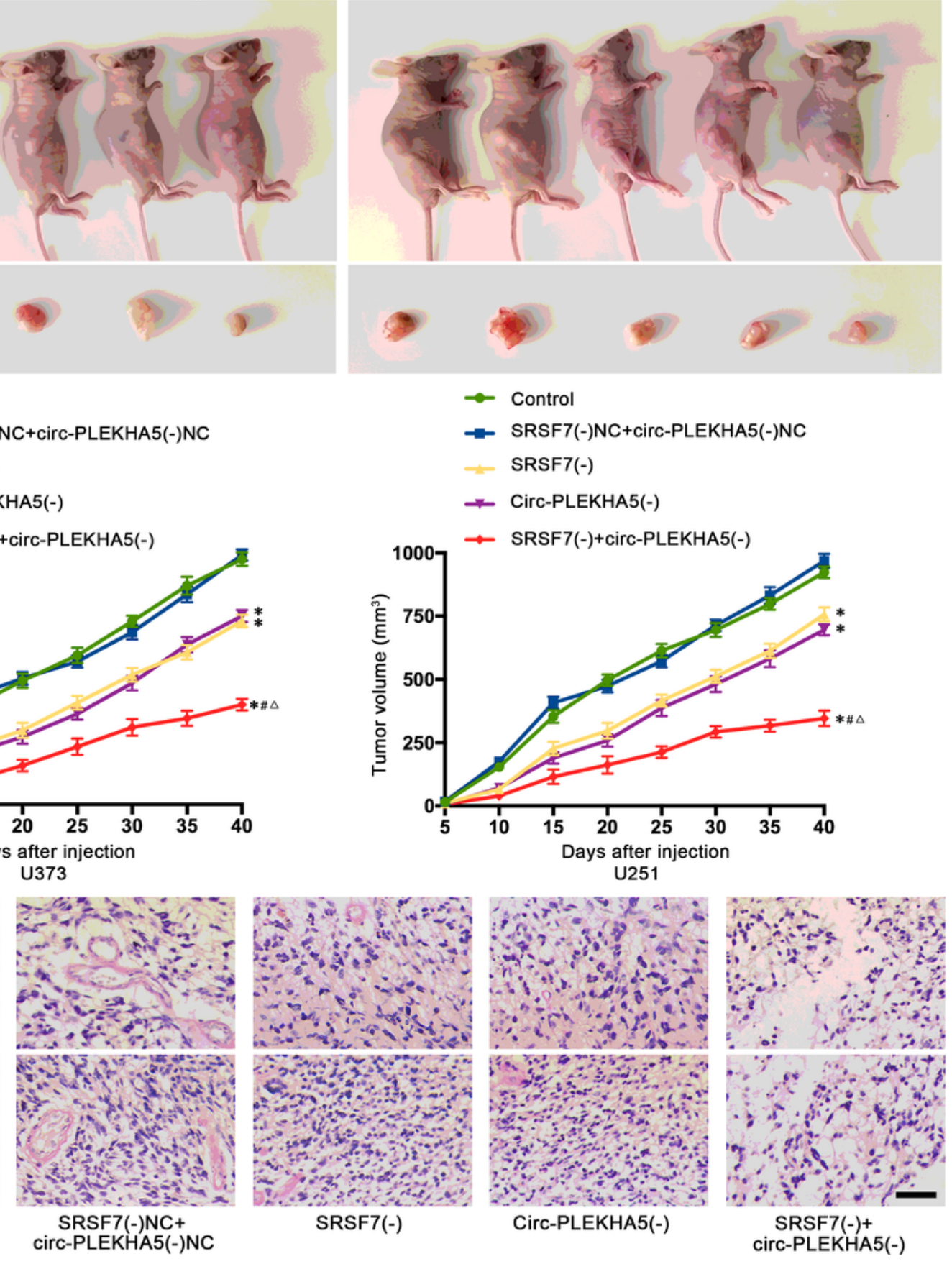

\section{Figure 6}

In vivo tumor xenograft study. A. The nude mice carrying tumors from respective groups were shown, and the sample tumors form respective group were shown. B. Tumor growth were recorded and the curves were shown. Tumor volume was calculated every 5 days after injection and taken after 40 days. C. PASCD34 assays were performed to evaluate the VM formation in xenografted tumor (scale bar represents $50 \mu \mathrm{m})$. 

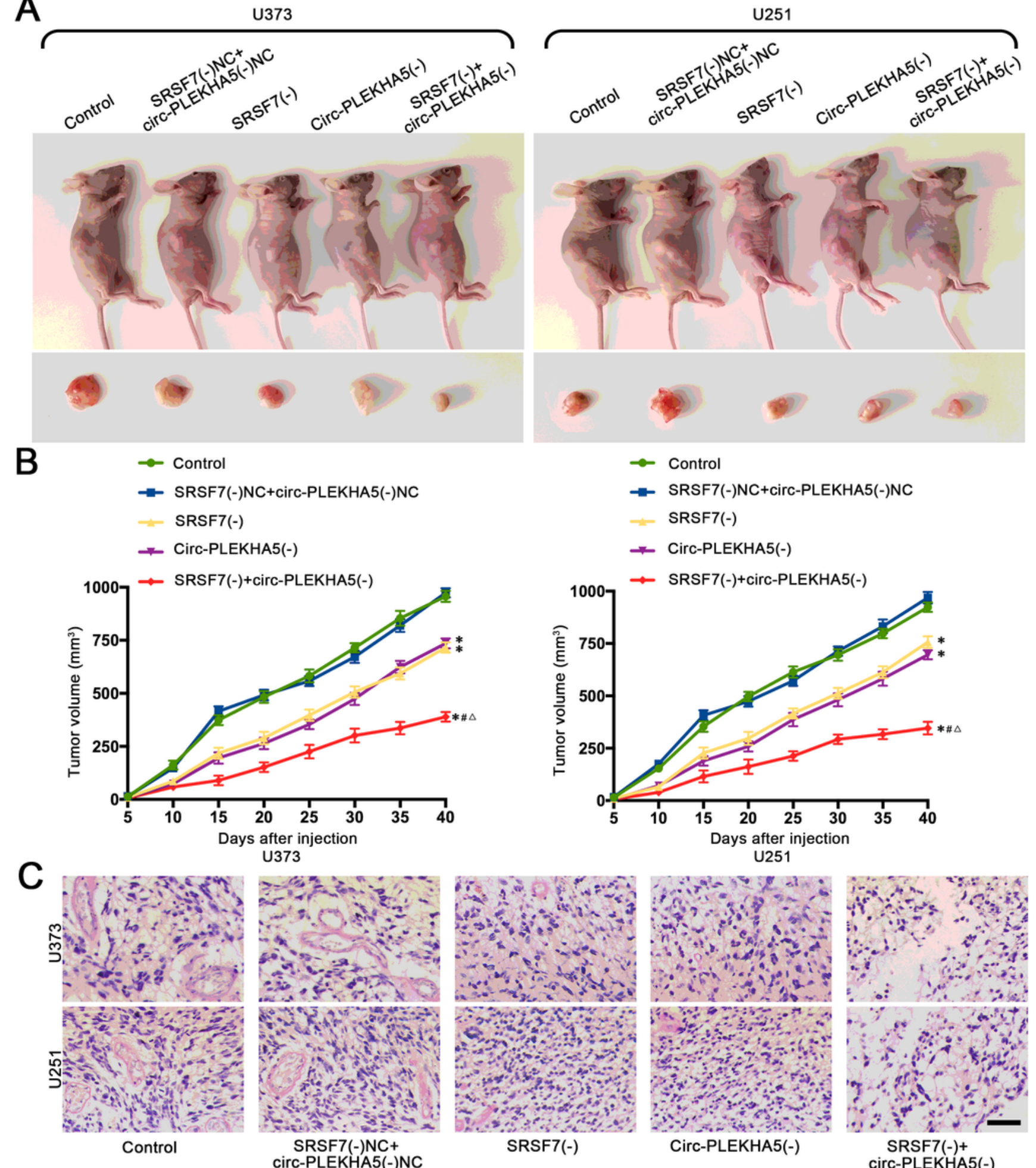
U373
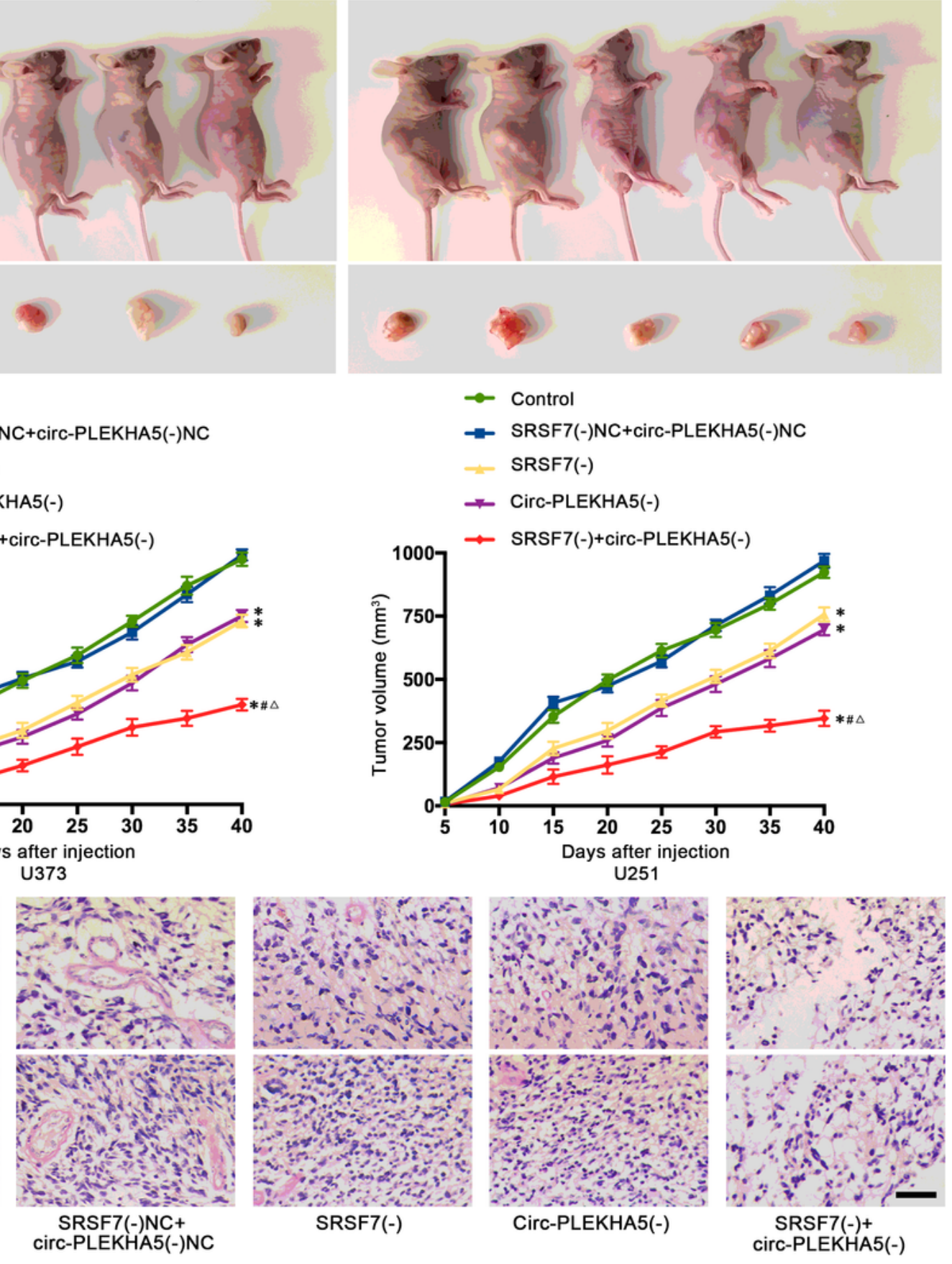

\section{Figure 6}

In vivo tumor xenograft study. A. The nude mice carrying tumors from respective groups were shown, and the sample tumors form respective group were shown. B. Tumor growth were recorded and the curves were shown. Tumor volume was calculated every 5 days after injection and taken after 40 days. C. PASCD34 assays were performed to evaluate the VM formation in xenografted tumor (scale bar represents $50 \mu \mathrm{m})$. 

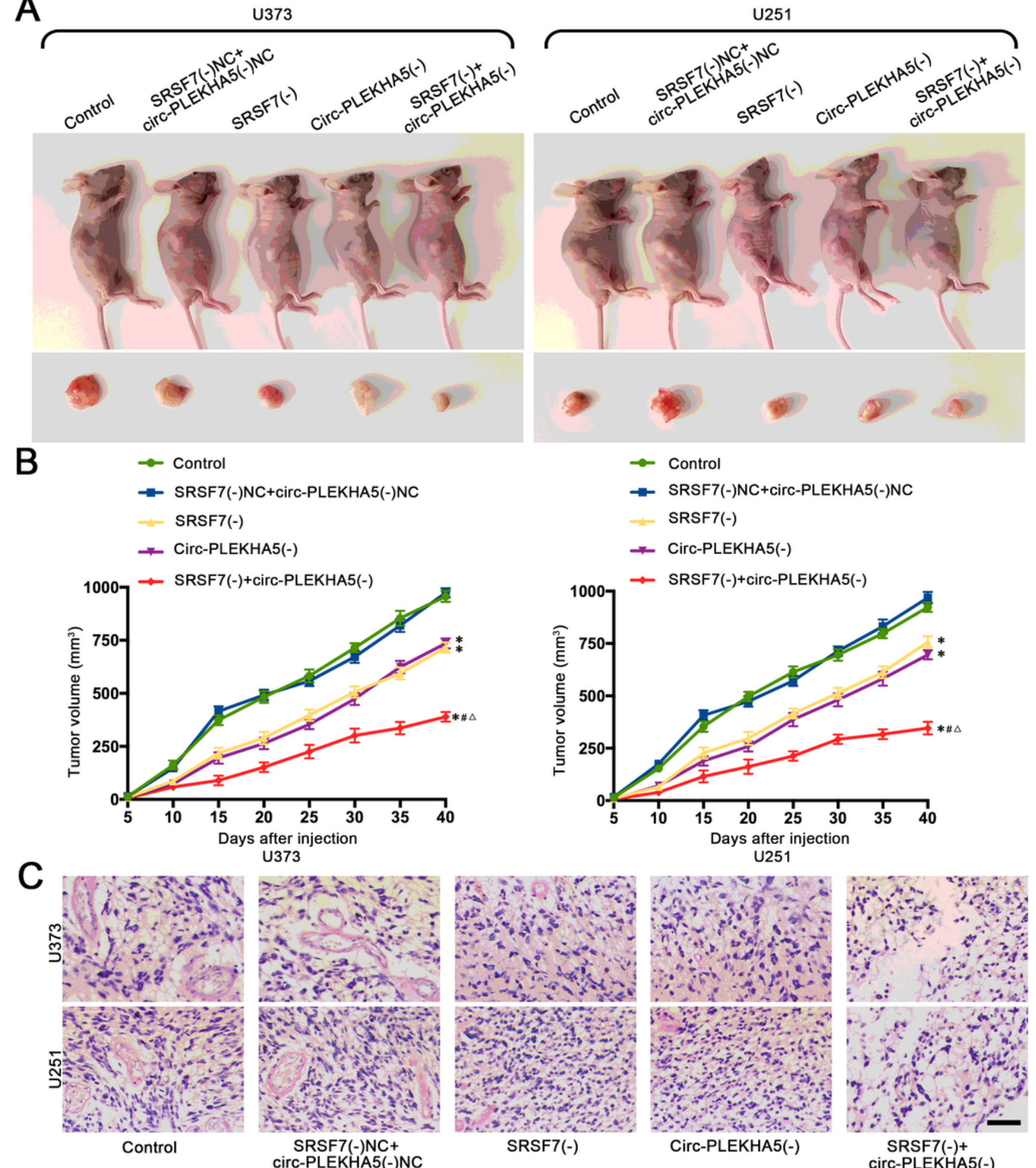
U373
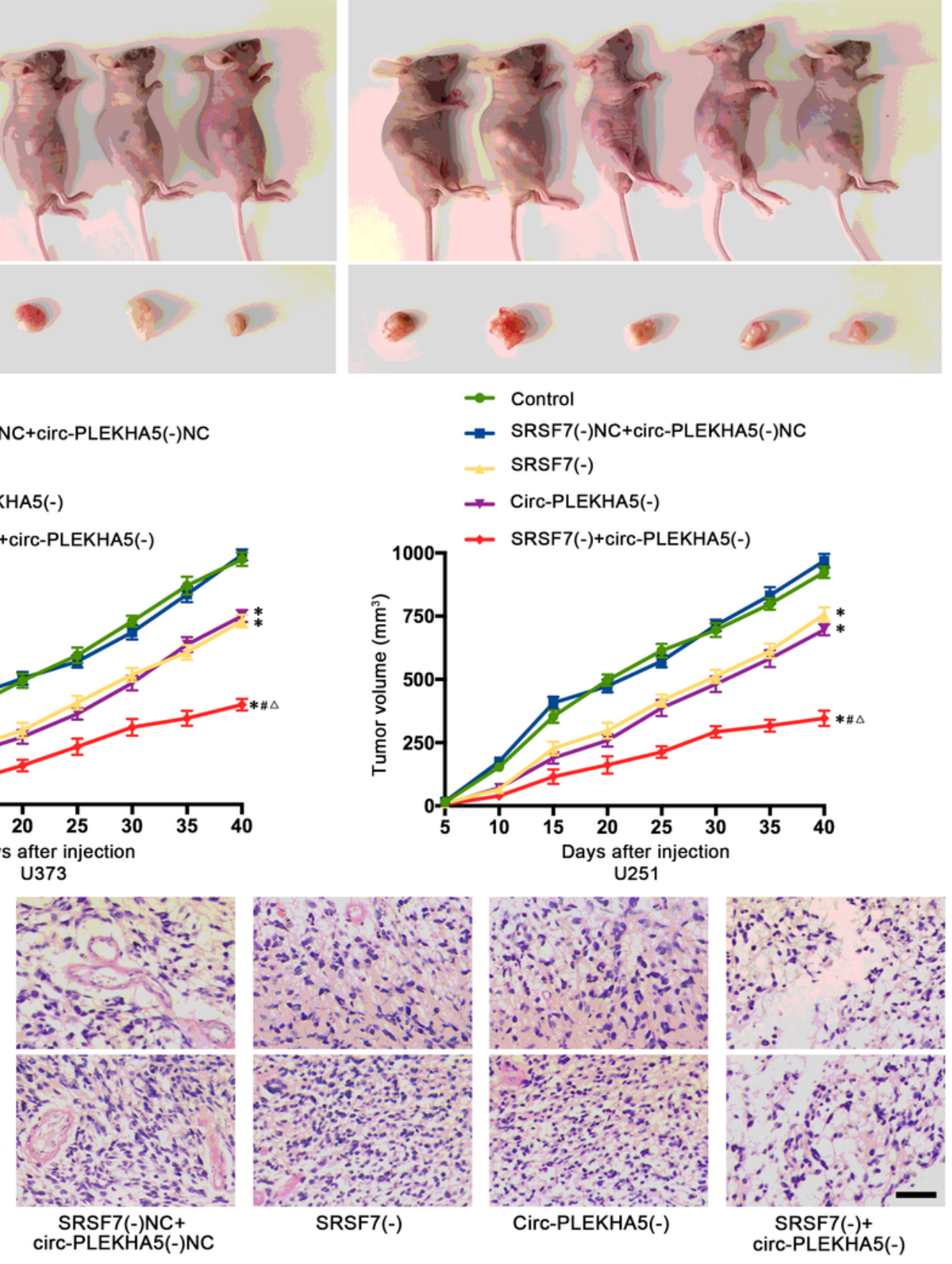

\section{Figure 6}

In vivo tumor xenograft study. A. The nude mice carrying tumors from respective groups were shown, and the sample tumors form respective group were shown. B. Tumor growth were recorded and the curves were shown. Tumor volume was calculated every 5 days after injection and taken after 40 days. C. PASCD34 assays were performed to evaluate the VM formation in xenografted tumor (scale bar represents $50 \mu \mathrm{m})$. 


\section{Supplementary Files}

This is a list of supplementary files associated with this preprint. Click to download.

- OnlineFigureS1.Png

- OnlineFigureS1.Png

- OnlineFigureS1.Png 